Portland State University

PDXScholar

5-13-1974

\title{
Vibration Damping Characteristics of Typical Harpsichord Strings
}

Jack Lee Simmons

Portland State University

Follow this and additional works at: https://pdxscholar.library.pdx.edu/open_access_etds

Part of the Physics Commons

Let us know how access to this document benefits you.

Recommended Citation

Simmons, Jack Lee, "Vibration Damping Characteristics of Typical Harpsichord Strings" (1974).

Dissertations and Theses. Paper 1993.

https://doi.org/10.15760/etd.1992

This Thesis is brought to you for free and open access. It has been accepted for inclusion in Dissertations and Theses by an authorized administrator of PDXScholar. Please contact us if we can make this document more accessible: pdxscholar@pdx.edu. 
AN ABSTRACT OF THE THESIS OF Jack Lee Simmons for the Master of

Science in Physics presented May 13, 1974.

Title: Vibration Damping Characteristics of Typical Harpsichord Strings.

APPROVED BY MEMBERS OF THE THESIS COMMITTEE:

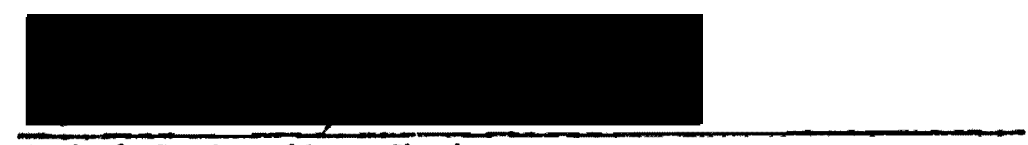

Laird C. Brodie, Chairman
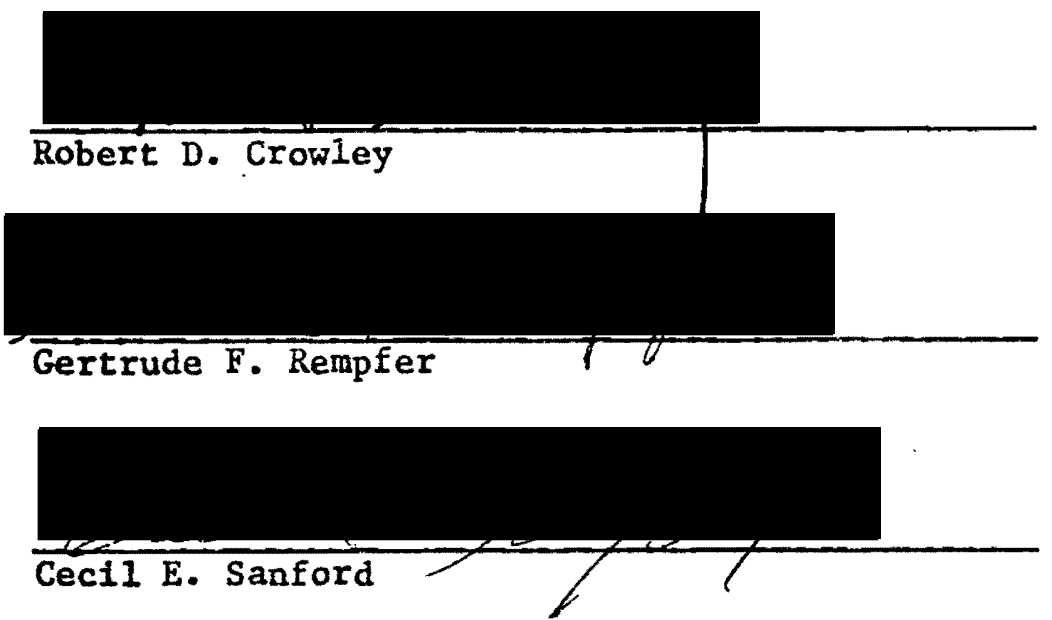

Present-day builders of harpsichords disagree as to the use of Iron or carbon-steel wire in their attempt to duplicate the tonal qualities of the early 16 th century instruments. The variations in tone produced by vibrating iron and steel wires may be due, at least In part, to differences in their decay characteristics.

A wire was set into vibration by placing a section in a magnetic 
fleld and passing a variable-frequency alternating current through it. A condition of resonance was established by appropriately selecting frequencies, lengths, and tensions that would simultaneously sat1sfy the relationship: $f_{r}=n / 2 L(T / \mu)^{1 / 2}$. Then measurements of decay time as a function of frequency were made for a variety of typical harpsichord strings: iron, steel, brass, bronze, etc. Samples varied in diameter from $170 \mathrm{~mm}$ to $600 \mathrm{~mm}$ and the resonant frequencles ranged from $20 \mathrm{~Hz}$ to $12,000 \mathrm{~Hz}$.

Changes in energy loss through the supports were measured by varying the size and mass of the supports and by modifying the method of attachment of the wire. Differences in loss of energy due to internal friction were noted in the comparison of decay times for different wire materials and diameters. The energy losses due to sound radiation and viscous damping were examined by placing the vibrating wire in a vacuum.

Two significant conclusions, among others gathered from the data, indicate that:

1. For similar samples of iron and steel wire vibrating under like conditions, the steel wire will vibrate for a longer period of time than the iron wire.

2. Energy losses to sound radiation and viscous damping greatiy exceed all other modes of energy loss from the wire. Suggestions for additional investigations based on the results of this paper are presented in the concluding pages. 
VIBRATION DAMPING CHARACTERISTICS OF TYPICAL HARPSICHORD STRINGS

by

JACK LEE SIMMONS

A thesis submitted in partial fulfillment of the requirements for the degree of

MASTER OF SCIENCE

in

PHYSICS

Portland State University

1974 
TO THE OFFICE OF GRADUATE STUDIES AND RESEARCH:

The members of the Committee approve the thesis of Jack Lee Simmons presented May 13, 1974.

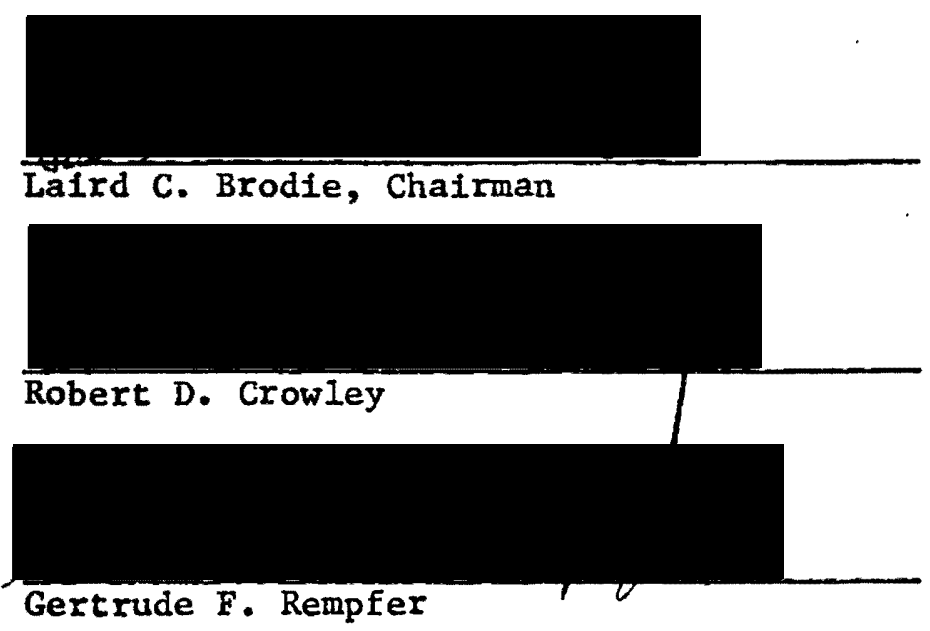

APPROVED:
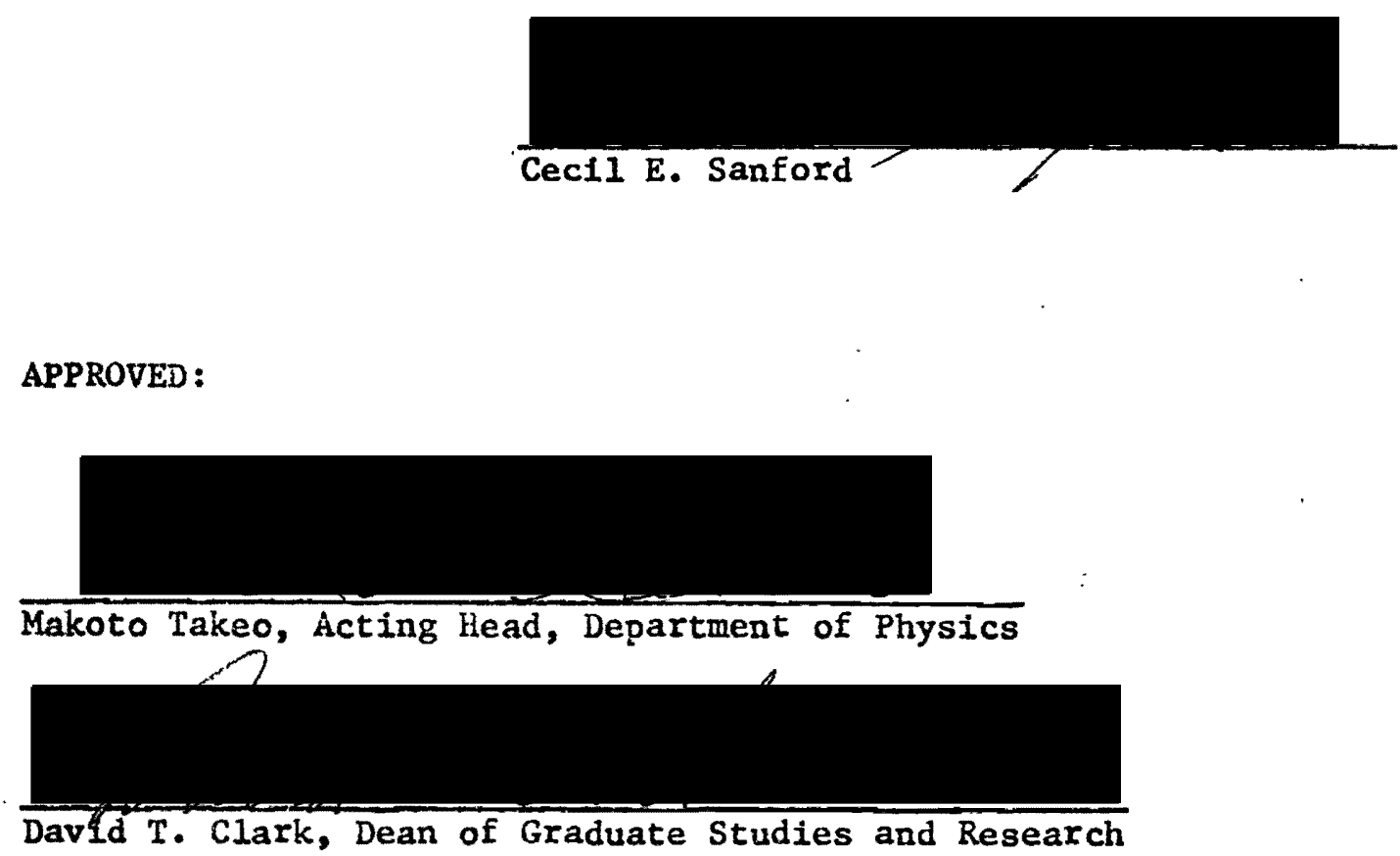

Nay 17,1974 


\section{ACKNOWLEDGEMENTS}

I would like to sincerely thank Dr. Laird Brodie for his constant encouragement over the duration of this research. The guidance which Dr. Brodie gave me during the experimental work and his suggestions and criticism of the writing of this report were Invaluable.

Mr. Cecil Sanford and Dr. Gertrude Rempfer were always available for consultation and advice, and both made several contributions regarding experimental procedure and interpretation.

This research was originally suggested by Mr. William Ratajak, a builder of harpsichords who was concerned with damping capacities of Iron and steel harpsichord wire. Mr. Ratajak generously supplied wire samples and necessary tools along with ideas for the general direction of the research.

The informal conversations which I have had with several members of the physics department relating to harpsichord string investigations were enlightening and gave new perspective to the overall problem. 
TABLE OF CONTENTS

PAGE

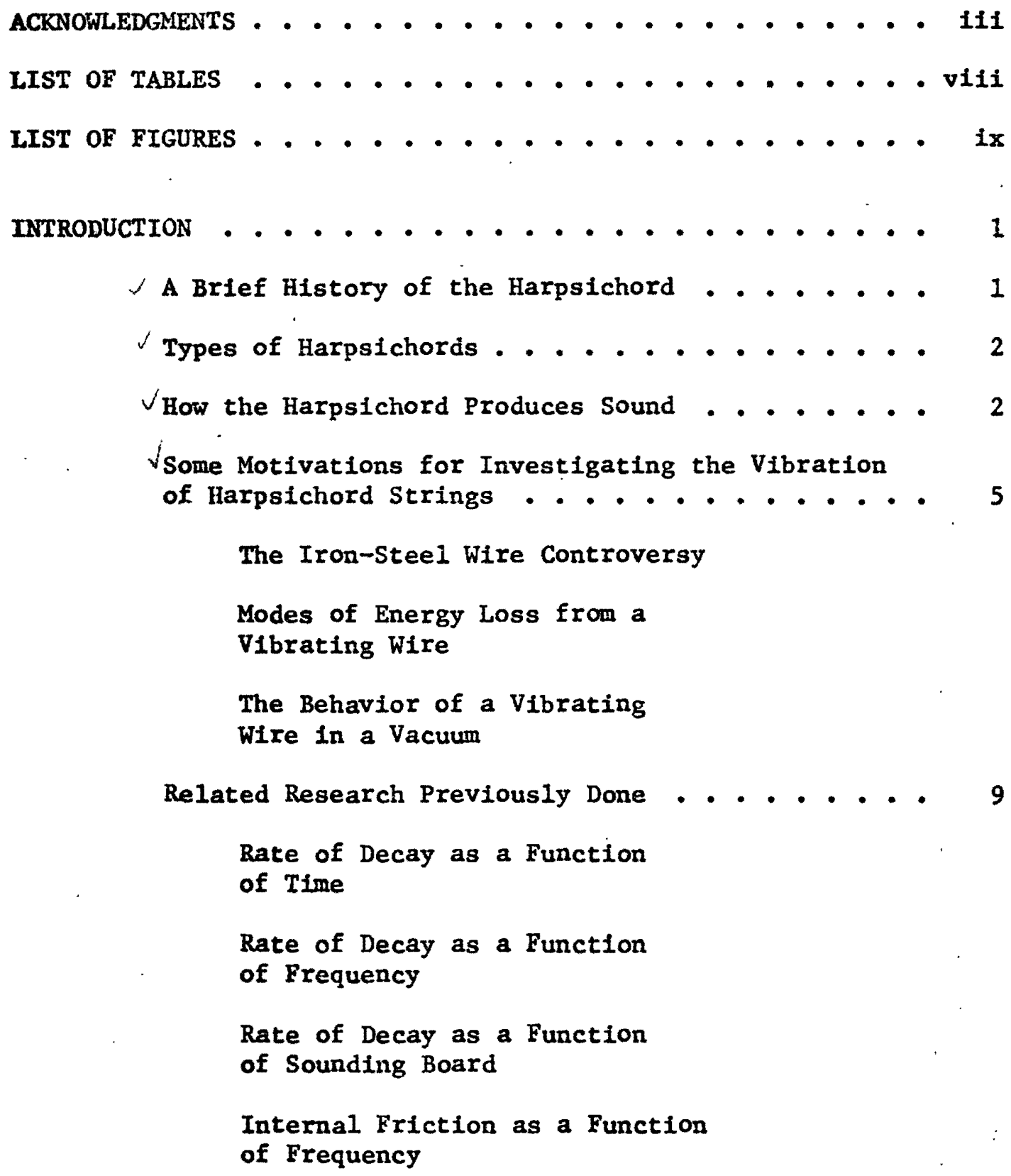


Internal Friction due to Microscopic

Transverse Thermal Currents

objectives................ 10

THEORY OF VIBRATING STRINGS . . . . . . . . . . 12

Resonance and Standing Waves . . . . . . . 12

Energy of a Standing Wave on a String . . . . . 13

Velocity as a Function of Amplitude . . . . . . 14

EQUIPMENT . . . . . . . . . . . . . . . 15

Electrical Circuitry . . . . . . . . . 15

Method by which the Wire is

Set into Vibration

Method by which the Decay Pattern

of the Wire was Monitored

Technical Description of

CIrcuit Elements

Types of Magnets Used . . . . . . . . . . 19

Permanent Magnets

Pole Plece Width and

Internodal Distance

Electromagnet

Types of TerminatIng Blocks Used . . . . . . 22

Wood/Wood

Lead/Wood

Lead/Rubber/Wood

Lead/Rubber/Countertop

Cylindrical Steel Terminal Blocks

Types of Wire Tested . . . . . . . . . 27 
PAGE

The Vacuum Systems... . . . . . . . 30

Preliminary System

Final System

MEASUREMENT TECHNIQUES . . . . . . . . . . . . 33

Oscilloscope.................. 33

Filtering

Wave Shapes

Visual Measurement Techniques . . . . . . 36

Standing Wave Ratio

Resonant Peak

PROCEDURE

Acquisition and Measurement of

Decay Curves . . . . . . . . . . . . 38

Comparisons .. . . . . . . . . . . 41

RESULTS . . . . . . . . . . . . . . . . 42

Amplitude as a Function of Frequency . . . . . . 42

Resonant Frequency as a Function of Pressure . . . 44

Decay Time as a Function of Frequency . . . . . 46

Decay Time as a Function of Diameter . . . . . 56

Decay Time as a Function of Pressure . . . . . 56

Comparisons . . . . . . . . . . . 56

Afr-Vacuum Decay Times

CONCLUSIONS AND RECOMENDATIONS . . . . . . . . . . 61

Conclusions .. . . . . . . . . . 61

J Recommendations .............. 64 
vi1

PAGE

A SELECTED BIBLIOGRAPHY . . . . . . . . . . . . . 65

APPENDIX A . . . . . . . . . . . . . . . . . 67

APPENDIX B . . . . . . . . . . . . . . . . . . 70 


\section{LIST OF TABLES}

TABLE

PAGE

I Decay Time as a Function of Support. . . . . . . . . 24

II Decay Time as a Function of Support Insulation . . . . . 24

III Types of Wire Tested ................. 27

IV Drop in Resonant Frequency as a Function of Pressure - . 44 


\section{LIST OF FIGURES}

FIGURE

PAGE

1. Some basic harpsichord components . . . . . . . . 3

2. The harpsichord plucking mechanism . . . . . . . . 4

3. Feedback loops through common base . . . . . . . . 7

4. Feedback with isolated bases . . . . . . . . . 7

5. An impulse moving along a string under tension. . . . . 12

6. A standing wave and its component waves . . . . . . . 14

7. The force on a current-carrying wire in a magnetic

field....................... 15

8. Decay of resonating wire as monitored by oscilloscope - - 16

9. Electric circuit . . . . . . . . . . . . 17

10. Frequency response selectivity of $2 A 61$ amplifier . . . 18

11. Non-uniformity of field of magnetron magnet . . . . . . 19

12. Maximum field strength vs gap for variflux magnet . . . 19

13. Tapered pole pieces . . . . . . . . . . . 20

14. a. Internodal distance compared to pole face dlameter at low frequencies ............. 20

b. Internodal distance compared to pole face diameter at high frequencles................. 20

15. Common antinode position for odd harmonics . . . . . . 21

16. Pin-block arrangement . . . . . . . . . . . . 22

17. C-clamp attachment of terminal blocks to maple table. . 22

18. Pin vibration . . . . . . . . . . . 26

19. Steel terminal block and clamping arrangement . . . . . 26 
20. Preliminary vacuum system . . . . . . . . . . 30

21. Brass vacuum cylinder .............. . . 31

22. Final vacuum system . . . . . . . . . . . . 32

23. Decrease of amplitude in time for a typical harpsichord string. ....................... 33

24. Illustration of filter effectiveness of the $2 \mathrm{~A} 61$ amplifier...................... 34

25. Input signal to wire. . . . . . . . . . . 35

26. A few cycles showing amplitude decay in time. . . . . 35

27. Paper riders used to indicate resonant peak . . . . . 36

28. Semi-log plot showing decay of harpsichord string . • - 39

29. Decay trace when oscillator slightly off resonance. . . 40

30. Symmetric resonance curve . . . . . . . . . 42

31. Asymetric resonance curve for a typical harpsichord string .... . . . . . . . . . . . . . 42

32. Frequency vs amplitude for non-linear oscillations. . . 43

33. Resonant frequency as a function of current at a
pressure of $35 \mathrm{microns}$. . . . . . . . . 45

34. Decay time for iron wire as a function of frequency
In air - . . . . . . . . . . 47

35. Decay time for steel wire as a function of frequency In air ..................... 48

36. Decay time for brass wire as a function of frequency in air .. . . . . . . . . . . . . . . 49

37. Decay time for bronze wire as a function of frequency in air .................... 50

38. Decay time for sllver and gold wire as a function of frequency in air . . . . . . . . . . . . 51

39. Decay time for iron, steel, brass, and bronze wire as a function of frequency in vacuum . . . . . . . 52 
40. Decay time for Iron, steel, and brass wire as a

function of low frequency in air ......... 53

41. Decay time for iron and steel wire as a function

of high frequency in air . . . . . . . . . . 54

42. Decay time for iron and steel wire as a function

of high frequency in vacuum . . . . . . . . . 55

43. Decay time for Iron, steel, brass, and bronze wire

as a function of diameter in air ......... 57

44. Decay time for iron and steel wire as a function of pressure .. . . . . . . . . . . . . 58

45. Log-log plot of decay time for iron and steel wire as

a function of pressure .. . . . . . . . . 59

46. Decay time for iron and steel wire as a function of

frequency, air-vacuum comparison. . . . . . . . 60

47. Decay trace illustrating the effect of air on a harpsichord wire vibrating originally in a vacuum . . . 63

48. Random orlentation of grains and microscopic heat flow in a flexing wire ... . . . . . . . . . . 68

49. Reciprocal amplitude vs time for data taken from the decay curve shown in Figure 23 . . . . . . . . . 71 


\section{INTRODUCTION}

\section{A Brief History of the Harpsichord}

It is commonly thought that the harpsichord derived from the psaltery, a plucked, stringed instrument of the Middle Ages, something on the order of the zither. Historically it is noted that keys were added to the psaltery as early as the twelfth century. The harpsichord may then be described as a psaltery with keys. It appears that although the earliest extant harpsichords date only from the sixteenth century, we can conclude that the basic members of the harpsichord family had been developed at least by the fifteenth century.

In the sixteenth century the building of harpsichords was centered in Italy, particularly in Venice. In the latter part of the sixteenth century Antwerp became an important center for harpsichord building. English harpsichord manufacturing came into its own in the eighteenth century when it reached an excellence that made it second to none.

It should also be mentioned that there was some interest in harpsichords and harpsichord building in the colonial United States. We have for instance, the correspondence of Thomas Jefferson in 1786 and of George Washington in 1793 with haxpsichord builders and dealers.

In the latter part of the eighteenth century the piano attracted more and more favorable attention at the expense of the harpsichord. 
After 1800 harpsichord building generally came to a complete halt, with only sporadic interest in the older instrument continuing here and there during the nineteenth century.

Towards the end of the nineteenth century it came to be realized, principaliy by those involved with music in the universities, that it was desirable to perform early music on the instrument for which it had been written. Consequently the manufacture of harpsichords has Increased steadily since the late $1800^{\prime}$ 's up to the present. Contemporary composers have even seen fit to compose music for the harpsichord and it has become possible for a few concert artists to make careers for themselves as harpsichordists. Kirby (1).

\section{Types of Harpsichords}

The name harpsichord applies particularly to a relatively elaborate instrument shaped like an early form of grand piano. The virginal is a smaller rectangular type, and the spinet has a polygonal shape. The word virginal was usually applied to any instrument of the harpsichord type in the seventeenth century, especially in England. Although the larger harpsichords were elaborate instruments with several sets of strings, two or even three keyboards, and various mechanical devices, the action of the smaller virginal was simple. A string for each note was stretched between bridges mounted on a wooden soundboard.

How the Harpsichord Produces Sound

The plucking mechanism consists of a jack, five to eight inches high, placed above the end of each key, (Figure 1). A slot is cut 
at the top of each jack and into this slot is placed an upright plece

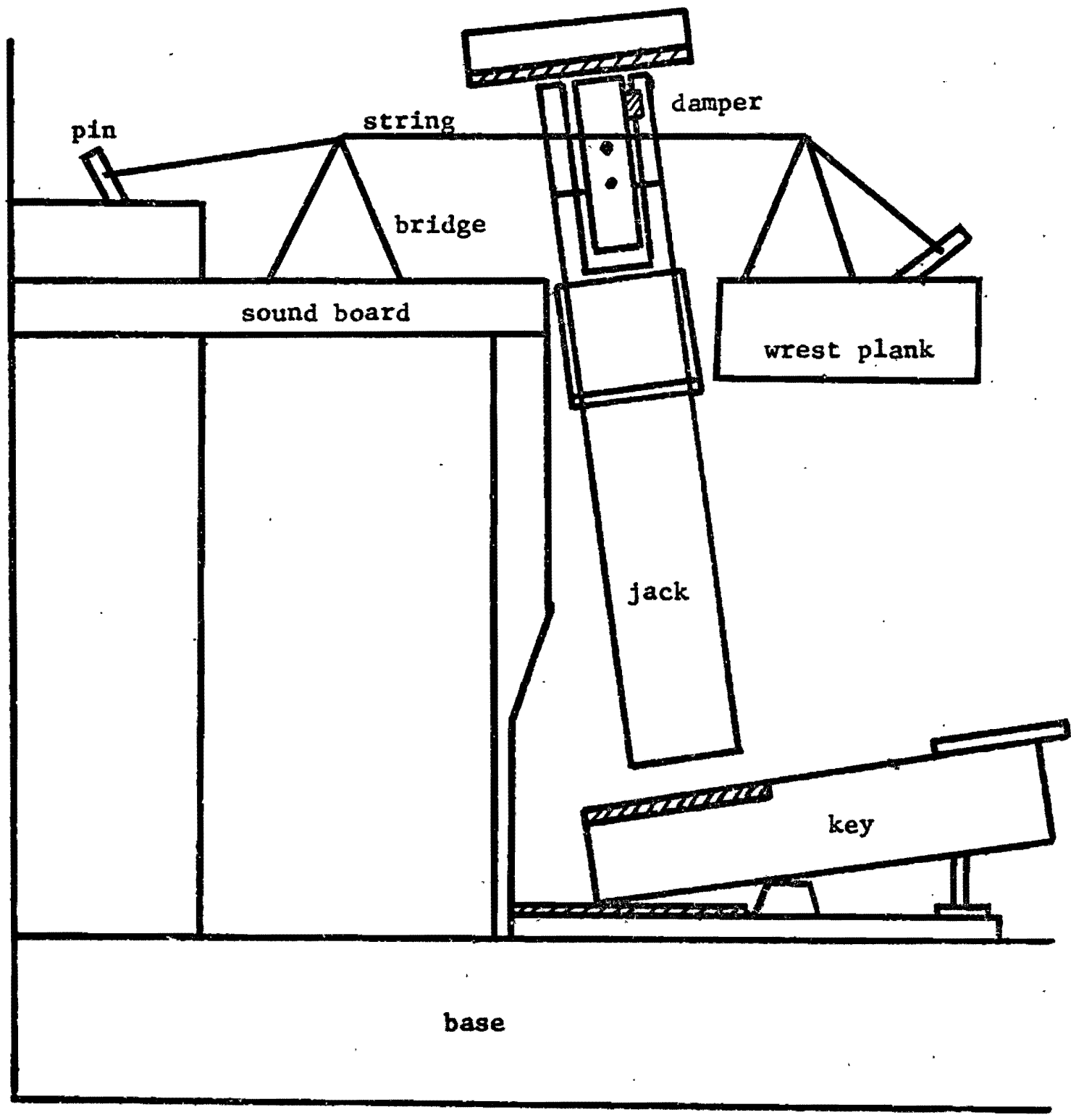

Figure 1. Some basic harpsichord components.

of wood about one and one-fourth inches long called a tongue, pivoted by means of a horizontal metal ring. A spring of hog's bristle presses on the tongue so that if it is displaced from the vertical it will return to this position, see Figure 2. 
The plectrum, a quill or small wedge of hard leather, is set Into a small slot in the tongue and projects from it about one-eighth inch, (Figure 2). At the side of the top of the jack is a damper

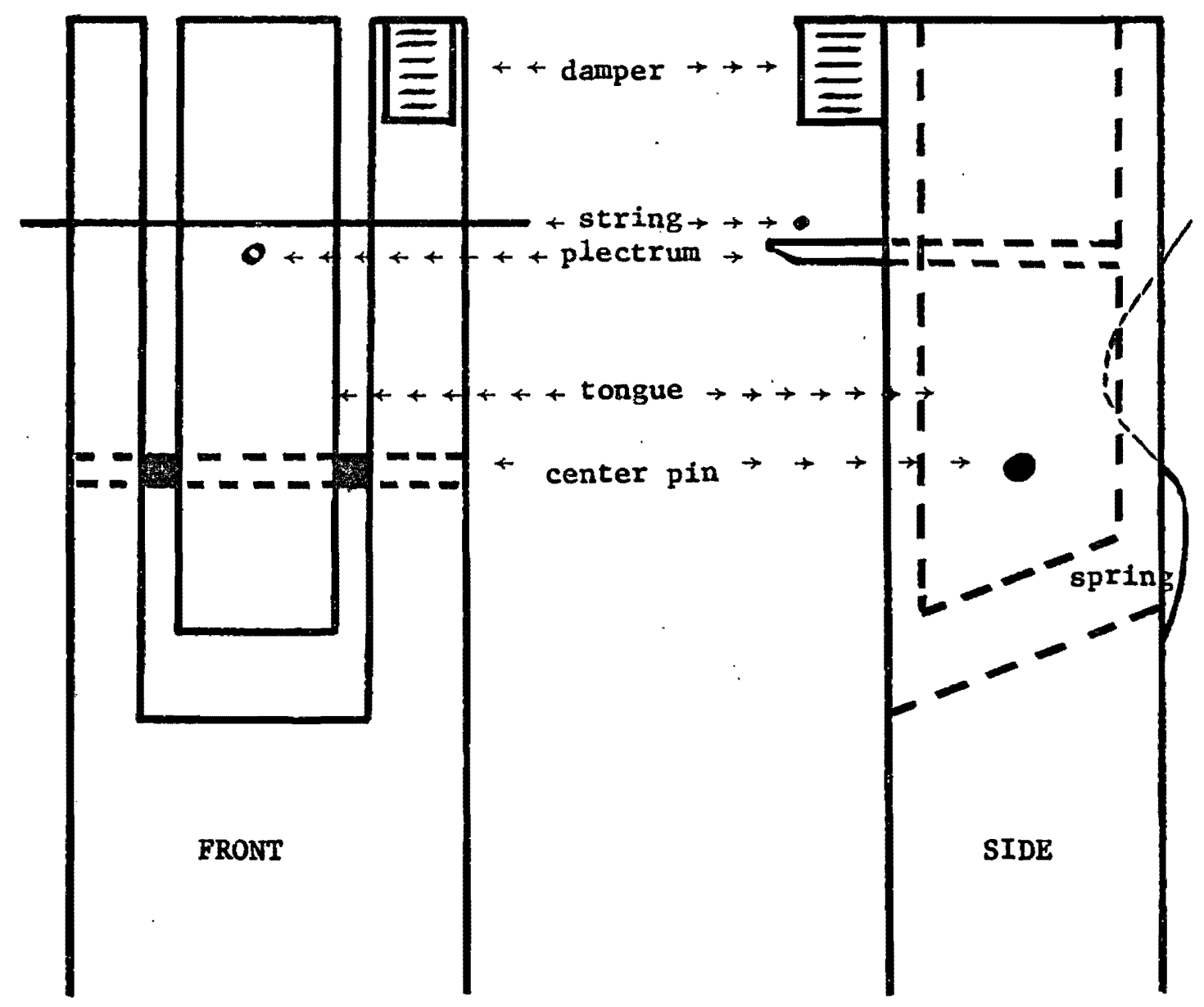

Figure 2. The harpsichord plucking mechanism.

made of a piece of felt. Each set of jacks is placed in registers or holes In a flat piece of wood. These serve two purposes: 1. They line up the jacks so that the plectra strike the strings exactly at the right places. 2. The register may be'moved by stop-levers so 
that the jacks are rendered inoperable and the strings are not struck.

The action of plucking a string is this: When a key is depressed, the jack rises and the plectrum is forced past the string and causes it to sound. When the finger is taken from the key, the jack descends and the plectrum, coming into contact with the string, turns the tongue on its pivot so that the quill passes the string without plucking it. When the jack has descended as far as it can go, the hog's bristle spring restores the upright position to the tongue, the damper descends to the string, silencing it, and the cycle of operations is completed. Since the tone is produced by plucking, there is little dynamic varlation possible on the harpsichord, at least in its simpler forms. Whether the key is struck hard or softly, it produces neither a louder nor a softer tone. Although some slight alterations of this sort are certainly possible, their effect may be regarded as negligible. The quality of the tone produced has been universally described, since the first instruments were designed, as soft, sweet, and mild, like the volce of a young lady. This is the desired tonal result sought by the contemporary harpsichord builder. Sumner (2).

Some Motivations for Investigating the Vibration of Harpsichord Strings

The Iron-Steel Wire Controversy. At the present time there is disagreement among harpsichord builders and also among performers regarding the use of modern carbon-steel music wire as a substitute for the iron wire used in early instruments. This disagreement centers around attempts to approximate the tonal characteristics of the ancient harpsichord. 
Note that iron wire differs from steel wire in its carbon content. The iron wire used in this investigation had a Young's modulus of $3.13 \times 10^{12}$ dynes $/ \mathrm{cm}^{2}$ while the Young's modulus for steel wire was $3.61 \times 10^{12}$ dynes $/ \mathrm{cm}^{2}$.

Those who advocate the suitability of carbon-steel wire point to the fact that the ratio of stress to strain, Young's modulus, is approximately the same for carbon-steel as it is for samples of iron wire used in harpsichords of the eighteenth century. This similarity holds for a wide range of states of work-hardening. The implication would be that both types of wire should contain similar families of harmonics when plucked, and consequently should produce similar tonal qualities.

others maintain that the old iron wire gives a sweeter and less plercing tone and suspect that this difference has something to do with the length of time it takes for the wire to stop vibrating, ie; its damping capacity. Apparently no one has sought to compare damping capacities of iron and steel harpsichord wire under properly controlled conditions; thus it was felt that such an investigation might help to settle the iron-steel wire controversy. Ratajak (3).

Modes of Energy Loss from a Vibrating Wire. If indeed, it is discovered that two wires of unlike chemical composition lose their vibrational energy at different rates, or that a single wire loses Its energy at differing rates dependent upon external conditions, then in order to determine why these differences exist, some thought must be paid to the modes in which energy can escape from a vibrating wire, and if possible, a comparison of the energy loss in each mode 
should be made.

A stretched wire attached at its endpoints will lose its vibrational energy in the following ways when vibrating in air:

1. The moving wire will emit sound energy.

2. The moving wire will lose energy due to viscous damping.

3. Due to continued flexion of the wire there will be loss of energy due to internal friction.

4. There will be energy loss at the bridges, or supports.

If the supports are connected to a common base (Figure 3 ) then feedback loops may be set up depending on the natural frequency of the base and its tendency to be set into forced oscillation.

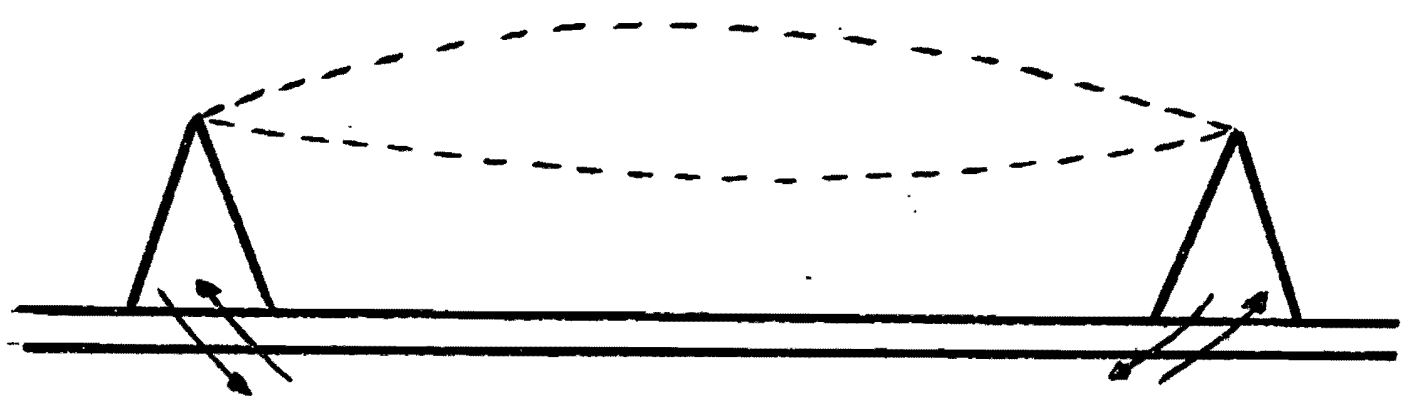

Flgure 3. Feedback loops through common base.

If the supports are isolated from each other, feedback may yet occur within each individual support (Figure 4). Also there will presumably be secondary emission and possible feedback of sound to and from the base and whatever media contact the base.

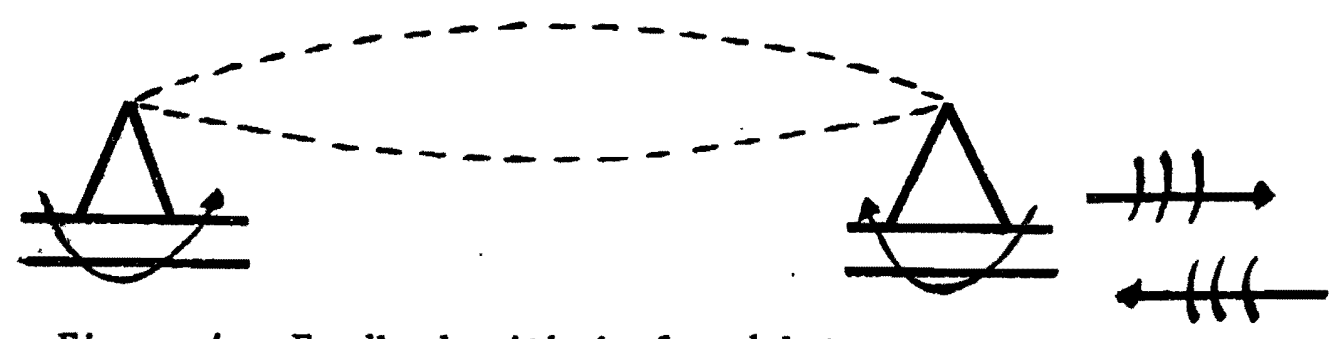

Figure 4. Feedback with isolated bases. 
In this investigation close attention was directed to the var-. ious methods of attaching the wire to the supports, the type of supports, and the relationship between support and contacting media.

These four modes of energy loss are not easily examined singly by experiment; however some idea of support effects was attained by use of a variety of supports, by comparing the damping capacity for each, and by removing the effect of air-wire interactions as explained in the following section.

The Behavior of a Vibrating Wire in a Vacuum. An obvious way to eliminate energy losses due to the surrounding air would be to remove the air and allow the wire to vibrate in a vacuum. (In this paper a vacuum is understood to mean a minimum pressure of between 25 and 30 microns of mercury). Any difference in the time it takes for the wire to lose its energy in a vacuum compared to the time taken in air, all other conditions being held constant, should be attributable to the interactions between the wire and the air. Thus It was felt that an examination of vibrating wires in a vacuum was an essential adjunct to this investigation.

Summary. In summary this paper will:

1. Ascertain what, if any, measurable differences in damping capacity may exist for iron and steel harpsichord wire.

2. Compare damping capacities and related characteristics for a varlety of harpsichord wire materials, diameters, lengths, and other adjustable parameters.

3. Investigate the modes of energy loss from the wires described above by varying the type of support and the air pressure. 
Related Research Previously Done

The following is a partial compilation of research findings pertaining to objectives similar to those of this paper. A broader coverage of a portion of this material is presented in Appendix A. Rate of Decay as a Function of Time. Pyle (4), Martin (5), and Hundley (6) measured the amplitude of vibrating piano and/or harpsichord strings as a function of time in order to compare the decay characteristics of these instruments. Although the rate of change of slope of the amplitude vs time curves varied from string to string and from instrument to instrument, each curve was characterized by a large initial slope and a smaller final slope. Rate of Decay as a Function of Frequency. Pyle (4) and Bennewitz (7) showed that higher frequencies decayed faster in time than lower frequencies for strings used typically in harpsichords. Rate of Decay as a Function of Sounding Board. Martin (5) found that, for piano strings, removal of the sounding board caused the amplitude of the string to decrease in time only about one-half as fast as when the sounding board was present.

Internal Friction as a Function of Frequency. Bennewitz (7) and Zener $(8,9)$ predicted and experimentally verified a maximum in internal friction as a function of frequency for harpsichord strings. Internal Friction due to Microscopic Transverse Thermal Currents. Zener (10) and others developed a theory indicating that internal friction in a vibrating wire was predominately due to intercrystalline heat flow. Zener showed that due to the random orientation of grains within the wire and the subsequent random stresses on these grains, 
when the frequency is low and the grain size is small, heat flow will be maximum. Thus energy losses under these conditions will be large. They were successful in detecting the contribution of this heat flow to the' internal friction of polycrystalline metals.

\section{Objectives}

As has been stated, the principal questions for which answers were sought are:

1. In what ways, if any, do iron and steel harpsichord wires differ in their decay characteristics?

2. What are the modes by which energy is lost from a vibrating harpsichord wire? How do the rates of energy loss from the various modes compare?

In seeking answers to these questions, many secondary objectives were established:

A. Measure the time it takes for the amplitude of a vibrating wire to be reduced to some given fraction of its initial value, usually one-half. This could be loosely termed the half-1ife of the decay.

B. Find the half-life at several frequencies for a wire of chosen material, diameter, length, etc., and kept at a fixed tension.

C. Determine the half-life as a function of frequency for a varlety of materials such as iron, steel, brass, bronze, silver, and gold.

D. Vary the length and tension of each type of wire within practical limits and find the half-life for each condition as as a function of frequency. 
E. Make cross-comparisons Involving these objectives in such a way that question one is answered.

F. Attach the wires to their supports using a variety of terminating blocks whose differences in material, mass, and contact with the surroundings provide a wide range of impedancematching combinations.

G. Look for differences in decay patterns as the supports are changed. Attempt to relate these differences to changes in energy loss rates at the supports.

H. Look for differences in decay patterns within the range of wire materials used. Attempt to relate these differences to the particular internal friction inherent in each wire.

I. Develop a vacuum system in order to minimize the loss of energy due to sound radiation and viscous damping.

J. Compare half-life vs frequency data under vacuum conditions to those under similar conditions in air.

K. Measure half-life vs frequency at a variety of air pressures to establish the dependence of half-life on pressure.

L. Measure amplitude as a function of frequency.

M. Measure frequency as a function of pressure. 
THEORY OF VIBRATING STRINGS

Resonance and Standing Waves

Consider a string of length $\mathrm{L}$, fixed at both ends and under a tension T. It may easily be shown, Sears (11), that the speed of propagation of a transverse impulse on this string, (Figure 5), is given by the relationship: $v=(T / \mu)^{1 / 2}$, where $\mu$ is the mass per unit length of the string.

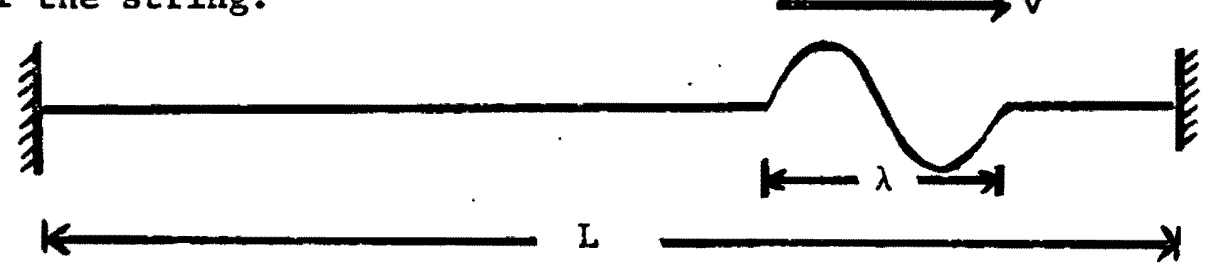

Figure 5. An impulse moving along a string under tension.

Standing waves, (Figures 3 and 4 ), may be set up on this string provided that the length $L$ contains an integral number of half-wavelengths. This is the condition for resonance, and may be expressed as: $\mathrm{L}=\mathbf{n} \lambda / 2$ or $\lambda=2 \mathrm{~L} / \mathrm{n}$ where $\mathrm{n}$ is the number of loops. The frequency of a wave is: $f=v / \lambda$, thus by substitution, $f=v n / 2 L$.

Again, by substituting $v=(T / \mu)^{1 / 2}$ into this equation, the result is: $f_{r}=n / 2 L(T / \mu)^{1 / 2}$ where $f_{r}$ is the resonant frequency of the wire for the stated conditions. This relationship describes the resonant condition for standing waves on a string or wire and illustrates the interdependence of frequency, length, tension, and mass per unit length.

The majority of the wires tested were given a tension of $10 \mathrm{lbs}$ 
or 44.5 newtons, which is a typical harpsichord string tension. The fundamental frequency, $\left(f_{1}\right)$, was arbitrarily chosen to be $100 \mathrm{~Hz}$. With these two parameters pre-determined, the resonant length for each wire depended simply on $(\mu)^{1 / 2}$.

Low-frequency $\left(f_{1}=20 \mathrm{~Hz}\right)$ testing was done with long, massive wires at minimum tensions, high-frequency $\left(f_{1}=450 \mathrm{~Hz}\right)$ testing was done with short lightweight wires at maximum tensions.

Energy of a Standing Wave on a String

The vibrating string is merely a collection of elementary oscillators. If $\mathrm{dx}$ is taken as an elementary length, the mass of each such oscillator will be $\mu d x$, and its amplitude will be $A$ sin $n_{\pi} x / L$, where $A$ is the peak amplitude of any segment, and the factor sin $m x / L$ indicates that the element may not be at a point of peak amplitude. If the string is in vibration in its nth normal mode, it consists of n similar vibrating segments, see Figure 8.

The total energy $E$ of an oscillator is the sum of its potential energy $E_{p}$ and its kinetic energy $E_{k}$, where $E_{p}=(1 / 2) k y^{2}$ and $E_{k}=(1 / 2) m(d y / d t)^{2}$. Using the familiar expressions for the oscillator: $y=A \cdot \sin (\omega t+\delta)$ and $\omega=(\mathrm{k} / \mathrm{m})^{1 / 2}$, it is easy to show that the total energy of the oscillator is: $E=1 / 2 \mathrm{~m}_{\omega}^{2} \mathrm{~A}^{2}$.

We therefore have for the energy in any element of the string,

$$
d E=(1 / 2) \omega^{2} A^{2} \mu\left(\sin ^{2} n \pi x / L\right) d x
$$

and for the total energy in a string of length $L$,

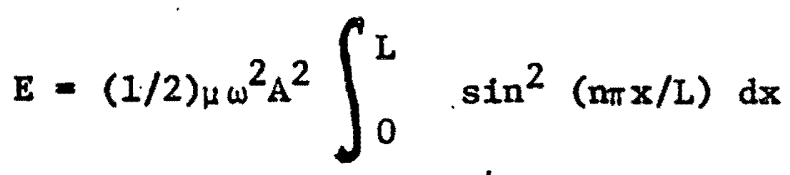




$$
\begin{aligned}
& E=(1 / 2) \mu \omega^{2} A^{2}\{x / 2-\sin 2 a x / 4 a\}_{0}^{L} \\
& \text { where } a=n / L
\end{aligned}
$$

Therefore,

$$
\begin{aligned}
E & =(1 / 2) \mu \omega^{2} A^{2}\{L / 2-0-0+0\} \\
& =(1 / 2) \mu \omega^{2} A^{2} L / 2=\mu \omega^{2} A^{2} L / 4 \\
& =m \omega^{2} A^{2} / 4 \text { where } m \text { is the total mass of the string. }
\end{aligned}
$$

The energy of a standing wave is proportional to the square of its amplitude.

The maximum amplitude $A$, of a standing wave is twice the amplitude $A^{\prime}$ of each of its component waves, Figure 6 , thus

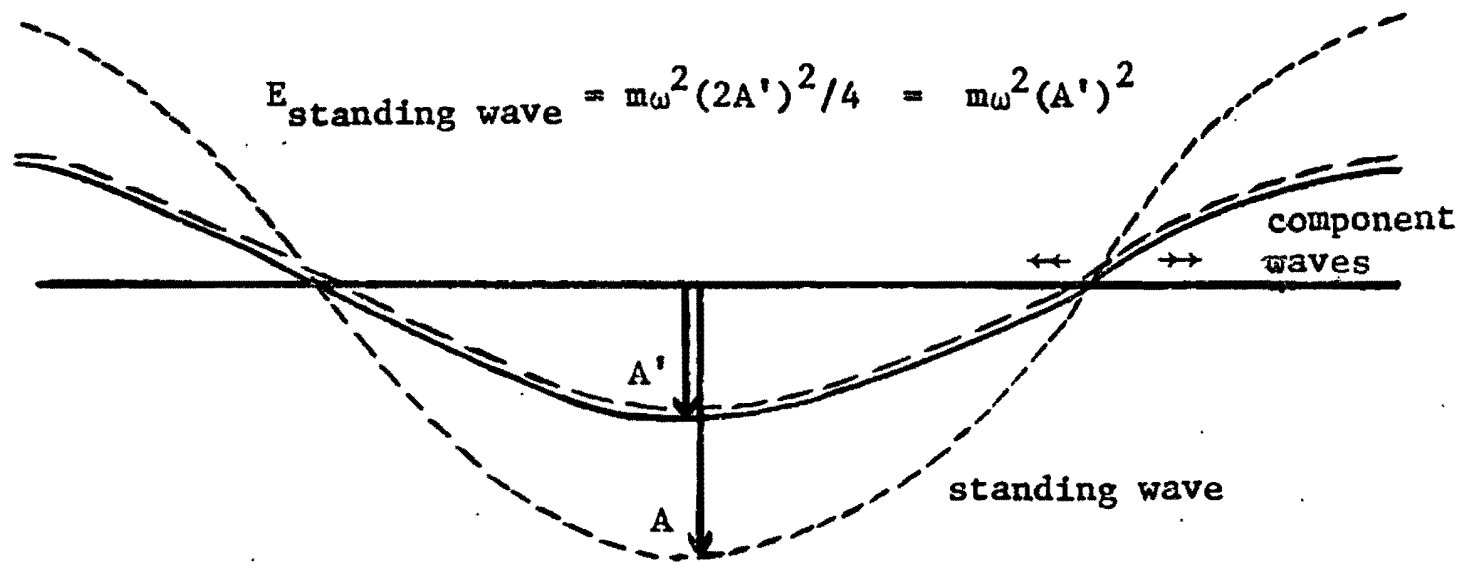

Figure 6. A standing wave and its component waves.

\section{Velocity as a Function of Amplitude}

If a wire is caused to move by the application of a transversely applied sinusoldal driving force, its position as a function of time w111 be described by the relationship, $y=A \sin (\omega t+\delta)$. Therefore the transverse velocity, $d y / d t=\omega A \cos (\omega t+\delta)$.

The transverse velocity of a vibrating wire is directly proportional to its amplitude. 
EQUIPMENT

The following is a description of some of the major pieces of equipment used in this investigation.

\section{Electrical Circuitry}

Although the harpsichord string on the instrument is plucked, producing a complex tone consisting of several harmonics, it was decided that rather than attempt to analyze this complex wave form, It would be more fruitful to simply cause the wire to vibrate in a single mode. As suggested by Sanford (12) this may be accomplished In a precise manner by applying an alternating current to the wire while it is in a uniform magnetic field.

Method by which the Wire is set into Vibration. A stretched wire of length $L$ in a uniform

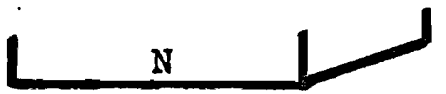
magnetic field B will experience $a$ force $F=B i L$ if $a$ current $i$ is passed through the wire. The directional relationships between the force, current, length, and

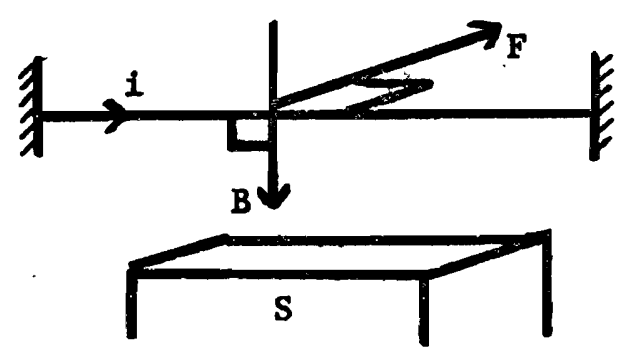

Figure 7 . The force on a currentcarrying wire in a magnetic field. magnetic field are shown in Figure 7 . If the current varies sinusoidally with time, then the force will vary in like manner. The effect of this sinusoidally varying force will be to set the wire Into transverse vibrational motion in a plane parallel to the plane 
of the pole faces of the magnet. When the frequency of the driving force is such that the length of the wire $L$ contains an integral number of half wave lengths, the phenomenon of resonance occurs, the result of which is a visible transverse amplitude. Since the decay pattern of the wire was studied by measuring the magnitude of this amplitude as a function of time after removal of the driving force, resonant frequencies were used throughout to excite the wire.

Method by which the Decay Pattern of the Wire was Monitored.

If the transversely vibrating

wire is then disconnected

from the alternating current

source and connected to the vertical amplifier of an oscilloscope (Figure 8) the generated voltage $\mathrm{E}_{\text {gen }}=\mathrm{BLv}$ may be detected. ( $v$ is the velocity of the wire in the field.) As the wire's motion decreases, ie decays, the amplitude of the scope trace will diminish as an indication

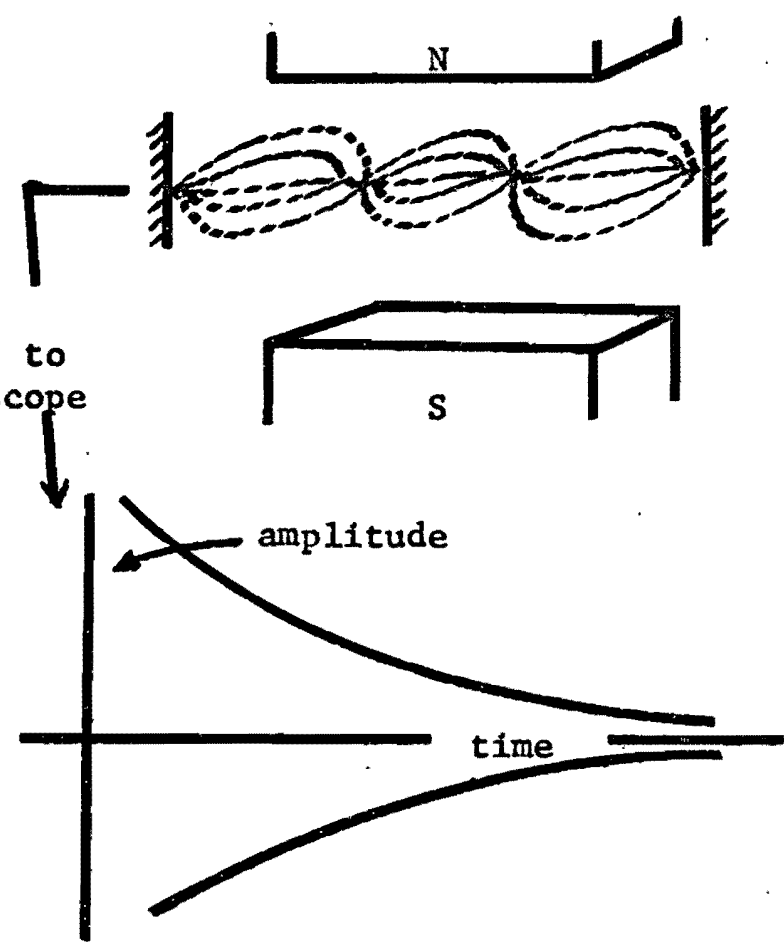

Figure 8. Decay of resonating wire as monitored by oscilloscope. of the decreasing velocity of the wire. The amplitude of a sinusoidally vibrating object is directly proportional to its velocity. Thus the escliloscope trace is a reproduction of the amplitude of the wire as a function of time as the resonance decays. The entire electrical circuit is shown in Figure 9 on the next page. 


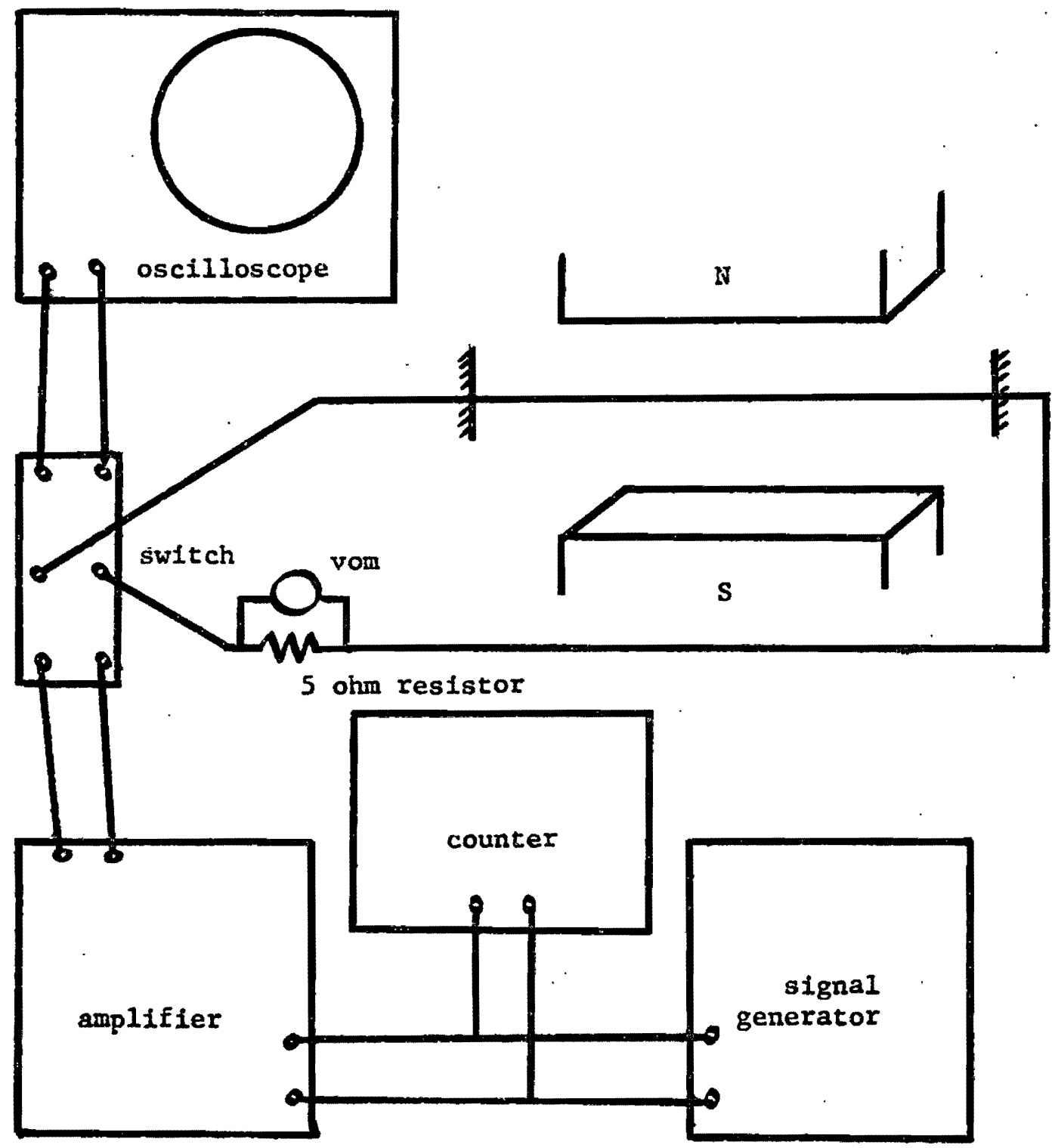

Figure 9. Electric circuit. 
It was necessary to separate the scope as far as possible from the other components in order to minimize background noise pick-up from the other equipment, especially the signal generator. The current through the wire was regulated by a control on the signal generator.

Technical Description of Circuit Elements:

Oscilloscope: Type 564B storage oscilloscope with auto-erase.

Equipped with type $2 \mathrm{A61}$ differential amplifier and type 3B3 time base. Tektronix, Inc.

Signal Generator: Continuously variable, 5 to $600 \mathrm{~K} \mathrm{~Hz}$, audio oscillator. Hewlett-Packard.

Counter: Type 5246L electronic counter with digital readout. One second time base. Hewlett-Packard.

The type $2 A 61$ amplifier was equipped with filter circuitry which provided frequency selectivity over specific ranges (Figure 10).

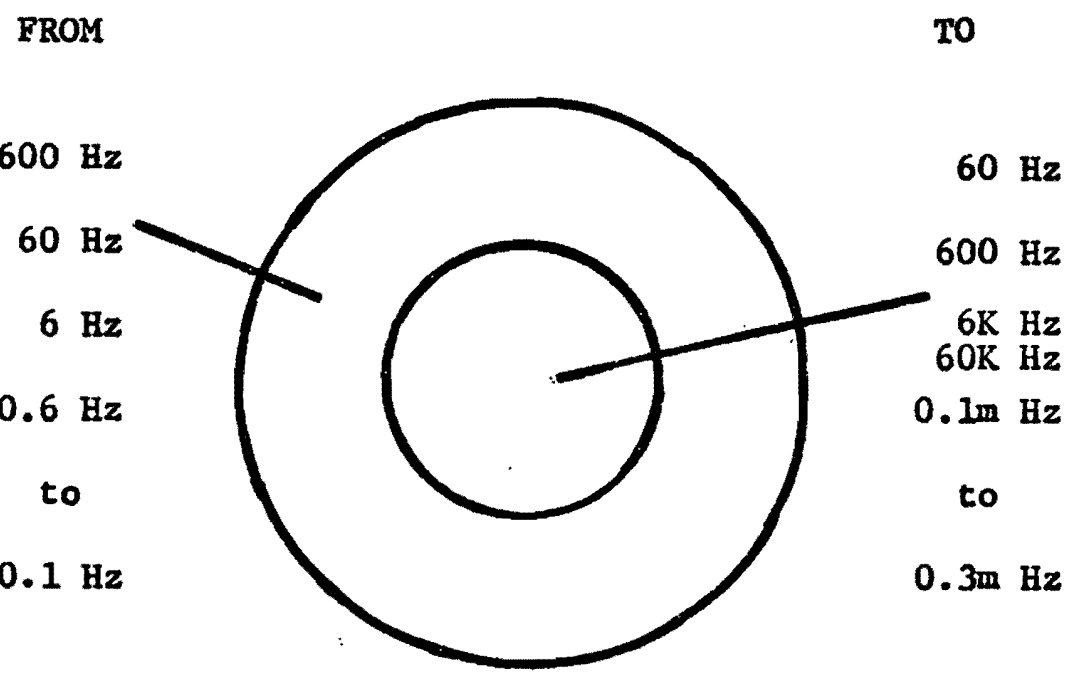

Figure 10. Frequency response selectivity of $2 \mathrm{A61}$ amplifier. 
Types of Magnets Used

Permanent Magnets. The initial experiments were done using a U-shaped magnetron magnet rated at approximately 1800 gauss. Due to the shape of the magnet, the field is not uniform; thus sinusoidally generated voltages were not possible for the wire moving as indicated in Figure 11. The magnetron-type magnets were used for preliminary rough checking only during the Initial phases of experimentation.

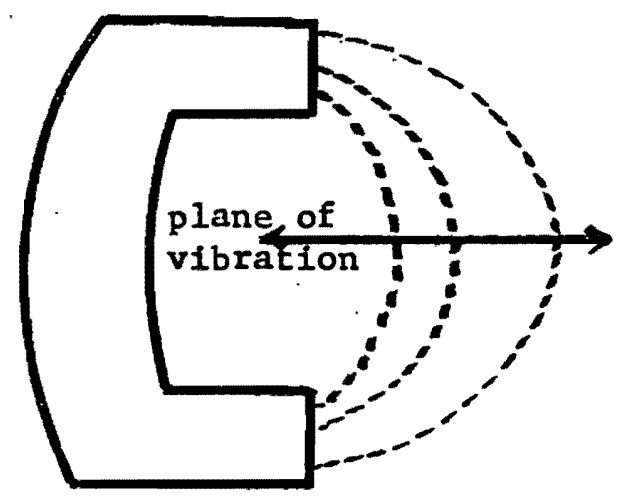

Figure 11. Non-uniformity of field of magnetron magnet.

The next permanent magnet to be used was a Laboratory For Sclence variflux magnet which is a variable-field magnet, equipped with interchangeable pole pieces.

This variflux magnet was used with the $10 \mathrm{~cm}$ diameter ceramic pole pieces and with a pole separation which varied from several centimeters to a few millimeters. The field strength (Figure 12) never exceeded 2000 gauss.

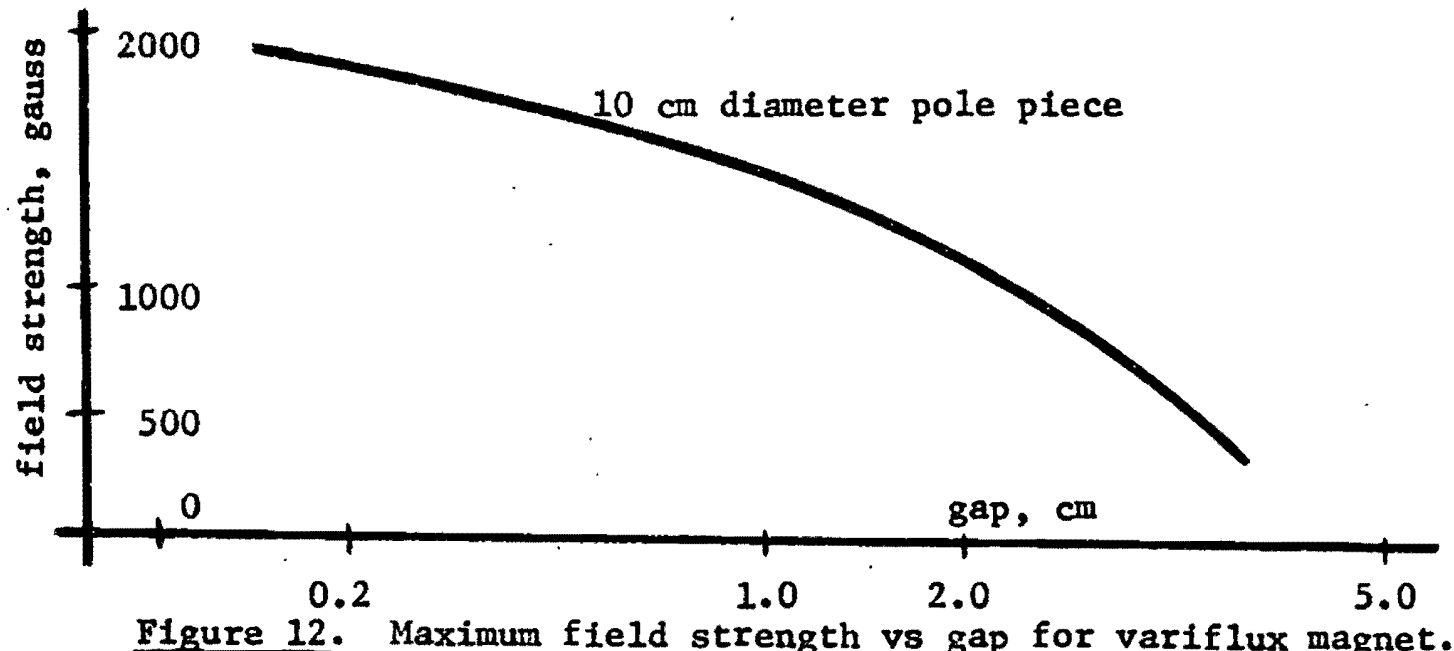


In later phases of the investigation it became necessary to increase the field strength and also limit the amplitude of vibration to less than one-half centimeter. In this case the variflux magnet was used again, fitted with tapered pole pleces (Figure 13) whose smaller diameter was $1.5 \mathrm{~cm}$. The gap was reduced to a minimum of $7 \mathrm{~mm}$ and the resulting field was estimated to be in excess of

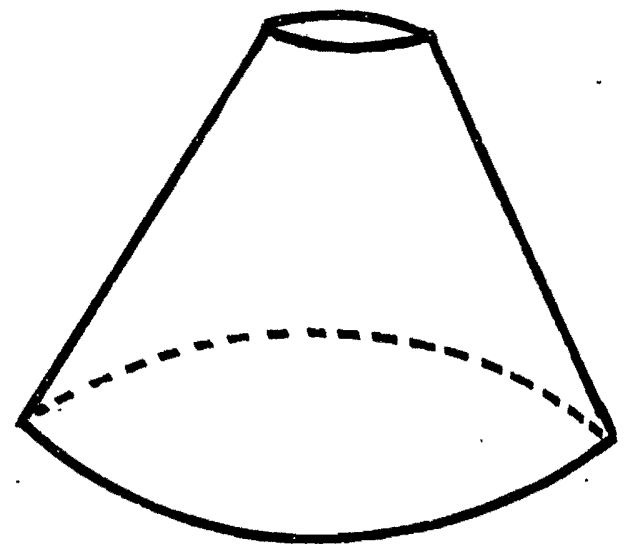

Figure 13. Tapered pole plece. 5000 gauss.

Pole Plece Width and Internodal Distance. The use of tapered pole pleces was necessary for reasons other than that of increasing fleld strength. When the wire was set into vibration at some of the higher harmonics, the internodal distance along the standing wave sometimes approximated the diameter of the pole pleces (Figure 14).

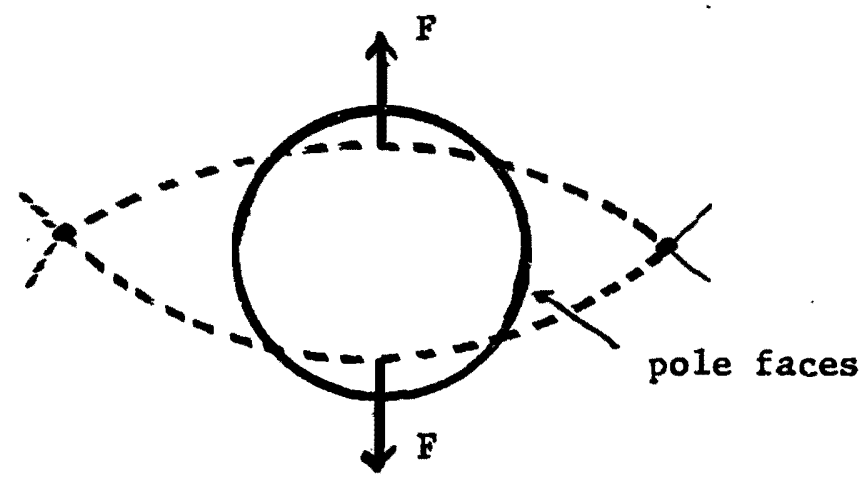

Figure 14a. Internodal distance compared to pole face diameter at low frequencles.

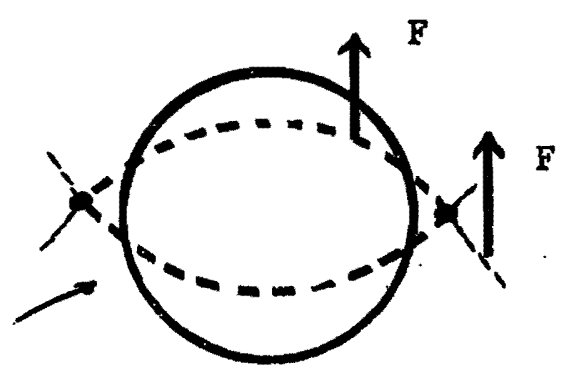

Figure 14b. Internodal distance compared to pole face diameter at high frequencies.

As this began to occur, it became increasingly difficult to maintain 
the wire's motion and the decay curves obtained on the scope became more and more distorted. Apparently the action of the forces shown In Figure 14b tended to destroy the node.

A third reason for using minimum-area pole faces was so that the driving force could be centered as close as possible to the antinode. This resulted in maximum efficiency in terms of driving the wire and also in terms of the generated voltage. The generated voltage is velocity-dependent and thus will be greatest where the velocity of the wire is maximum, at the antinode. Indeed, in some of the final testing, if the pole pieces were not precisely centered on the antinode, it was not possible to get a scope traca.

The position of the antinode

is the same for all odd harmonics,

$\mathrm{n}=1,3,5, \ldots$, (Figure 15).

This simplified magnet-alignment

problems in many instances.

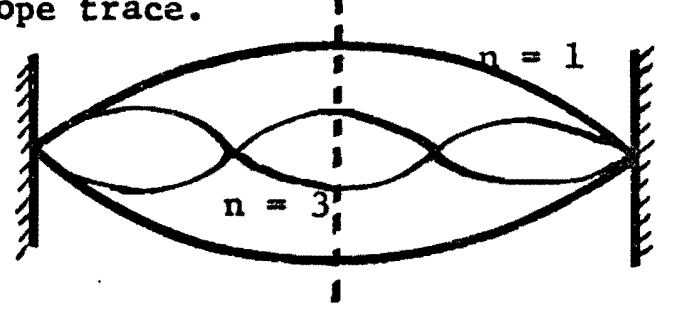

Figure 15. Common antinode position for odd harmonics.

Electromagnet. In order to attain higher fields than was possible with the permanent magnets, an air-cooled Atomic Research electromagnet was used, also equipped with interchangeable pole pleces. A field of $8 \mathrm{~K}$ gauss was possible for limited periods of time when tapered pole pieces were used with an air gap of $2 \mathrm{~cm}$. The adjustability of the field produced by the electromagnet was a decided improvement which allowed precision measurements not possible with the permanent magnets. However, a problem arose with regard to the Iarge size of the field coils, necessitating a return to the variflux magnet when working with shorter wires. 
Types of Terminating Blocks Used

As may be seen by reference to Figure 1 on page 3, on the instrument itself, the harpsichord string is stretched between two pins and over a sound board bridge and a wrest plank bridge.

In an attempt to reduce the number of unknown variables and generalize the problem it was decided to approximate this configuration by simply attaching the test wire to two pins, similar to those used on the harpsichord and embedded in some type of board, block, wall, or mass of some type, either common to both pins or "separate". (It would be exceedingly difficult to arrange two blocks so that they were 100 per cent vibrationally separate).

Wood/Wood. Initially a steel pin was screwed into a block of Douglas fir as shown at the right. Two of these served as the terminal blocks. The mass of each was about $0.3 \mathrm{~kg}$. The blocks were then clamped to the top of a maple table by means of C-clamps, Figure 17. This established a

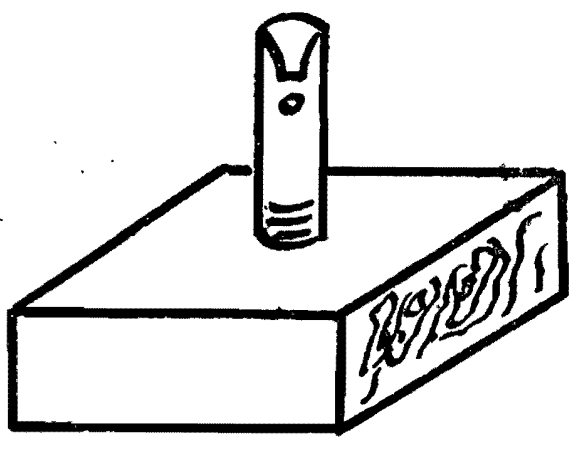

Figure 16. Pin-block arrangement.

wood-to-wood contact with a relatively close impedance match between

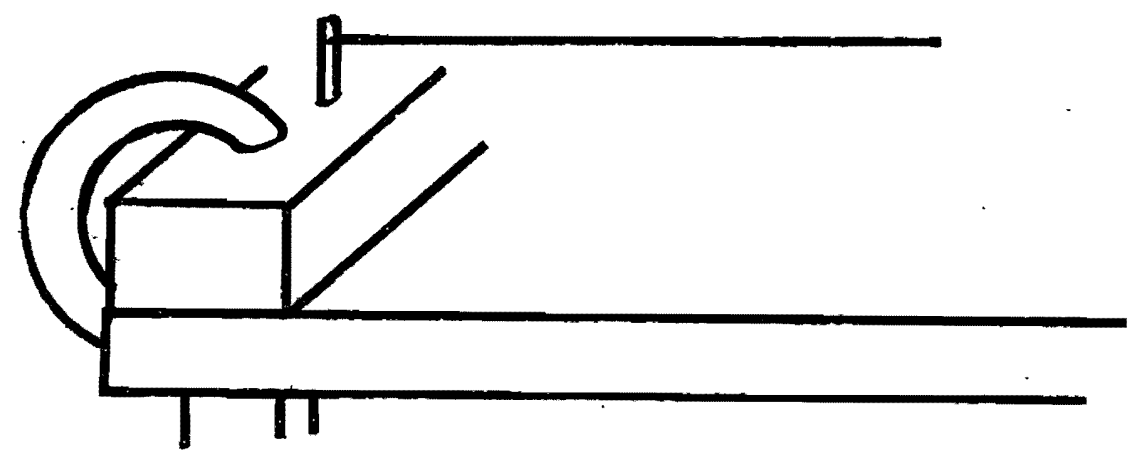

Figure 17. C-clamp attachment of terminal blocks to maple table. 
the block and the table top. When the wire resonated at $100 \mathrm{~Hz}$, the sound of the table top vibrating could be easily heard and its movement could be felt. Certainly some energy was being lost from the system, and perhaps a good deal was also being exchanged between members of the table-block-pin-wire system.

Lead/Wood. Since it was one of the objectives to examine modes of energy loss from a vibrating system, it was desirable to somehow control and perhaps minimize the loss through the supports. In order to find out what physical features of the system determined this loss, it was decided to change to massive, dense, lead terminal blocks. The use of the lead was thought to do two things:

1. Create an impedance mismatch between the table and the block, thereby reducing the table's vibration.

2. The lead would act as an absorber, or sink, for the wire's vibrational energy, allow less energy to feedback to the wire, and thus decrease the decay time for the wire.

If the wire decayed faster with lead terminal blocks, the factors responsible for this decay were, at most, being minimally influenced by feedback. Therefore lead blocks having a mass of nearly $11 \mathrm{~kg}$ each were substituted for the wooden blocks.

The results of this substitution were quite evident, and they are presented in Table I on the following page. The vibration of the table was reduced below the audible range at least.

From the data it can be seen that the decay times were reduced by 13 to 14 per cent by the substitution of lead for wood terminal blocks, while keeping all other factors constant. 
TABLE I

DECAY TIME AS A FUNCTION

OF SUPPORT

\begin{tabular}{c|c|c}
\hline Frequency, $\mathrm{Hz}$ & Half-Life, seconds \\
\cline { 2 - 3 } & Wood/Wood & Lead/Wood \\
\hline 90 & 1.76 & 1.50 \\
180 & 1.50 & 1.32 \\
270 & 1.18 & 1.03
\end{tabular}

Lead/Rubber/Wood. As a means of further isolating the wire and the lead blocks from the table, the lead-wood system was modified by Inserting rubber washers $1 \mathrm{~cm}$ thick at all contact points between the blocks and the table. The results indicated another 13 to 14 per cent decrease in decay time as shown in Table II below.

TABLE II

DECAY TIME AS A FUNCTION

OF SUPPORT INSULATION

\begin{tabular}{c|c|c|}
\hline \multirow{2}{*}{ Frequency, $\mathrm{Hz}$} & \multicolumn{2}{|c|}{ Half-Life, seconds } \\
\cline { 2 - 3 } & Lead/Wood & Lead/Rubber/Wood \\
\hline 90 & 1.50 & 1.31 \\
180 & 1.32 & 1.16 \\
270 & 1.03 & 0.88
\end{tabular}


It was becoming clear at this time that the type of support was strongly influential in determining the decay time. This served to emphasize the importance of terminal block considerations when accounting for overall energy losses.

Lead/Rubber/Countertop. Even with the lead-rubber-wood system the vibration of the table could be detected with a sensitive pickup. The research lab was equipped with massive, soapstone counters solidly fixed to the building and these were used as a foundation for all subsequent work. No vibration of this base could be detected.

Cylindrical Steel Terminal Blocks. It was later decided that an 1mprovement was possible on the lead'blocks. Larger cylindrical steel blocks were machined that had a mass of $21 \mathrm{~kg}$ each and whose diameter and height were both $15 \mathrm{~cm}$. The use of such blocks had been suggested by Ratajak (3) in order to eliminate the possibility of having vibrational waves contained within the confines of the block 1tself. Since the velocity of sound is the product of its frequency and its wavelength, $v=f \lambda, \lambda=v / f$. Taking the speed of sound in steel to be roughly $5 \times 10^{5} \mathrm{~cm} / \mathrm{sec}$ together with the maximum frequencies usea, about $1.2 \times 10^{4} \mathrm{~Hz}$, the minimum wavelengths to be expected in the steel blocks would have been $5 \times 10^{5 / 1.2} \times 10^{4}$ or $42 \mathrm{~cm}$ which is nearly three times the largest dimension of the cylinders. Thus standing waves could not occur within these blocks.

A new clamping arrangement for the wire was necessary because 1t was feared that the pins previously used might be undergoing small vibrations, taking an unknown amount of energy from the wire, Figure 18. An 1mprovement was possible if the wire could be clamped 
firmly between two rigid blocks, each of which was solidly attached to the top of the large cylinder,

Figure 19. The

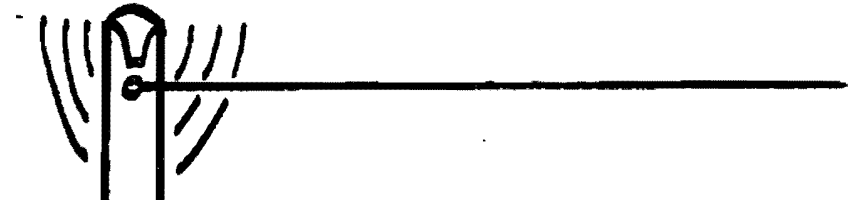

wire was led

Figure 18. Pin vibration.

through the clamping blocks to a pin for the purpose of adfusting tension. After the tension was set, the wire was firmly clamped in place so that no tension was acting on the pin while the wire moved. This proved to be a very sensitive method of attachment, making possible easy and precise adjustments of tension. It eliminated the chance of pin slippage under high tensions and at high frequencies.

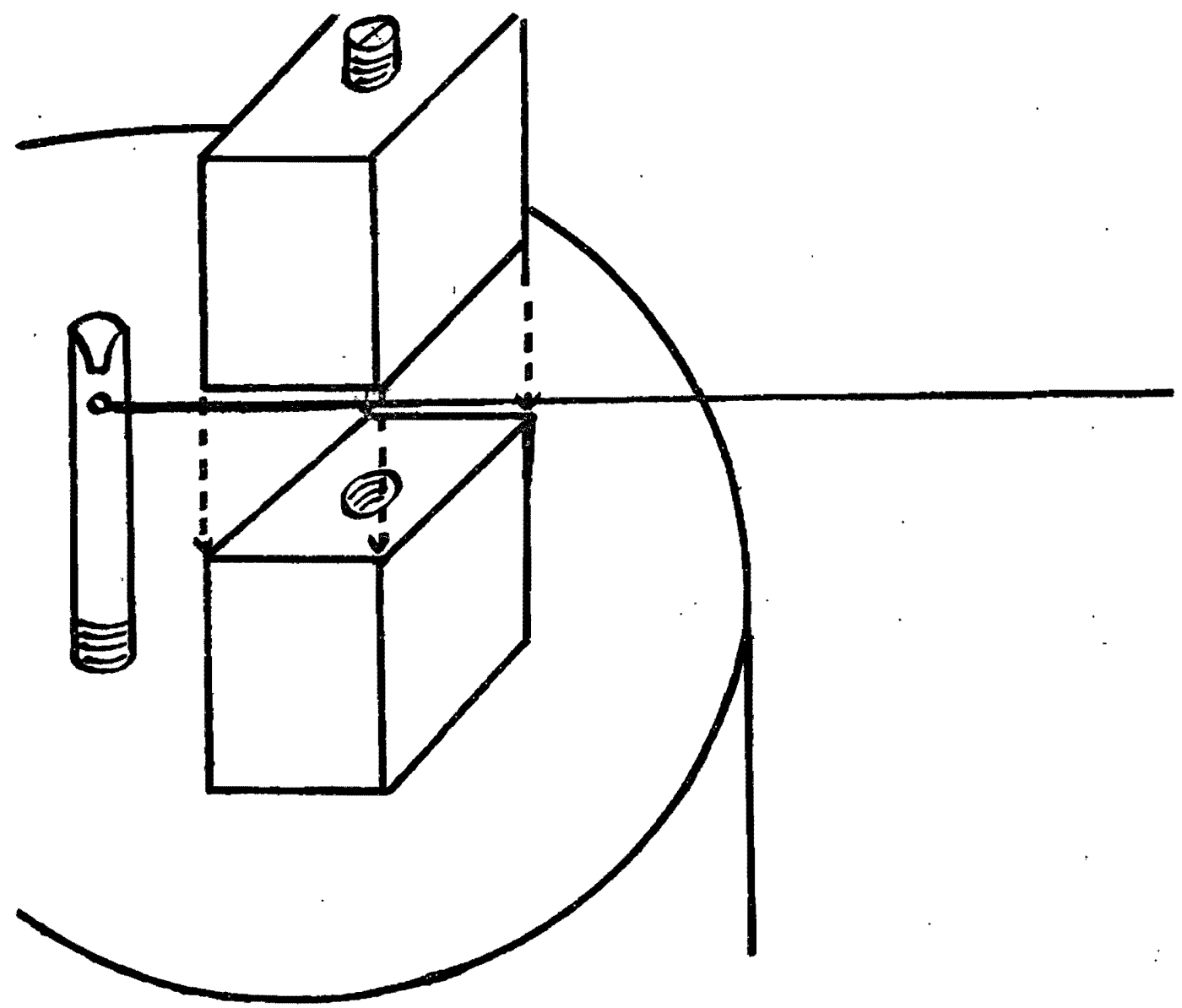

Figure 19. Steel terminal block and clamping arrangement. 
Types of Wire Tested

Although the primary objective was to compare the behaviors of Iron and steel harpsichord wires, a variety of other typical harpsichord wire was also tested for decay characteristics both in air and In vacuum. Table III provides a summary of all wires tested.

TABLE III

TYPES OF WIRE TESTED

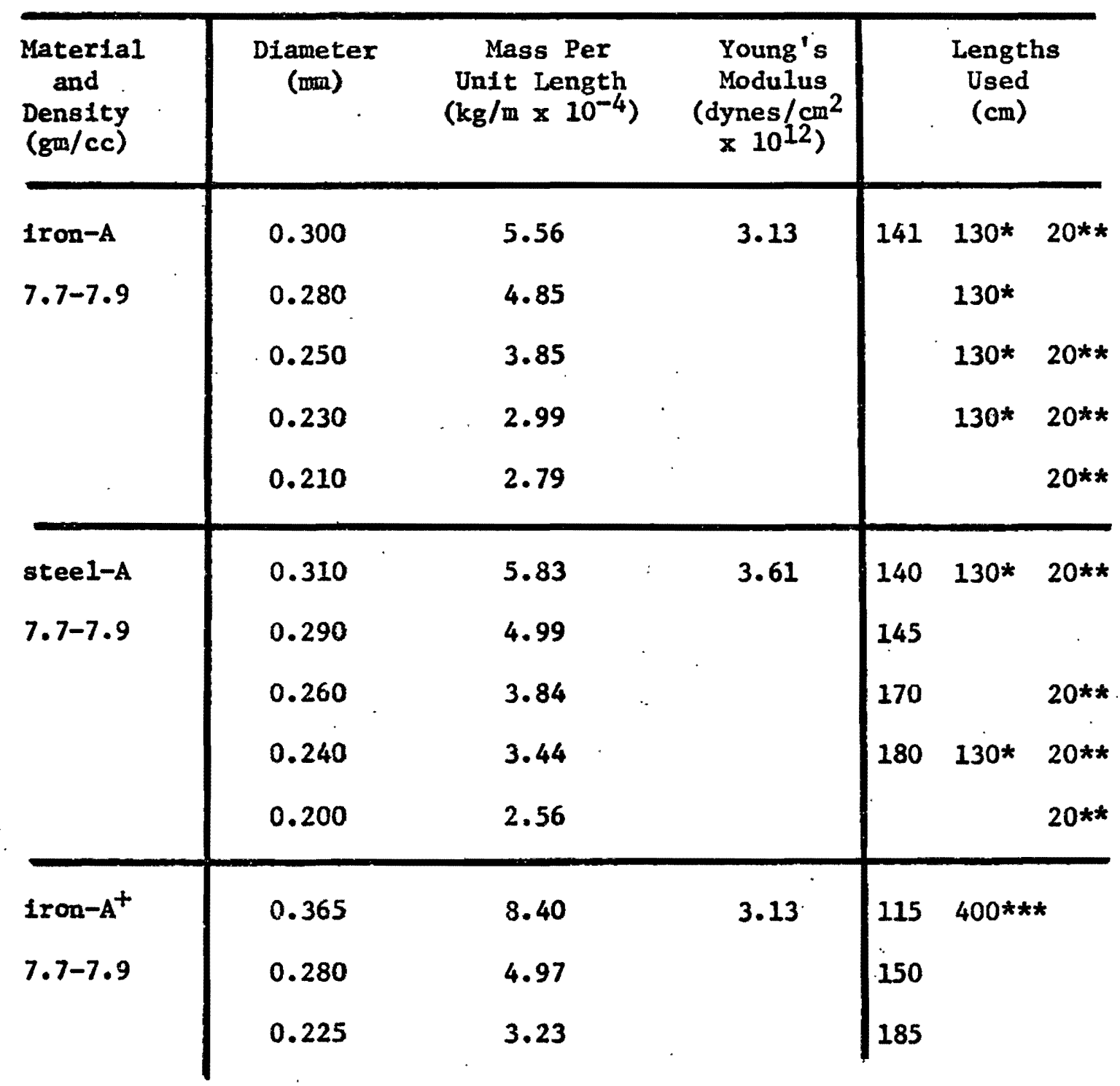


TABLE III (continued)

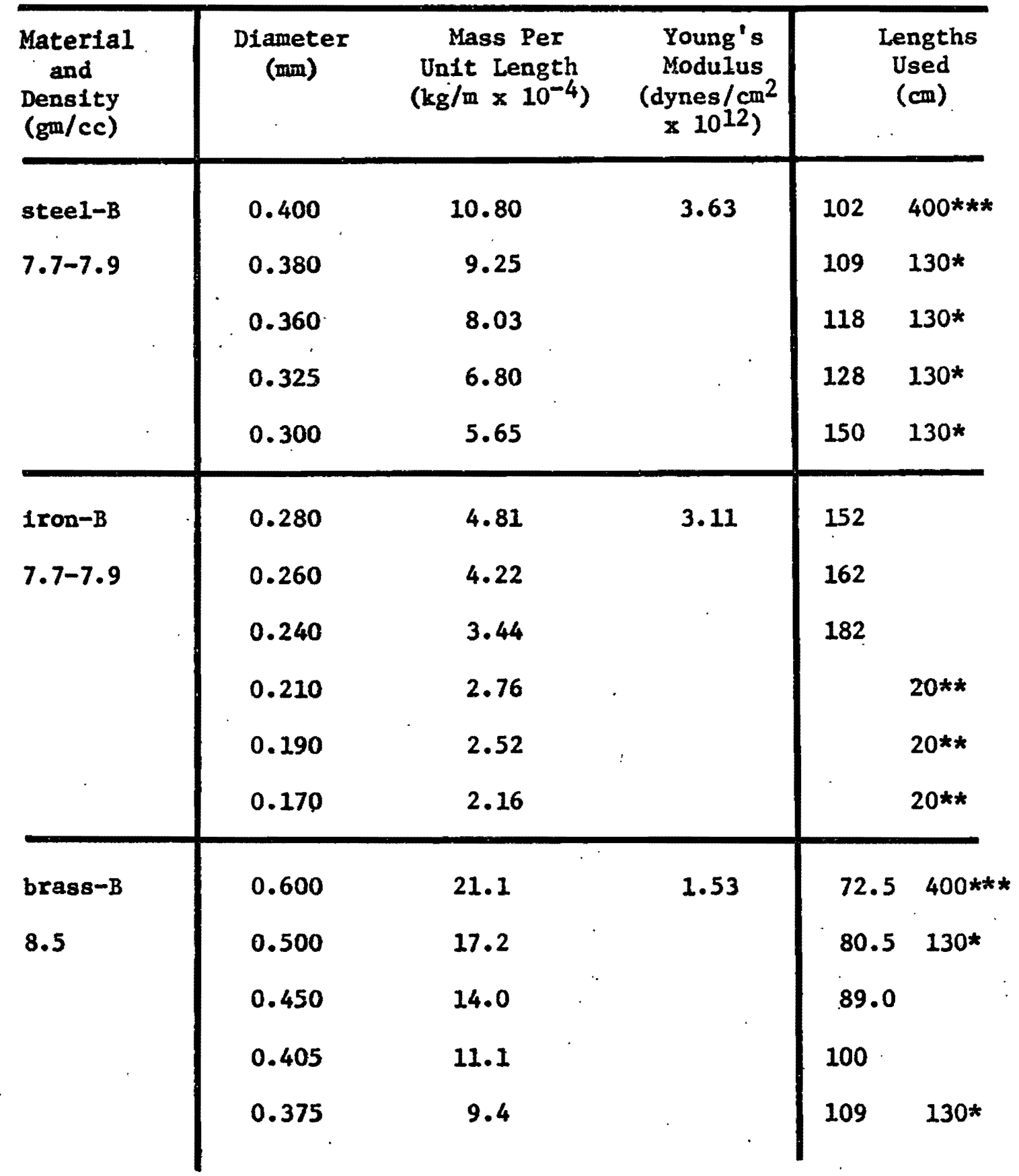


TABLE III (continued)

\begin{tabular}{|c|c|c|c|c|}
\hline $\begin{array}{l}\text { Material } \\
\text { and } \\
\text { Density } \\
\left(g^{m} / c c\right)\end{array}$ & $\begin{array}{c}\text { Diameter } \\
(\operatorname{mm})\end{array}$ & $\begin{array}{c}\text { Mass Per } \\
\text { Unit Length } \\
\left(\mathrm{kg} / \mathrm{m} \times 10^{-4}\right)\end{array}$ & $\begin{array}{l}\text { Young's } \\
\text { Modulus } \\
\text { (dynes } / \mathrm{cm}^{2} \\
\times 10^{12} \text { ) }\end{array}$ & $\begin{array}{l}\text { Lengths } \\
\text { Used } \\
\text { (cm) }\end{array}$ \\
\hline $\begin{array}{l}\text { bronze-B } \\
8.8\end{array}$ & $\begin{array}{l}0.560 \\
0.500 \\
0.450 \\
0.405\end{array}$ & $\begin{array}{l}22.3 \\
18.9 \\
15.2 \\
11.0\end{array}$ & 1.96 & $\begin{array}{l}70 \\
76.5 \\
85 \\
100\end{array}$ \\
\hline $\begin{array}{l}\text { silver-B } \\
10.6\end{array}$ & 0.400 & 15.4 & & 85 \\
\hline $\begin{array}{l}801 d-B \\
19.3\end{array}$ & 0.495 & 39.6 & & 53 \\
\hline
\end{tabular}

A Wire supplied by Zuckermann's Harpsichords, 160 6th Avenue, New York, 10013 .

$\mathrm{A}^{+} \quad$ Wire supplied by the above at a later date.

B Wire supplied by Mr. Wm. Ratajak of Corvallis, Oregon.

* Length in vacuum.

** Length in vacuum at high frequency.

*** Length in air at low frequency. 
The Vacuum Systems

In order to estimate the effect of sound radiation and viscous damping as modes of energy loss from the wire it was necessary to place the wire in a vacuum. Any changes in its decay times compared to the decay times measured in air under identical conditions would then be due to the effects of the surrounding air.

Preliminary system. This system consisted of a glass tube $130 \mathrm{~cm}$ in length and $5 \mathrm{~cm}$ in diameter into which was placed a steel bar $100 \mathrm{~cm}$ long containing pins placed $95 \mathrm{~cm}$ apart (Figure 20).

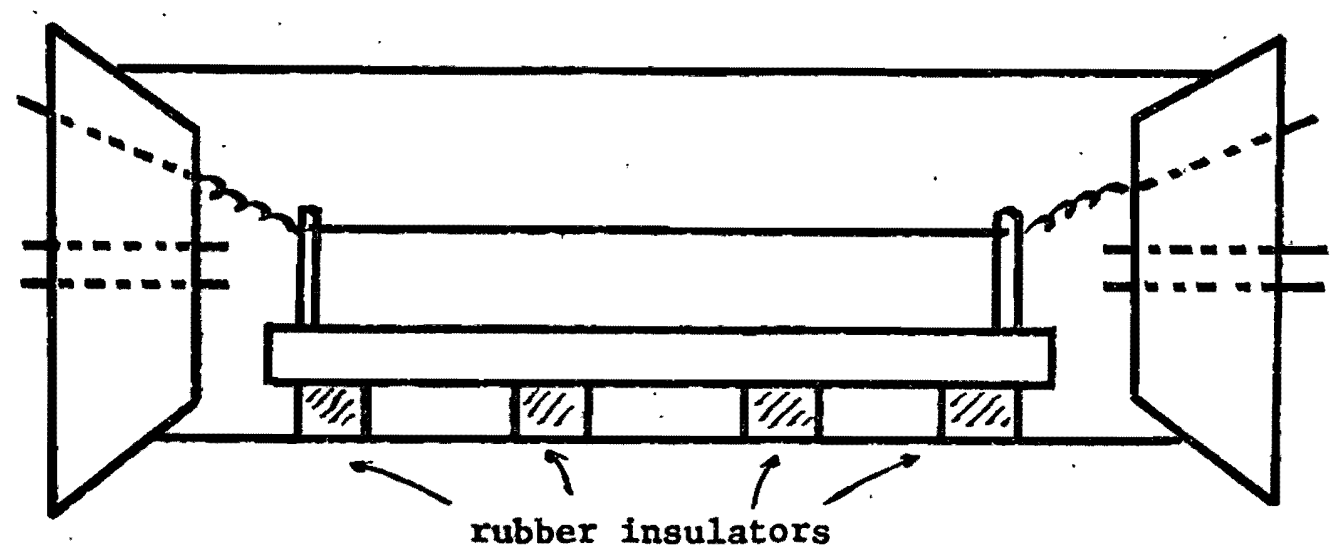

Figure 20. Preliminary vacuum system.

Feedback of vibrations through the steel bar was anticipated, but seemed unavoldable at the time. However, only comparisons from alr to vacuum were to be considered with this set-up and feedback would be a common feature of all measurements.

Final System. The preliminary system was needed to determine gross effects and to make rough estimates and comparisons of decay times. It had two major shortcomings:

1. Feedback from the common base could concelvably overshadow 
other factors in the decay patterns.

2. The $5 \mathrm{~cm}$ diameter of the glass tube was too large to allow sufficient reduction in air gap for the magnet when higher fields were needed.

Consequently a final vacuum system was designed which included the steel cylindrical terminal blocks mentioned earlier. Brass cylinders (Figure 21) were placed on the tops of the steel blocks and connected by an $18 \mathrm{~mm}$ diameter glass tube (Figure 22). This smaller diameter tube made it possible to use the electromagnet with tapered pole pieces. The air gap was slightly over $2 \mathrm{~cm}$.

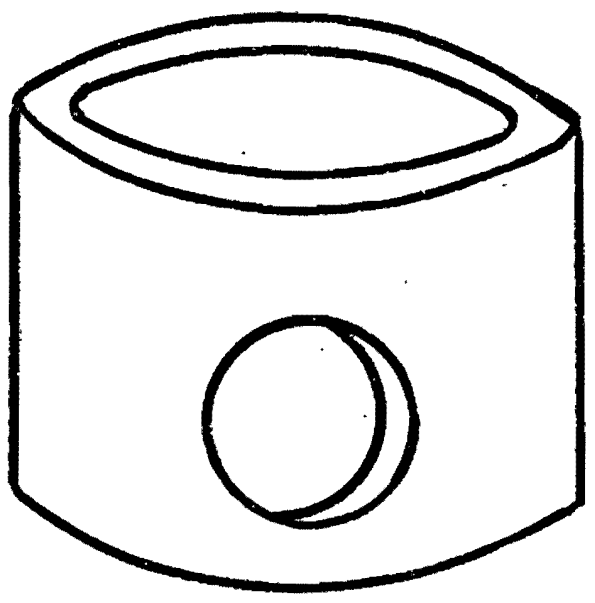

It was felt that this

Figure 21. Brass vacuum cylinder. combination of vacuum system and terminal blocks was superior to others in its sensitivity and ease of adjustment. Coupled with the varlability of the magnetic field, it became possible to produce decay traces which revealed small differences in the behaviors of the various wires in a controlled environment. 


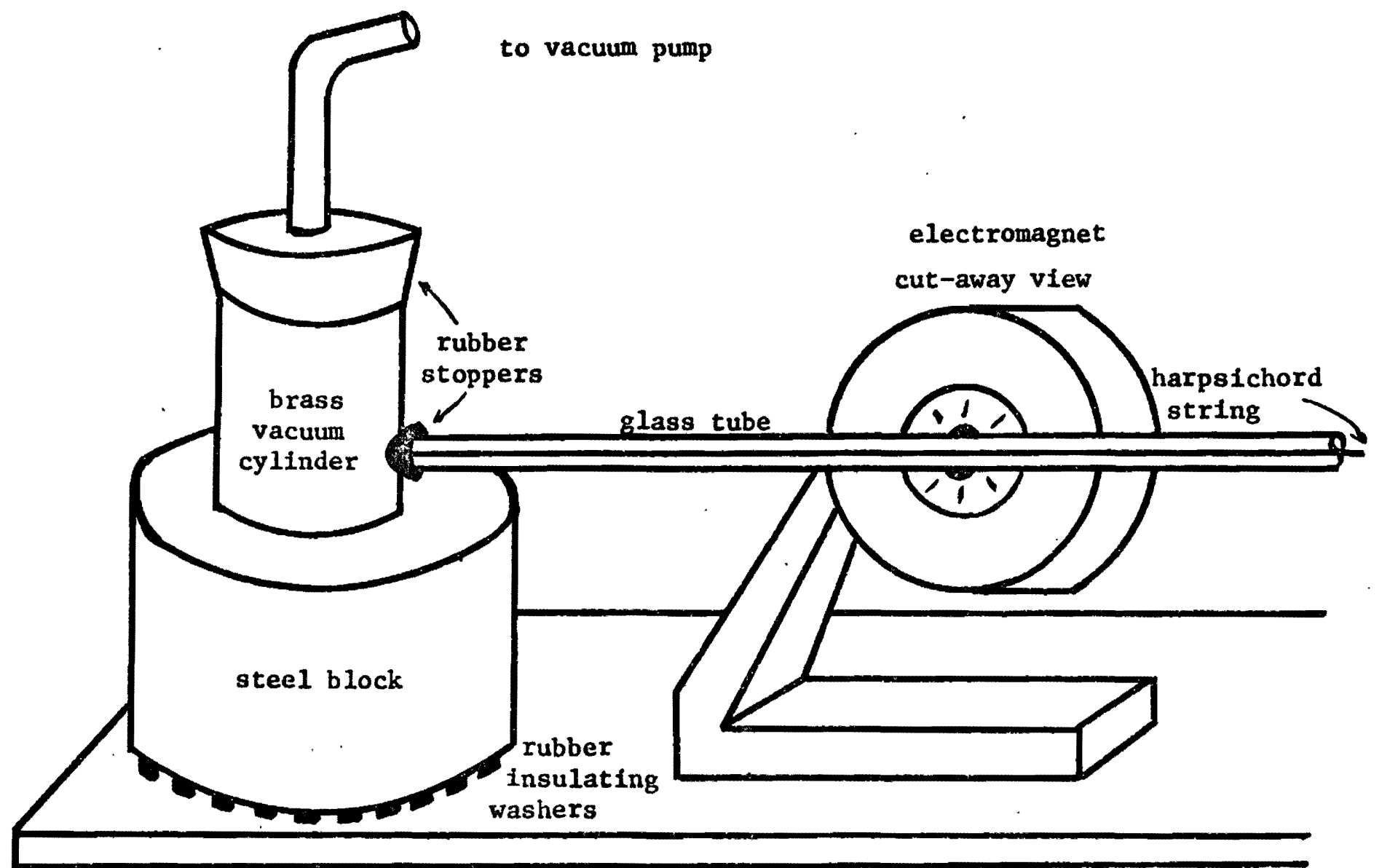

Figure 22. Final vacuum system. 
MEASUREMENT TECHNIQUES

\section{Oscilloscope}

The 564B storage scope was able to retain its trace for measurement purposes. Data could be taken directly from the scope or a polaroid photograph could be made. Figure 23 below is a reproduction of a typical photo showing the decrease in the amplitude of the wire as a function of time.

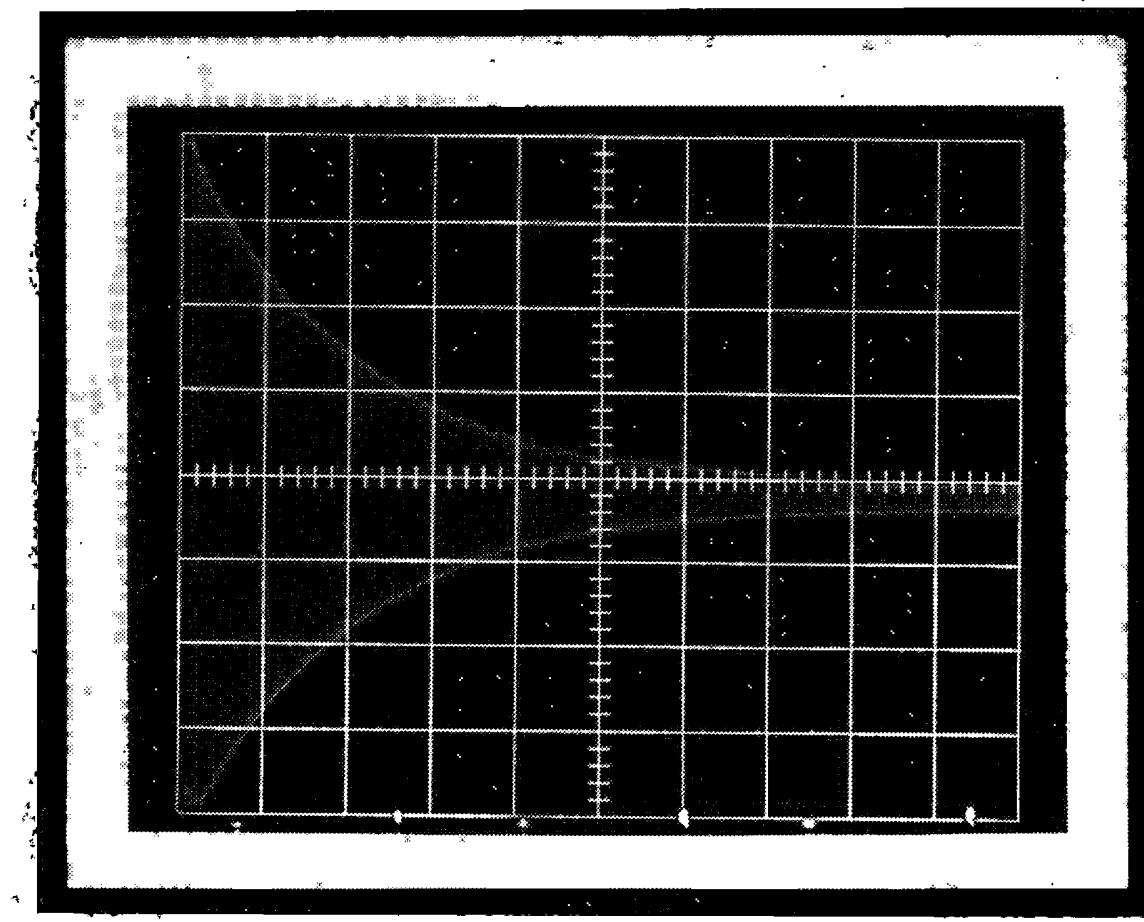

Figure 23. Decrease of amplitude in time for a typical harpsichord string.

The horizontal sweap time for this photo was 5 seconds and the frequency of the wire was $200 \mathrm{~Hz}$. The wire therefore executed 1000 
vibrations during this time and the electron beam swept out the area shown.

F11tering. As an illustration of the effectiveness of the filter circuits in the $2 \mathrm{A61}$ amplifier previously mentioned on page 18 , Figure 24 is a photo of the same situation with the exception that the frequency response was limited to the range: 6 to $60 \mathrm{~Hz}$.

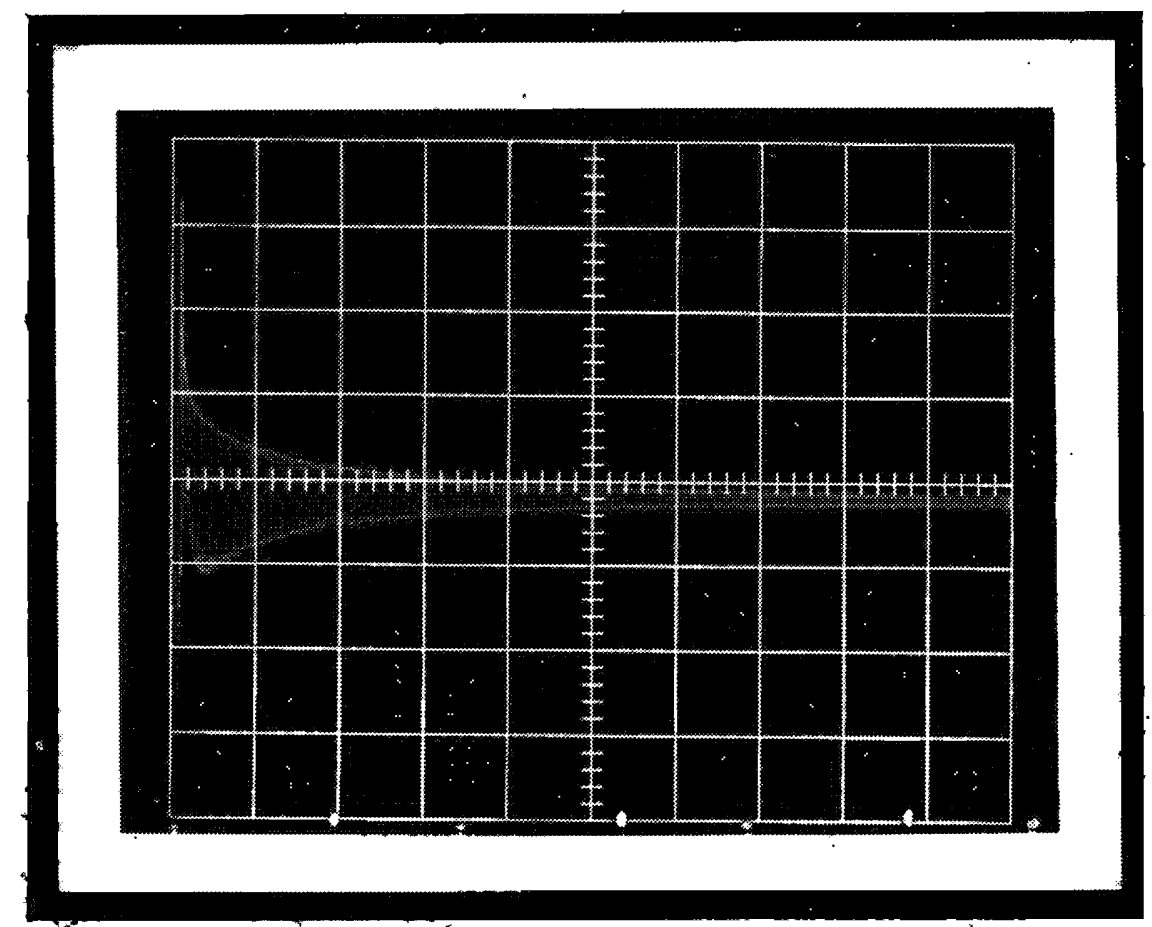

\section{Figure 24. Illustration of filter effectiveness of the $2 \mathrm{A61}$ amplifier.}

Wave Shapes. The scope was continuously used to monitor the waveform of the input signal from the audio oscillator and also that of the decay (single cycle). Figures 25 and 26 show typical wave shapes. The sinusoidal quality of the input signal was maintained to Insure that the driving force on the wire was reproducible from case to case. 


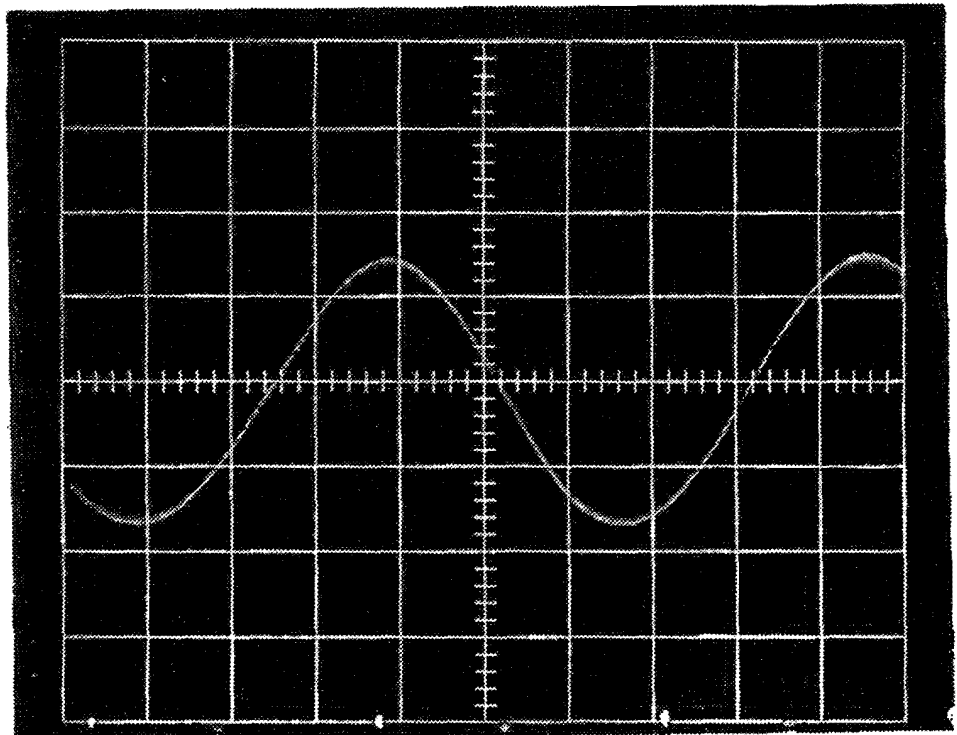

Figure 25. Input signal to wire.

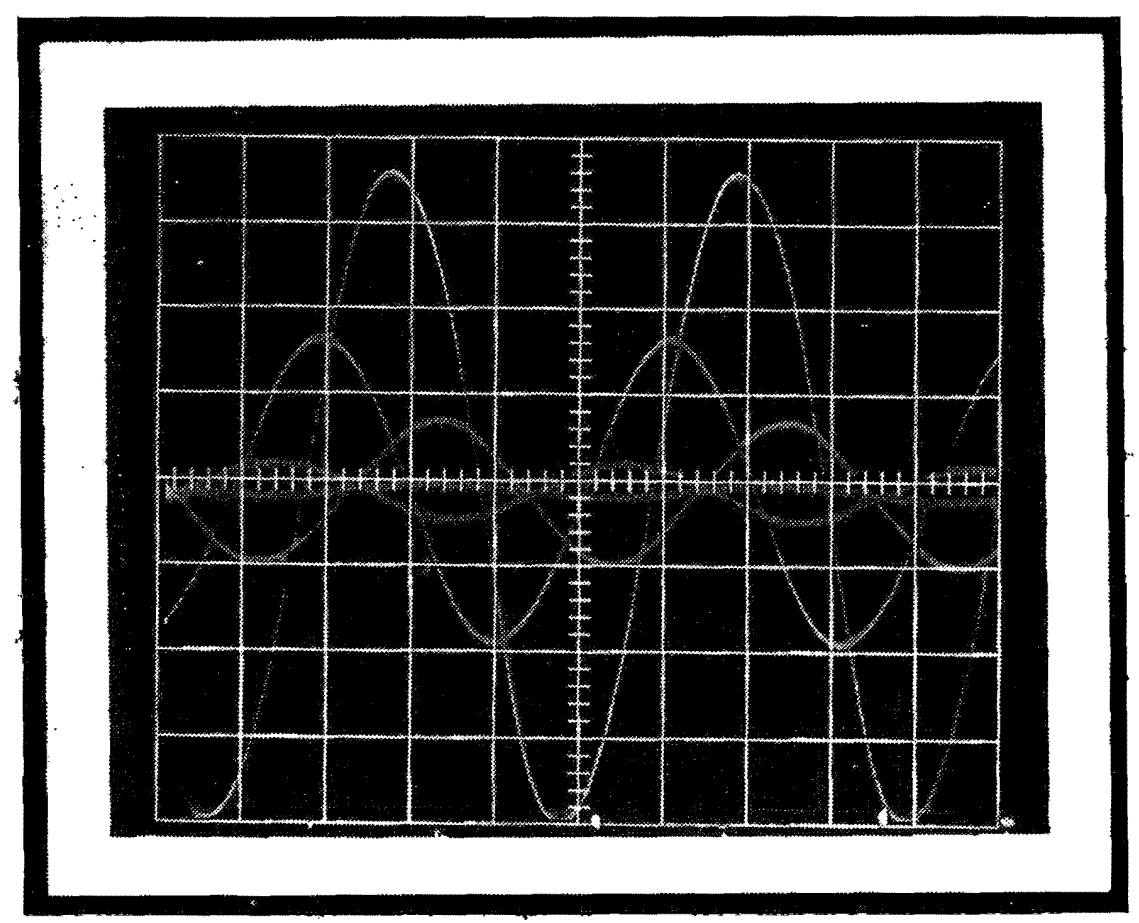

Figure 26. A few cycles showing amplitude decay in time. 
Visual Measurement. Techniques

Throughout the various phases of experimentation it was always necessary to monitor the wire visually for these reasons:

1. There was no other quick and rellable way to tell if the wire was vibrating. To merely calculate a resonant frequency and tune the oscillator to that value was usually not sufficient to induce vibration. It was necessary to begin increasing the frequency from about $15 \%$ below the calculated resonant value and then slowly approach the resonant peak. If this approach was made too rapidly, vibration would not take place.

2. Once the wire was vibrating with maximum amplitude at the peak of resonance, it would tend to drift from this peak after several seconds. This had to be constantly corrected for.

3. When testing at frequencies above roughly $5000 \mathrm{~Hz}$, the amplitude of the wire, even at the fundamental, was quite of ten too sma1l to be seen. In this case, paper riders (Figure 27) were

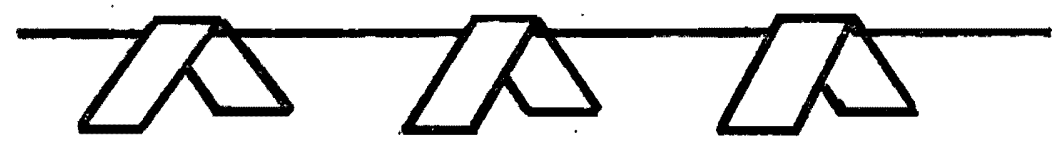

Figure 27. Paper riders used to indicate resonant peak.

placed along the wire and the resonant frequency peak was found by watching for agitated movement of the riders.

Standing Wave Ratio. Another visual technique used was that of checking the amount of movement at the nodal points with a traveling microscope. This was done in an attempt to determine the 
standing wave ratio, SWR, and hence the amount of power leaking out through the terminal blocks. The standing wave ratio is defined, Pain (13), as the ratio of maximum amplitude to minimum amplitude for a standing wave. Also the reflection coefficient for amplitude, $r$, is defined by the relationship: $\quad r=($ SWR -1$) /($ SWR +1$)$.

Resonant Peak. As was described on the previous page, the peak of the resonance curve could only be successfully approached from lower frequencies. This prompted an investigation of the shape of the amplitude vs frequency curve in the vicinity of the resonant frequency. Measurements were made with the traveling microscope. This curve and a discussion of its meaning are presented later. 


\section{PROCEDURE}

Acquisition and Measurement of Decay Curves

The decay curves were obtained in the following manner:

1. For a selected fundamental frequency and tension, the resonant length for a given wire was calculated from the expression $L_{r}=n / 2 f(T / \mu)^{1 / 2}$.

2. An alternating current with the required frequency was applied to the wire and its tension was increased to the point where 1t resonated in the fundamental mode.

3. The wire was fine-tuned by slight oscillator adjustments until the amplitude was maximum.

4. When the wire had stabilized after a couple of seconds, a switch was thrown, disconnecting the power and connecting the ends of the wire to the oscilloscope.

5. Simultanecusly the scope was triggered and a trace was produced. Figure 23 typifies this decay trace. Next, measurements were made of amplitude at various points in time. Using Figure 23 as an example, it can be seen that the time taken for the amplitude to decrease to half of its original value was about $0.7 \mathrm{sec}$. It took an additional $0.65 \mathrm{sec}$. to decrease to one-fourth of its original amplitude, and an additional 0.65 sec. to reach one-eighth of its original amplitude. Since these three successive time intervals are nearly the same, they could be considered 
half-lifes of an exponential decay. To verify that the amplitude decreases exponentially with time, a semi-log plot of amplitude vs time (Figure 28) is seen to be linear.

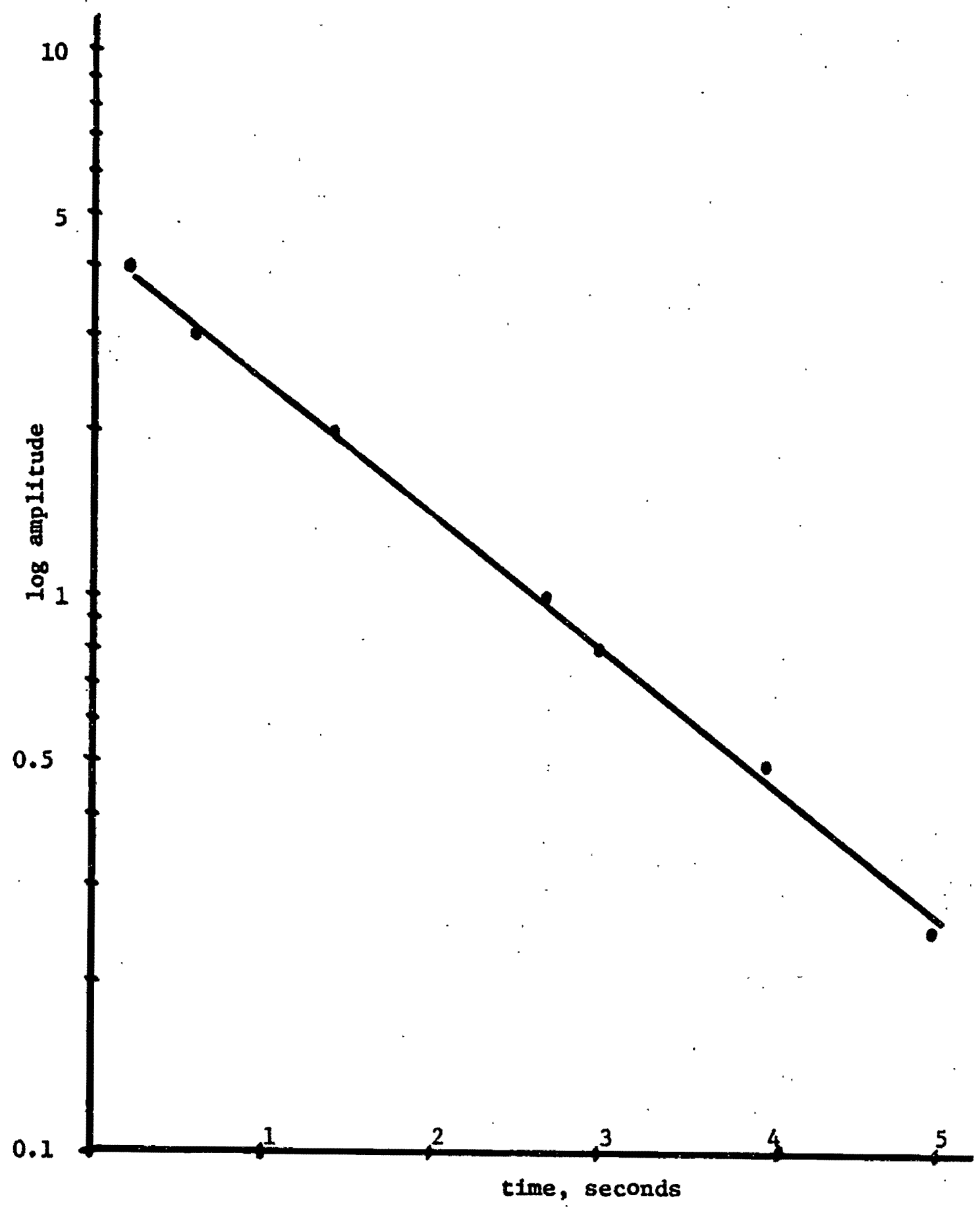

Figure 28. Semi-log plot showing decay of harpsichord string. 
Since the interaction force between a rigid body in subsonic motion relative to the surrounding fluid is largely determined by the Reynolds number, Morse (14), a brief discussion of this topic is presented in Appendix B.

It should be noted here that earlier decay traces deviated from exponentia1. It was suggested, Rempfer (15), that these traces contained noise which could be eliminated by simply lowering the vertical position of the curve on the scope. The slight broadening of the peaks of the decay curve, Figure 26, confirms the presence of this noise. All subsequent oscilloscope traces were adjusted so that the upper portion of the curve had a minimum value coincident with the time axis.

If the oscillator was not tuned to the resonant frequency of the wire, the decay trace was serrated as shown in Figure 29.

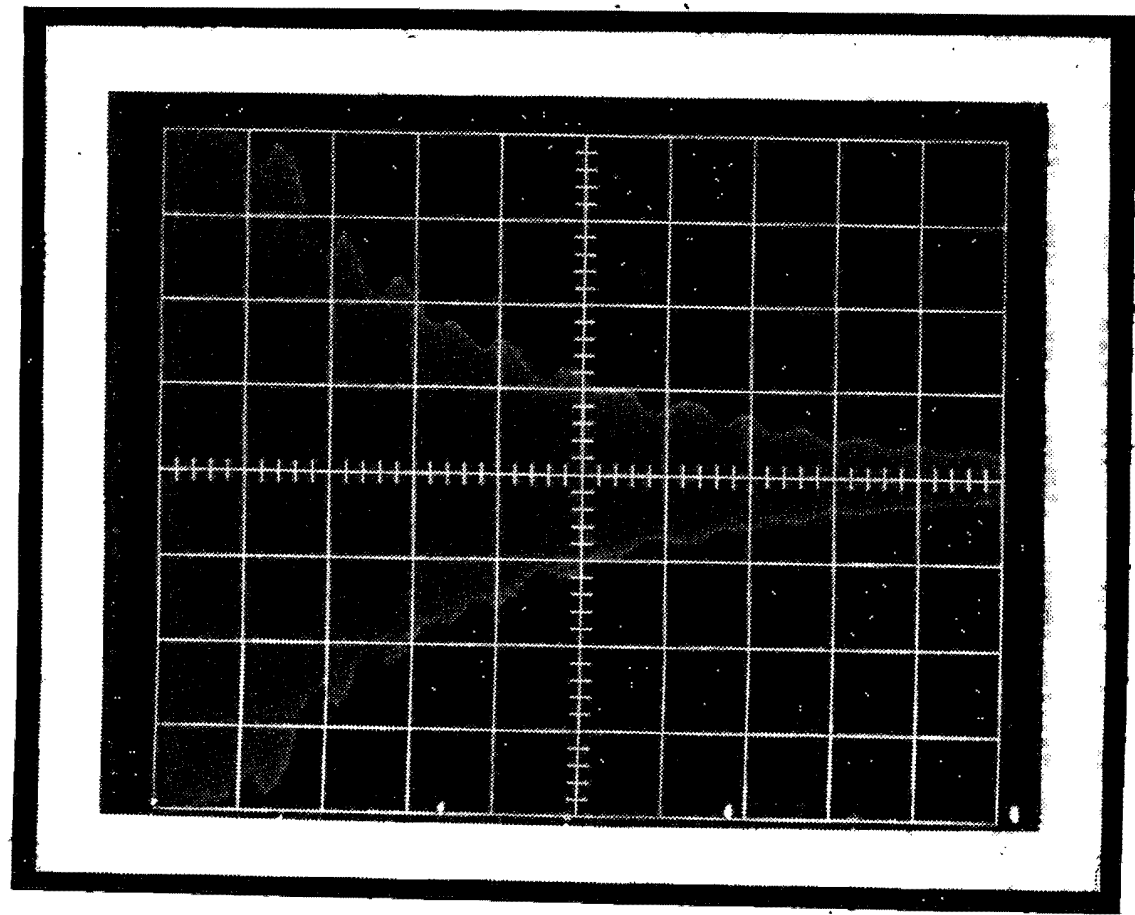

Figure 29. Decay trace when oscillator slightly off resonance. 


\section{Comparisons}

In spite of the apparent exponential nature of the decay curves, nevertheless some situations produced consistent, although slight, differences in successive half-lifes. The effect was that there was a tendency towards an increase in half-life with time.

Thus, in making comparisons between wires, or between the same wire under different pressures, precautions had to be taken to insure that the scope traces corresponded to identical periods of time with respect to the total span of time during which the wire moved. For example, a scope trace of an early portion of the decay might yield shorter half-lifès than a trace of a later portion of the decay. With proper adjustments of the vertical gain on the scope and of the magnetic field strength it was possible to maintain a high consistency with respect to this "viewing-time" problem. 
RESULTS

Amplitude as a Function of Frequency

A plot of amplitude vs frequency

for values near the resonant frequency

would be expected to have the symmetry

shown in Figure 30. However, when data was taken for the vibrating harpsichord wires used in this investigation, an asymmetry appeared, Figure 31 .

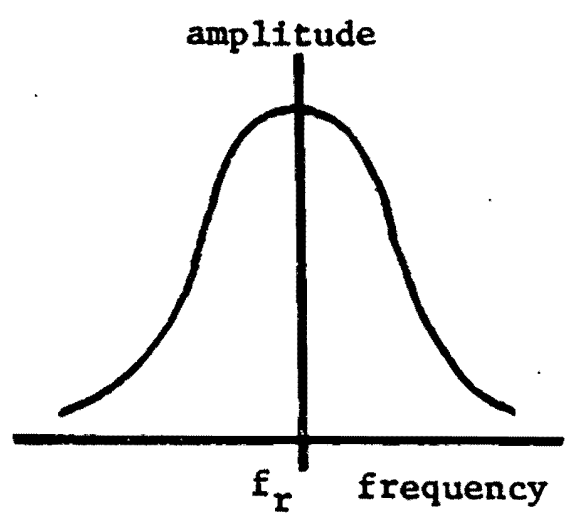

Figure 30. Symmetric resonance curve.

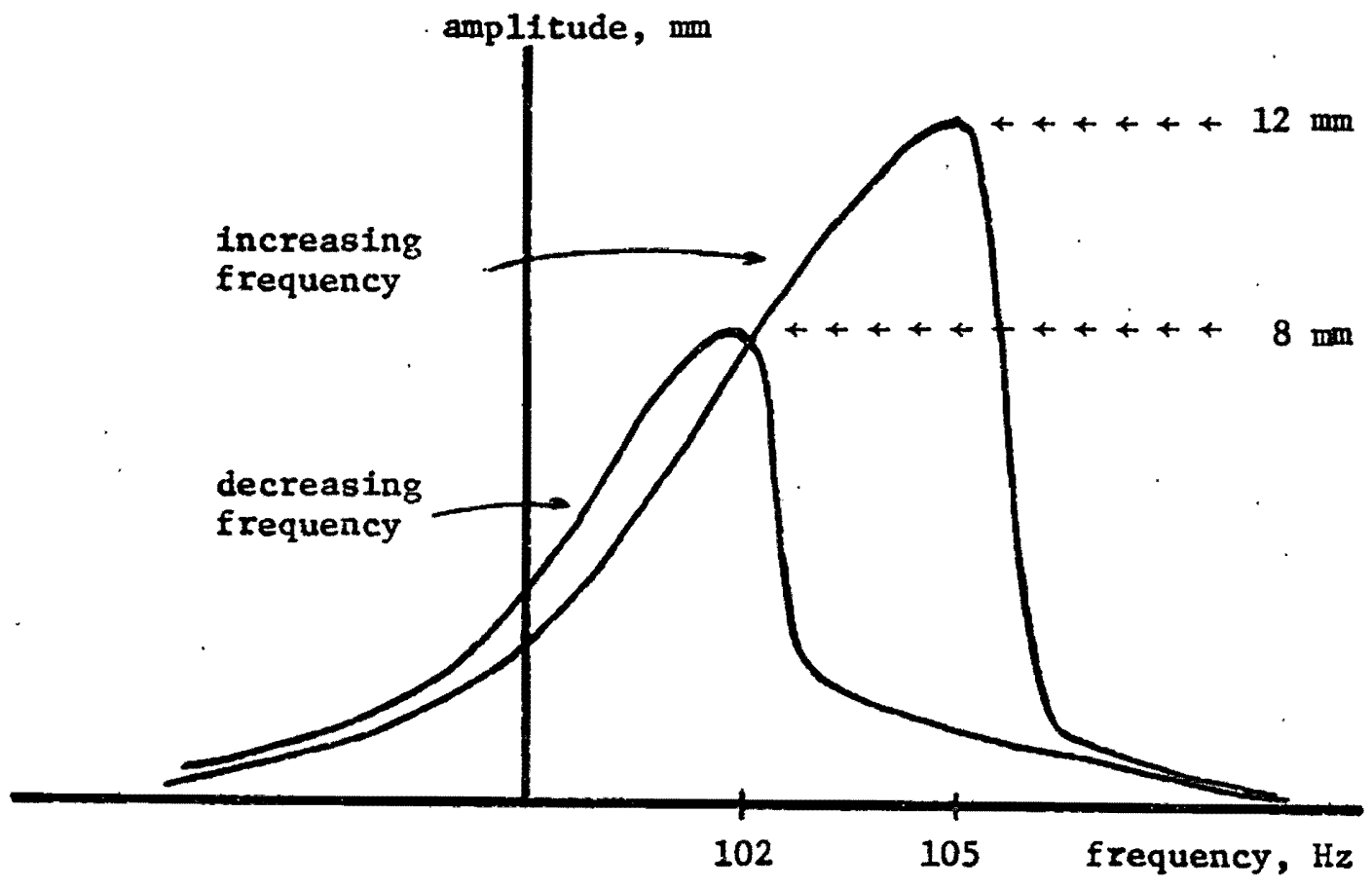

Figure 31. . Asymmetric resonance curve for a typical harpsichord string. 
In a section titled, Resonance in Non-Linear Oscillations, Landau (16) discusses a situation in which non-linear restoring terms are included in the equation for forced oscillations of a vibratory system. The solution to this equation gives rise to a cubic expression in terms of the amplitude of the oscillations.

For certain amplitudes of the driving force the three roots of this expression are real. The result is shown in Figure 32, where $B C$ and $D E$ represent stable oscillations corresponding to the largest and the smallest real roots. The middle root, represented by $\mathrm{CD}$, corresponds to unstable oscillations of the system. Hence there exists a range of frequencies in which two different amplitudes of oscillation are possible.

Landau's theoretical curve and Figure 31 compare favorably.

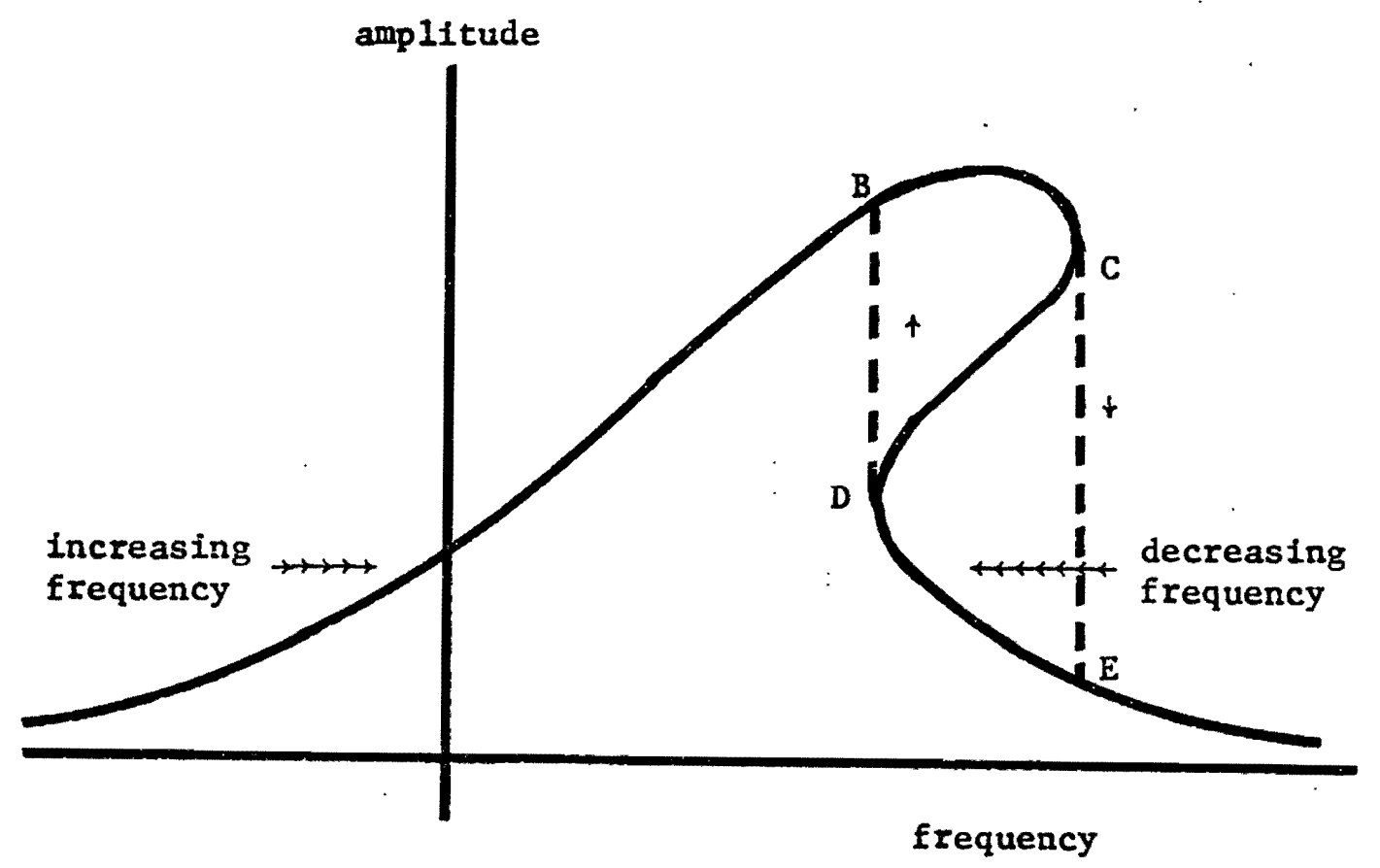

Figure 32. Frequency vs amplitude for non-linear oscillations. 
Resonant Frequency as a Function of Pressure

A drop in resonant frequency was observed whenever the pressure was reduced. This phenomenon occurred with all the wires. Sample. data is presented in Table IV.

Two possible causes were suggested:

1. The length of the wire increased, perhaps because of some slight movement of the pins or the terminal blocks. However, no movement could be detected with the traveling microscope.

2. The tension in the wire decreased. This could have been caused by heating effects of the current in the wire.

TABLE IV

DROP IN RESONANT FREQUENCY

AS A FUNCTION OF PRESSURE

\begin{tabular}{c|c}
\hline $\begin{array}{c}\text { Pressure } \\
\text { (microns) }\end{array}$ & Frequency in Air/Frequency in Vacuum \\
\hline $10^{3}$ & 1.13 \\
500 & 1.32 \\
200 & 1.49 \\
100 & 1.57 \\
50 & 1.66 \\
30 & 1.71 \\
\hline
\end{tabular}

Accordingly, the current was varied as the wire vibrated in air and then in a vacuum. Over a range of current values the resonant frequency in air did not change, but as the current was varied 
over the same range in a vacuum, the resonant frequency dropped. Figure 33 shows how the current affects the resonant frequency.

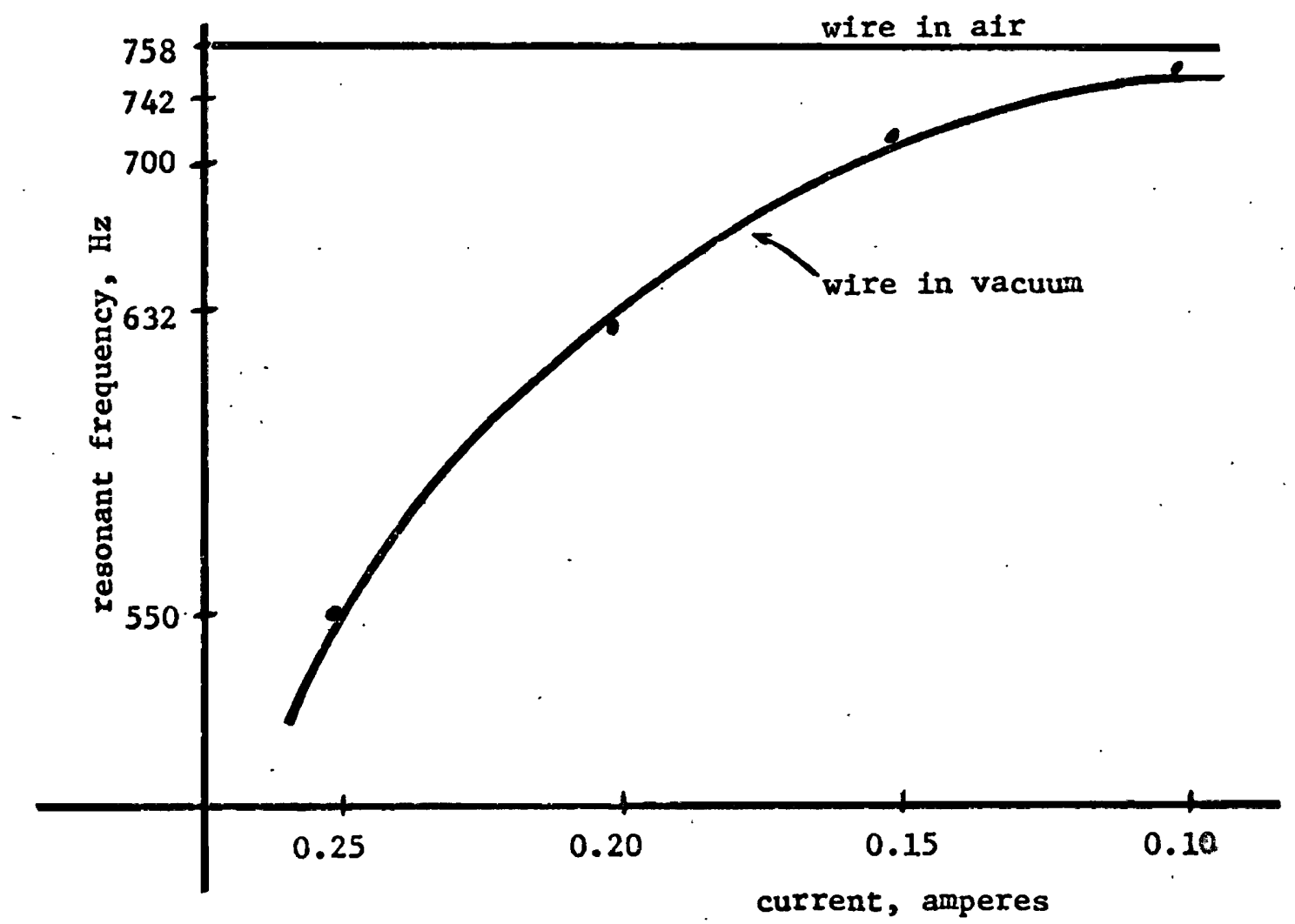

Figure 33. Resonant frequency as a function of current at a pressure of 35 microns.

As the wire vibrated in air it was apparently able to liberate heat via the surrounding air molecules with a greater efficiency than it could in a vacuum. As a result the wire heated in the vacuum, and since it was under tension the heating effect caused a slight reduction in tension.

In Figure 33 each data-point represents a steady-state condition where the rate of heat generated is equal to the rate of heat dissipated. The tension and frequency stabilized at these points.

Variations in pressure at constant current indicated that 
as pressure increased/decreased the frequency increased/decreased.

It is interesting to speculate that perhaps a pressure gauge could be based on the effect described above. In such an instrument, a resonating wire having a variable current would undergo slight changes in its resonant frequency with slight pressure changes. Adjustments in current necessary to reestablish resonance could be calibrated in units of pressure.

The advantage of such a device might lie in its application to pressure ranges outside the range of many existing gauges, such as the thermocouple gauge which is useful when the mean-free-path of the molecules is the order of magnitude of the dimensions of the container.

Decay Time as a Function of Frequency

Data on decay time (half-life) and frequency is presented in graphical form on the following pages. Due to limitations of space the decay curves are not given for every wire tested. However, those that were omitted conformed to the trend displayed by the representative samples. An index is provided to assist the reader in locating desired information.

INDEX

\begin{tabular}{l|c}
\hline \multicolumn{1}{c|}{ Data } & Pages \\
\hline Decay time vs frequency, air & $47-51$ \\
Decay time vs frequency, vacuum & 52 \\
Decay time vs low frequency, air & 53 \\
Decay time vs high frequency, air & 54 \\
Decay time vs high frequency, vacuum & 55
\end{tabular}




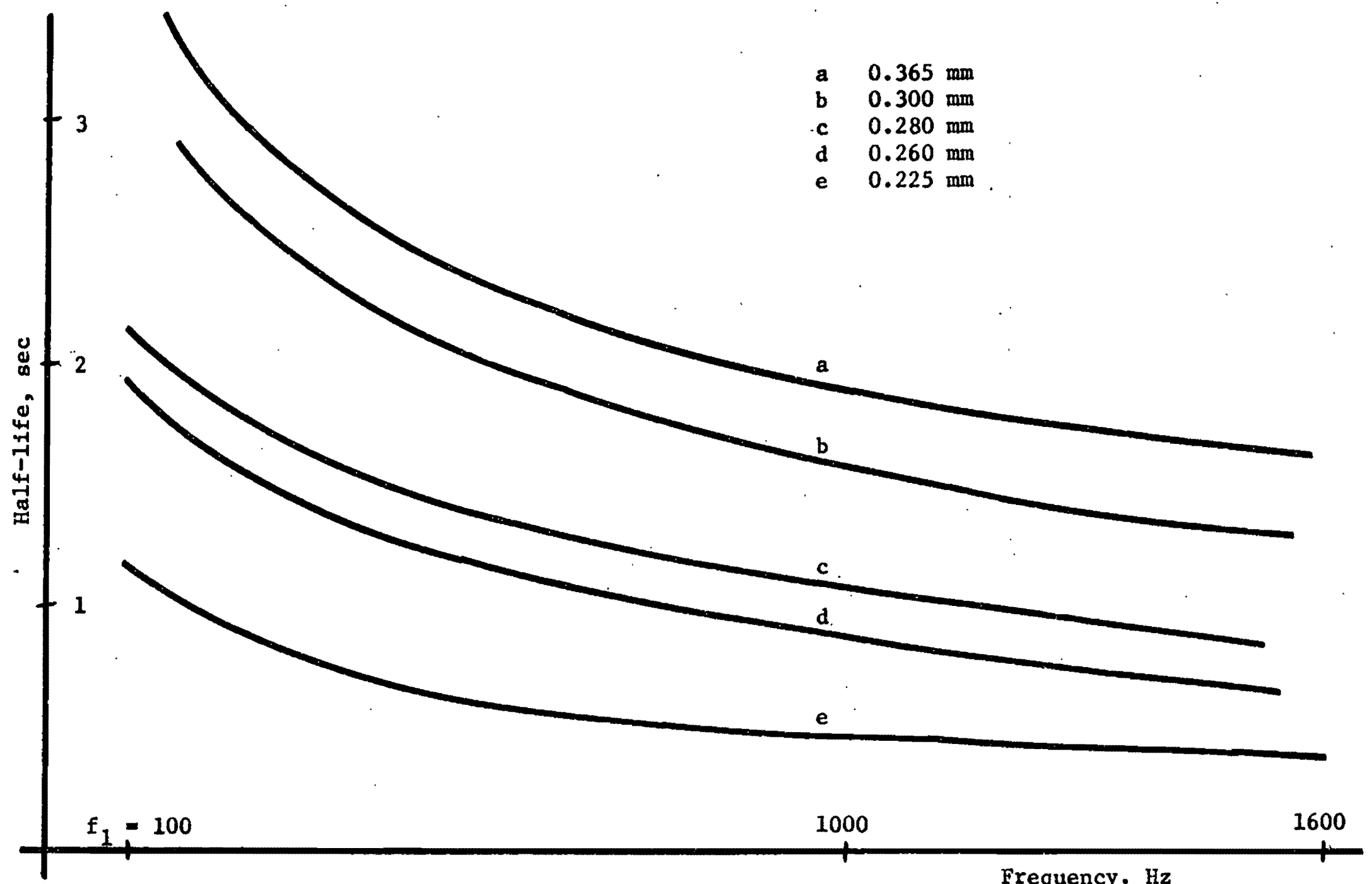

Figure 34. Decay time for iron wire as a function of frequency in air. 


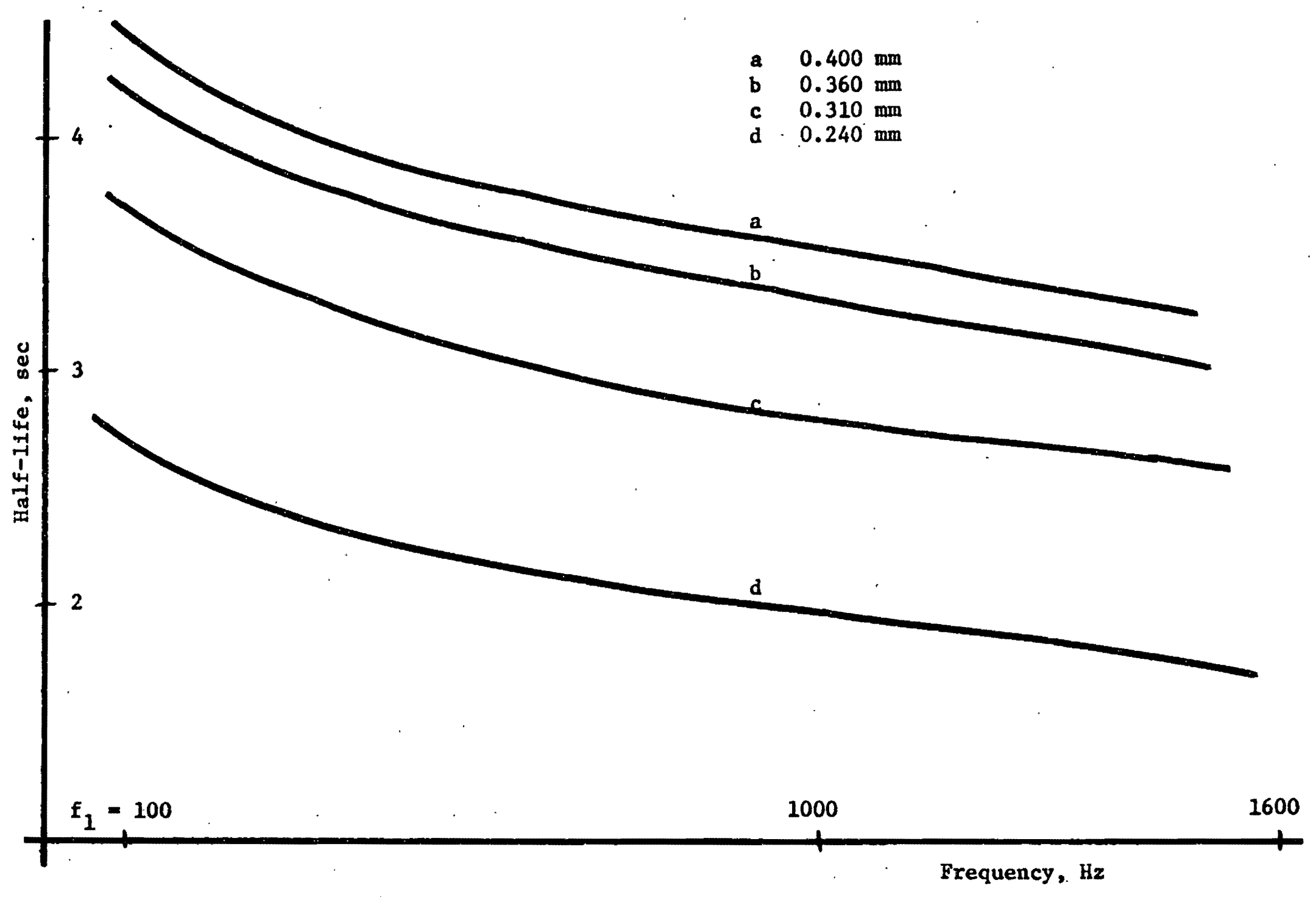

F1gure 35. Decay time for steel wire as a function of frequency in air. 


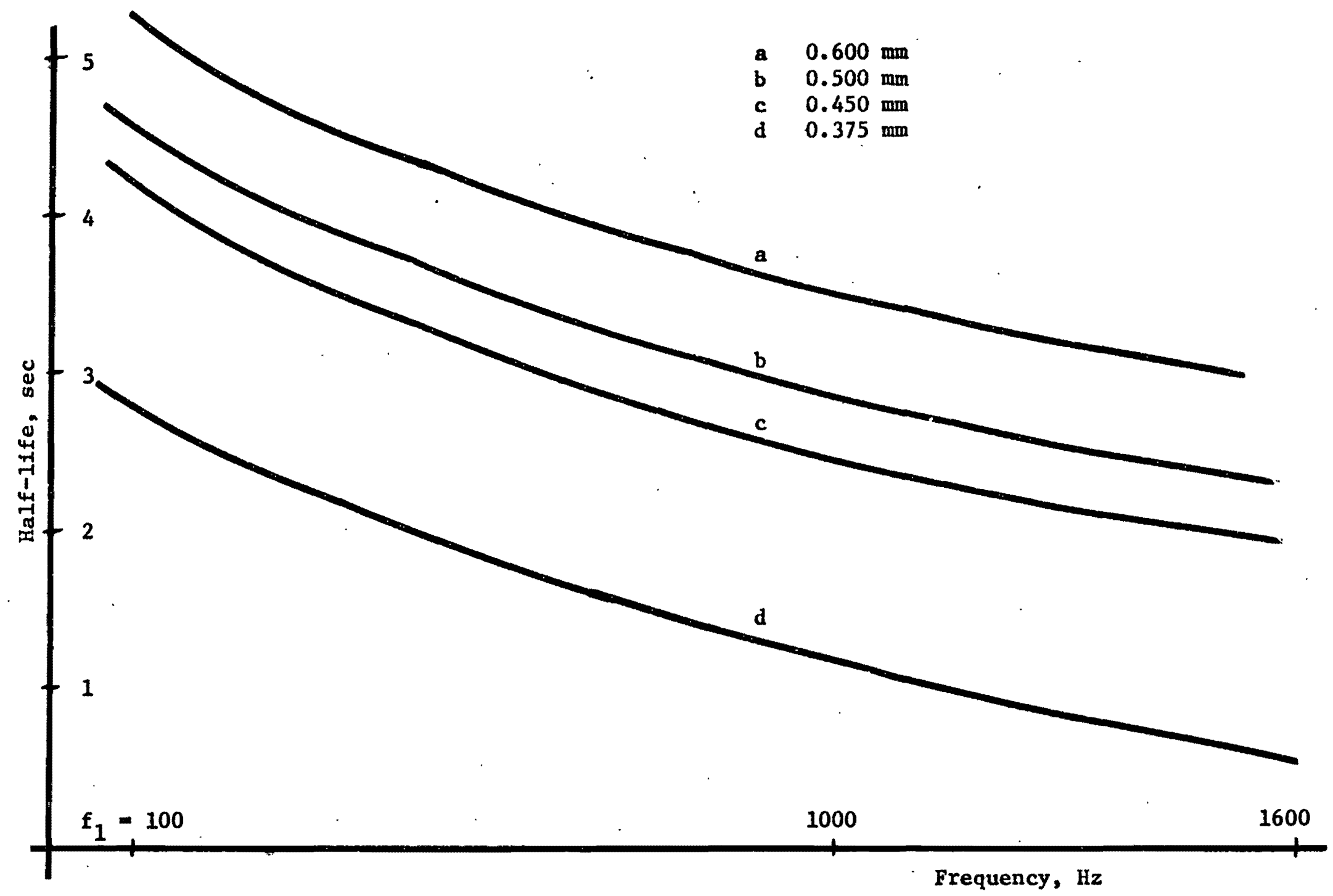

Figure 36. Decay time for brass wire as a function of frequency in air. 


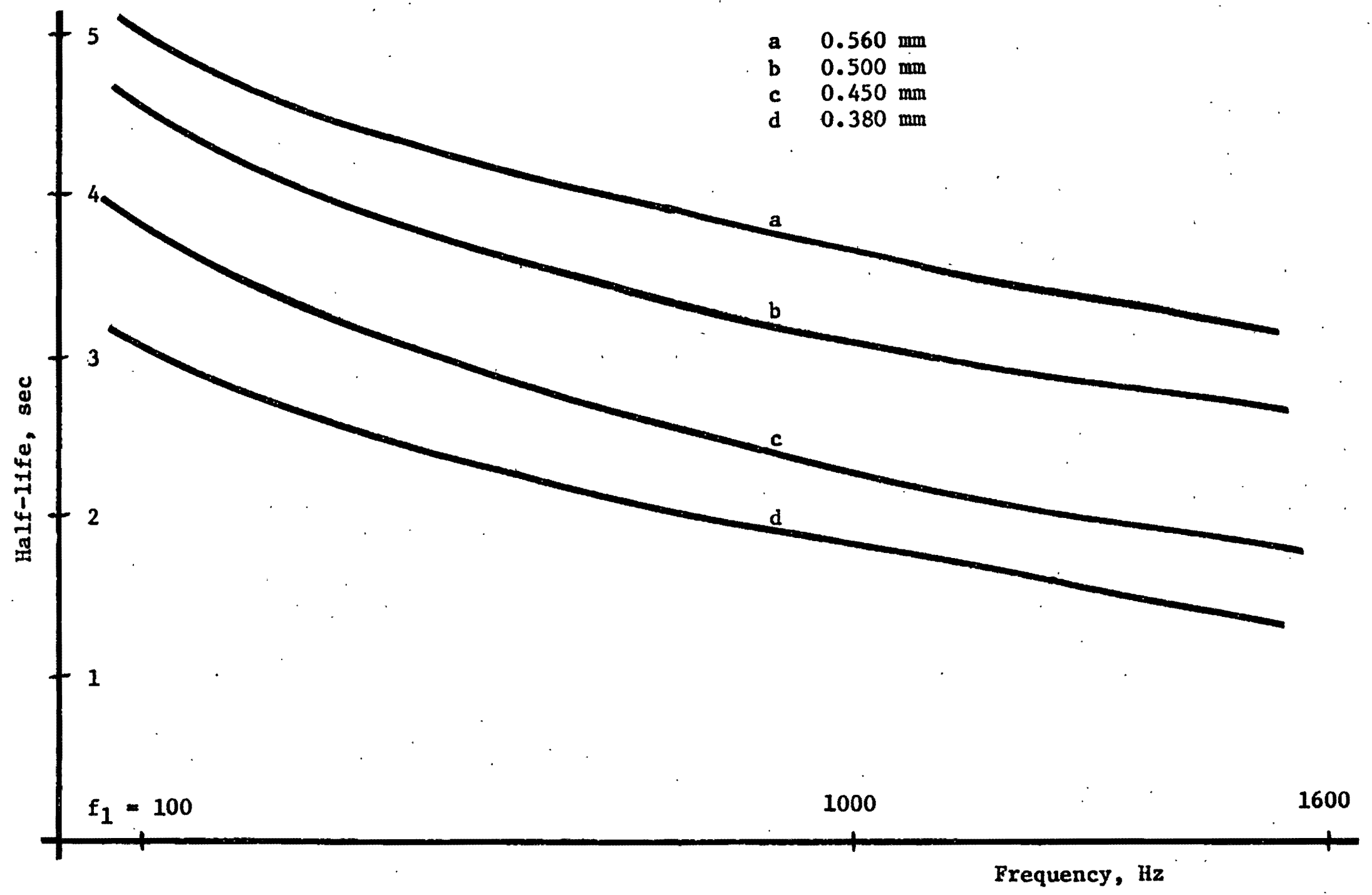

Figure 37. Decay time for bronze wire as a function of frequency in air. 


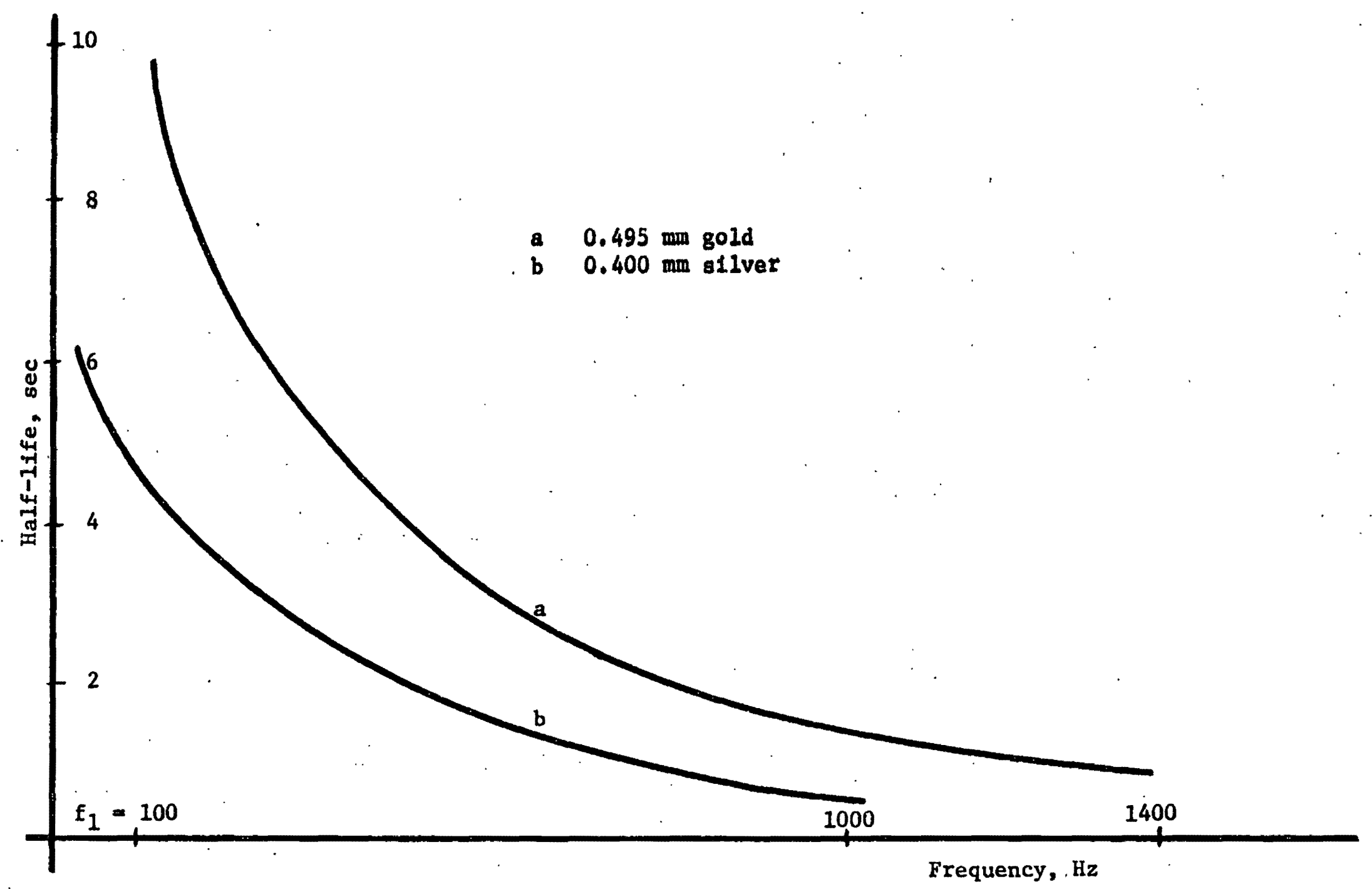

Figure 38. Decay time for silver and gold wire as a function of frequency in air. 


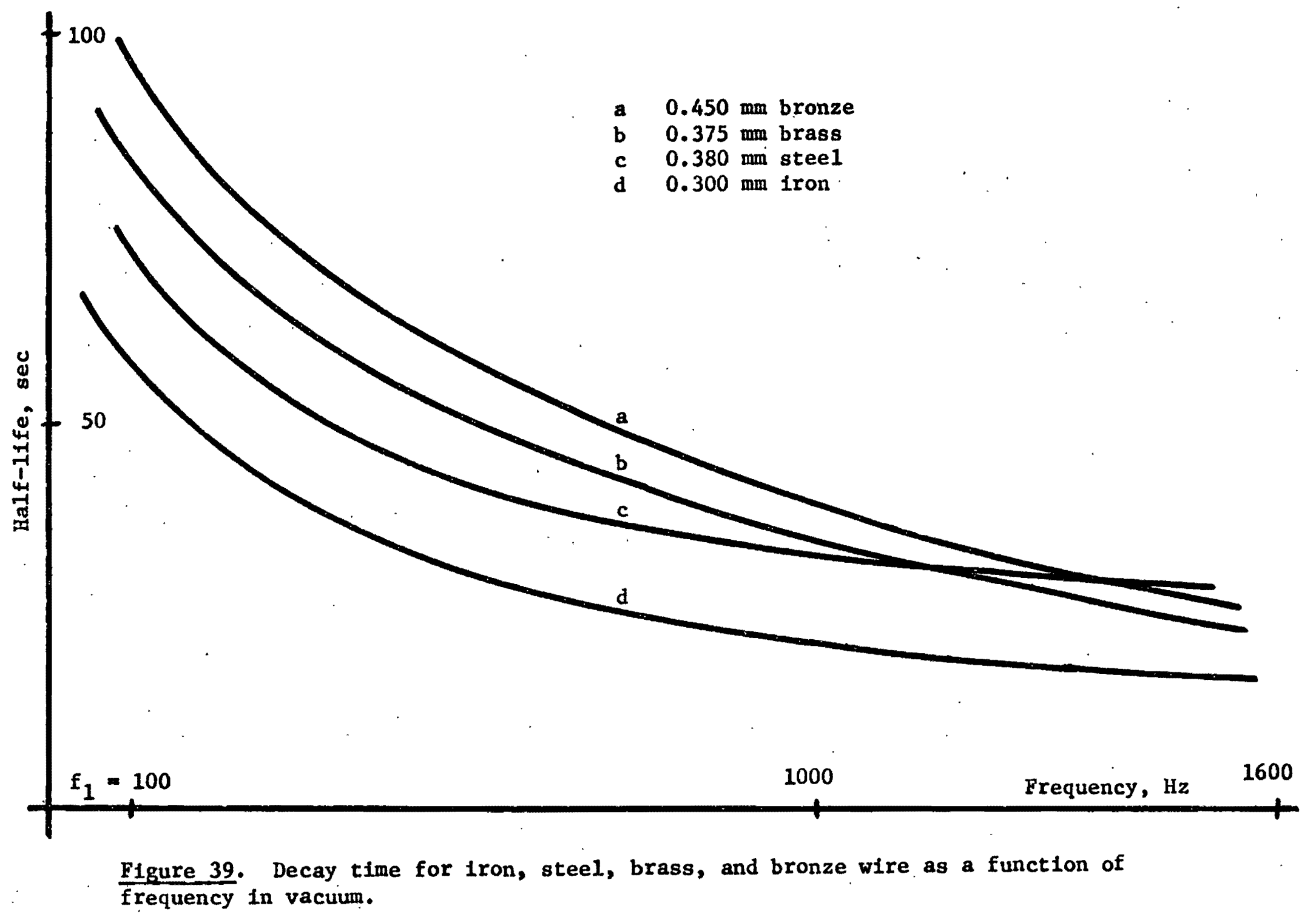




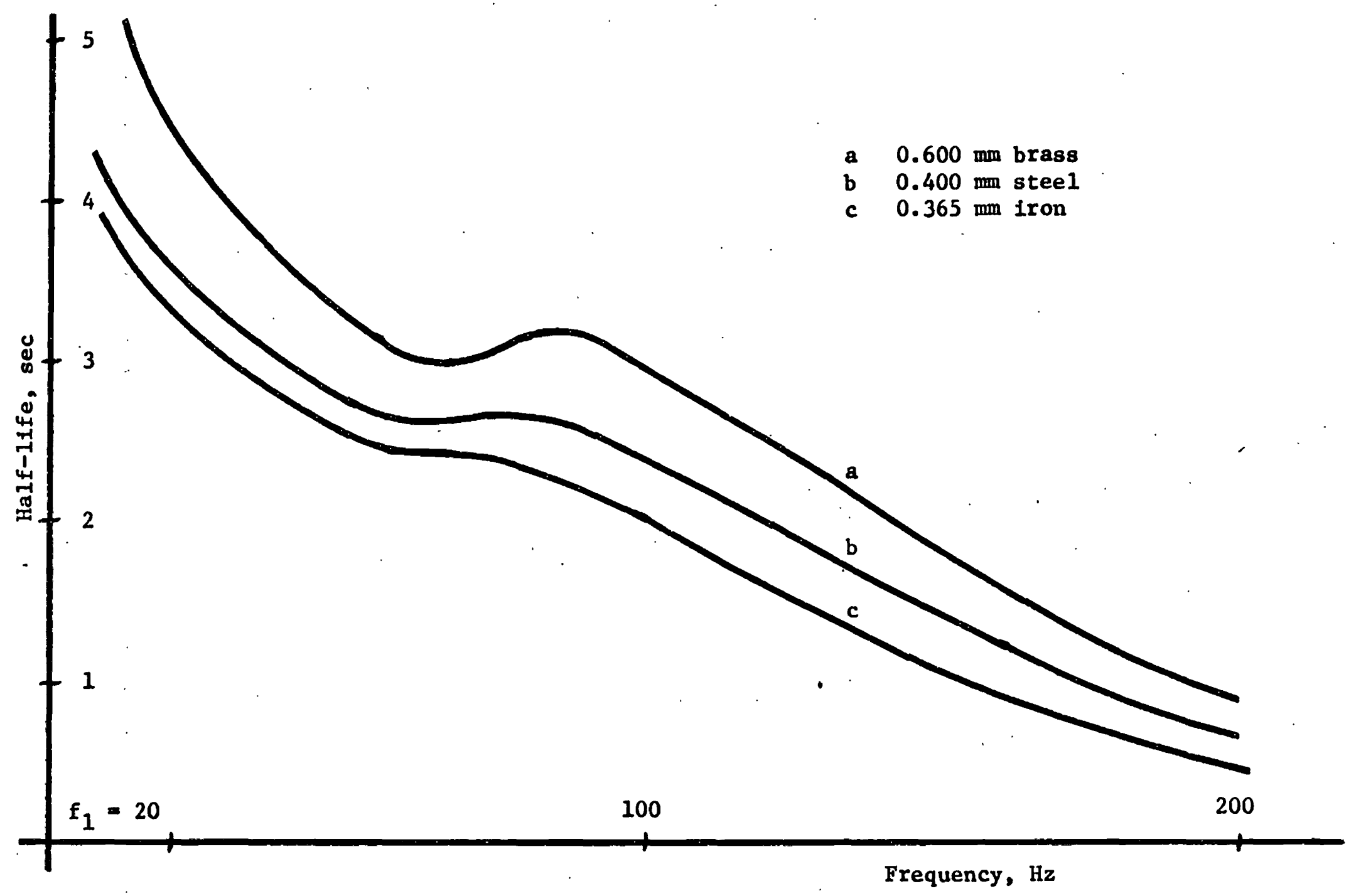

Figure 40. Decay time for Iron, steel, and brass wire as a function of low frequency in air. 


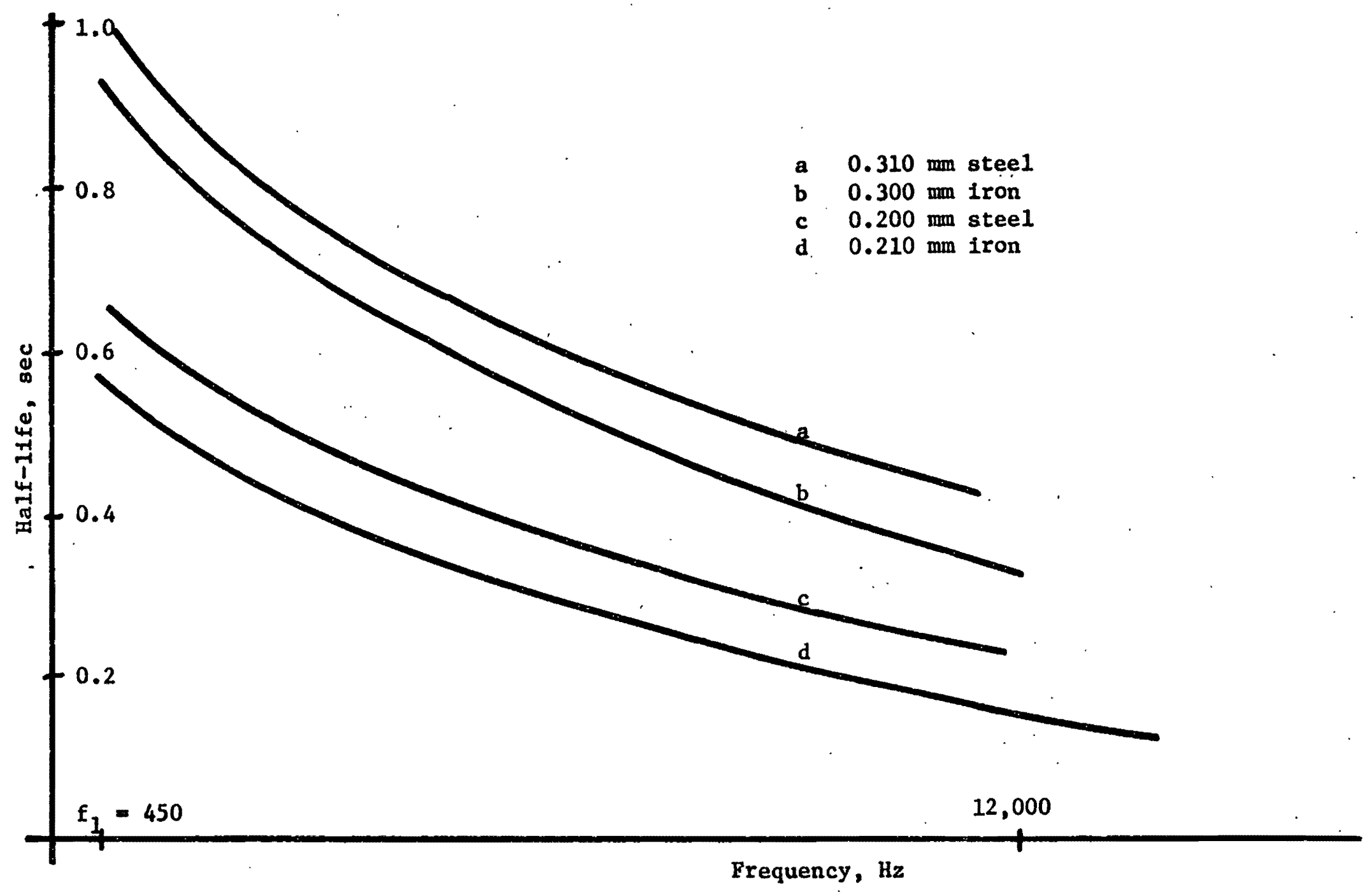

Figure 41. Decay time for iron and steel wire as a function of high frequency in air. 


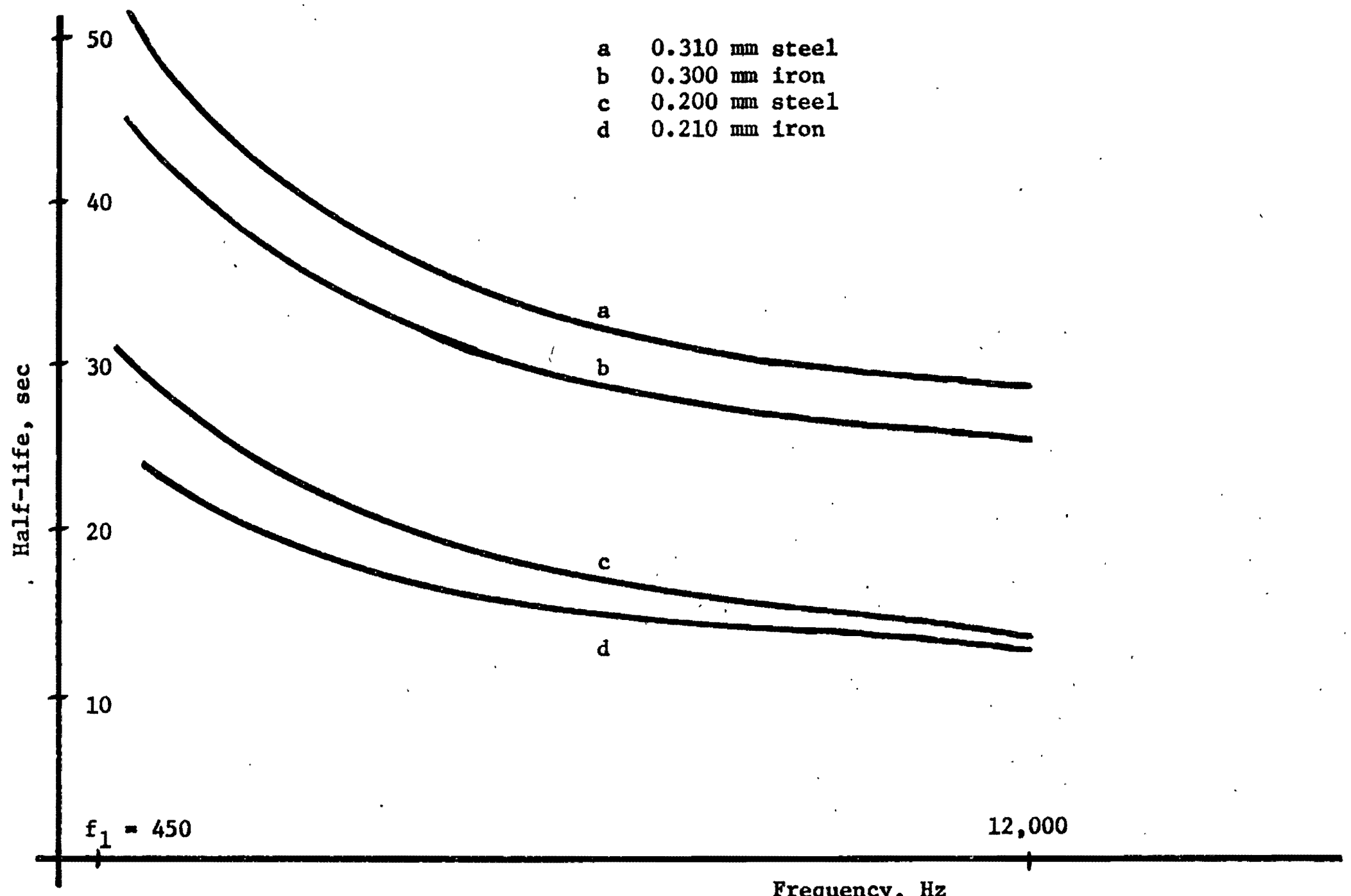

Figure 42. Decay time for iron and steel wire as a function of high frequency in vacuum. 
Decay Time as a Function of Diameter

On the following page is a plot of decay time vs diameter for each material. This data was taken from previous curves. The frequency was $1000 \mathrm{~Hz}$ in every case.

Decay Time as a Function of Pressure

Page 58 is a graph of decay time vs pressure for iron and steel wire. So that the full range of pressures may be presented, a log$10 g$ plot of decay time vs pressure is shown on page 59.

\section{Comparisons}

Due to the amount and diversity of data, any attempt to make all possible comparisons of decay times between various materials, diameters, environments, etc., would prove too lengthy. It is hoped that the data as presented will facilitate comparison-making as needed by the reader.

Air-Vacuum Decay Times. A comparison that needs to be made is that between a wire vibrating in air and then vibrating in a vacuum. The magnitude of the difference in decay tine had not been expected. Page 60 illustrates this difference for samples of iron and steel. All wires tested were found to have a longer vacuum decay time, some by as much as a factor of 25. This effect was pressure-dependent of course, and the decay times increased most markedly as the very lowest pressures were reached. 


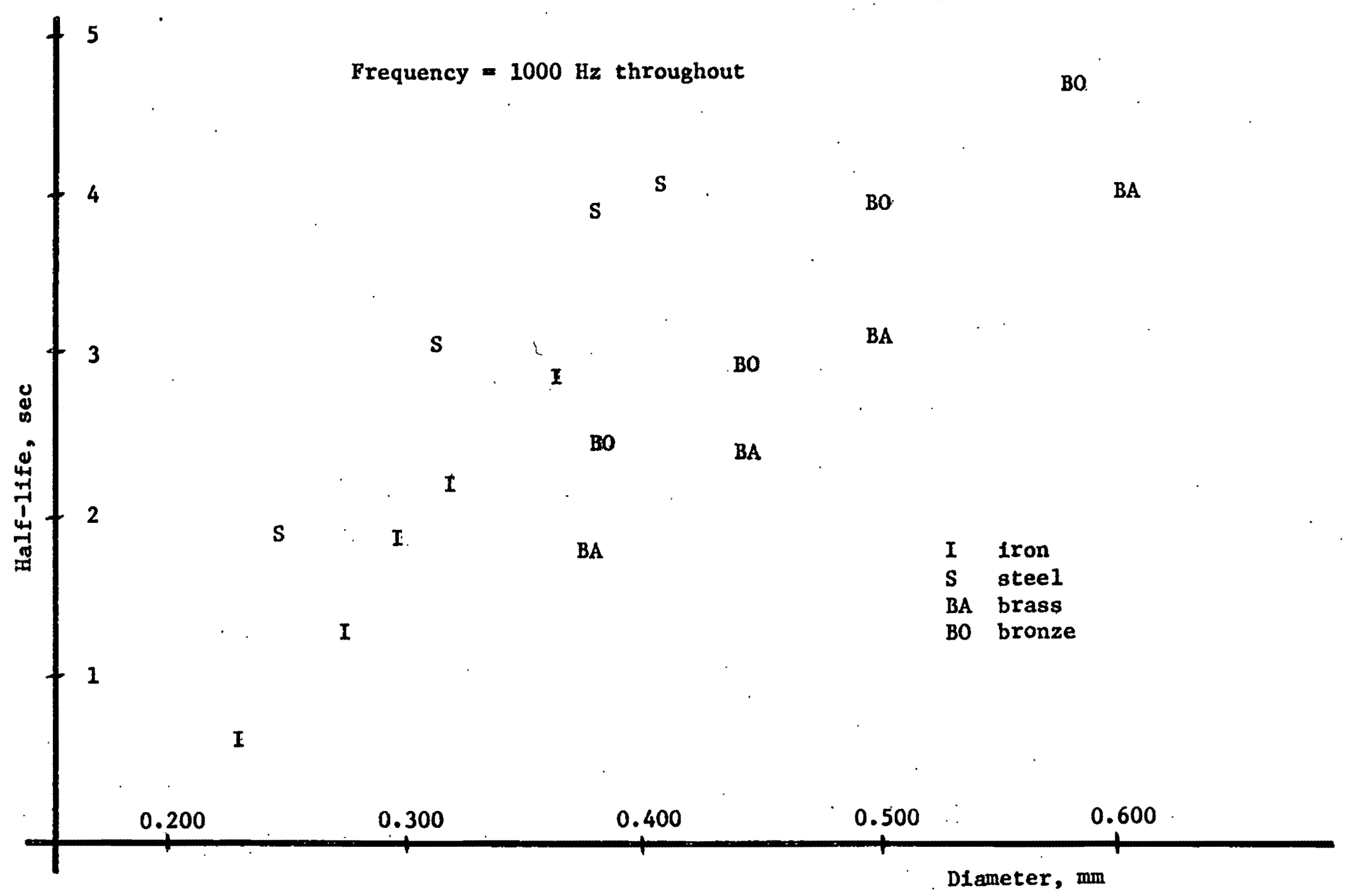

Figure 43. Decay time for 1 ron, steel, brass, and bronze wire as a function of diameter 1 in air. $U$ 


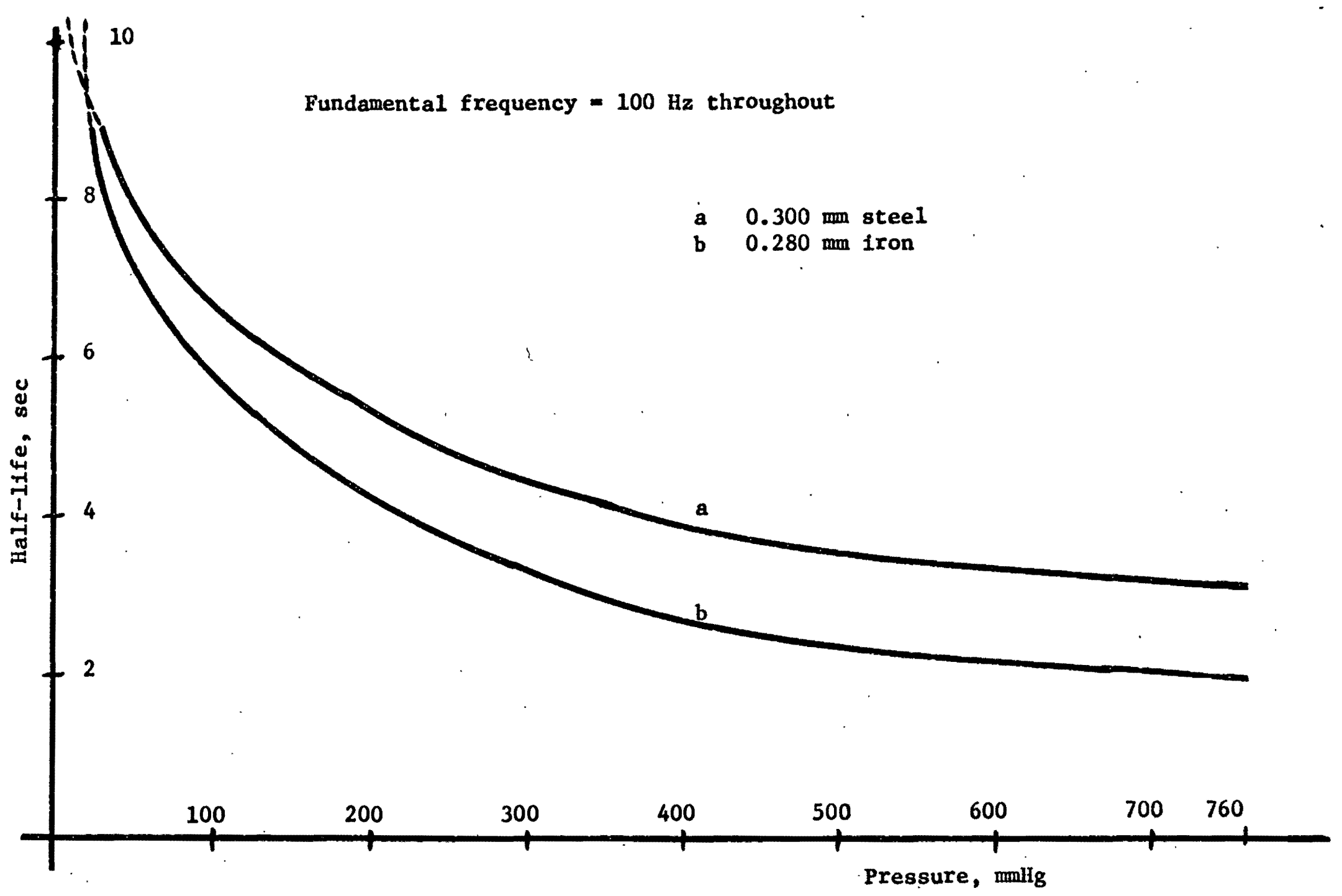

Figure 44. Decay time for Iron and steel wire as a function of pressure. 


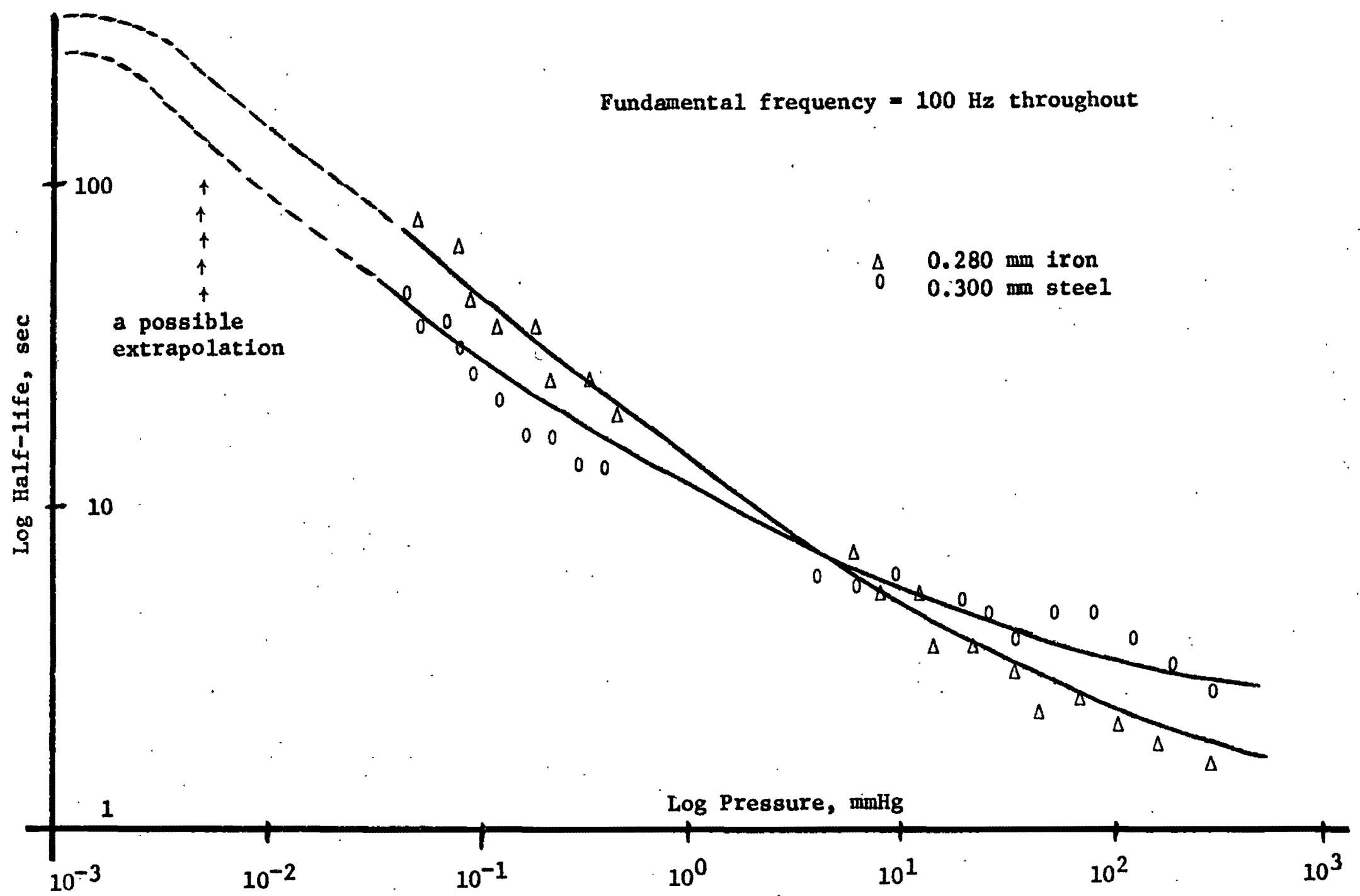

Figure 45. Log-log plot of decay time for iron and steel wire as a function of pressure. 


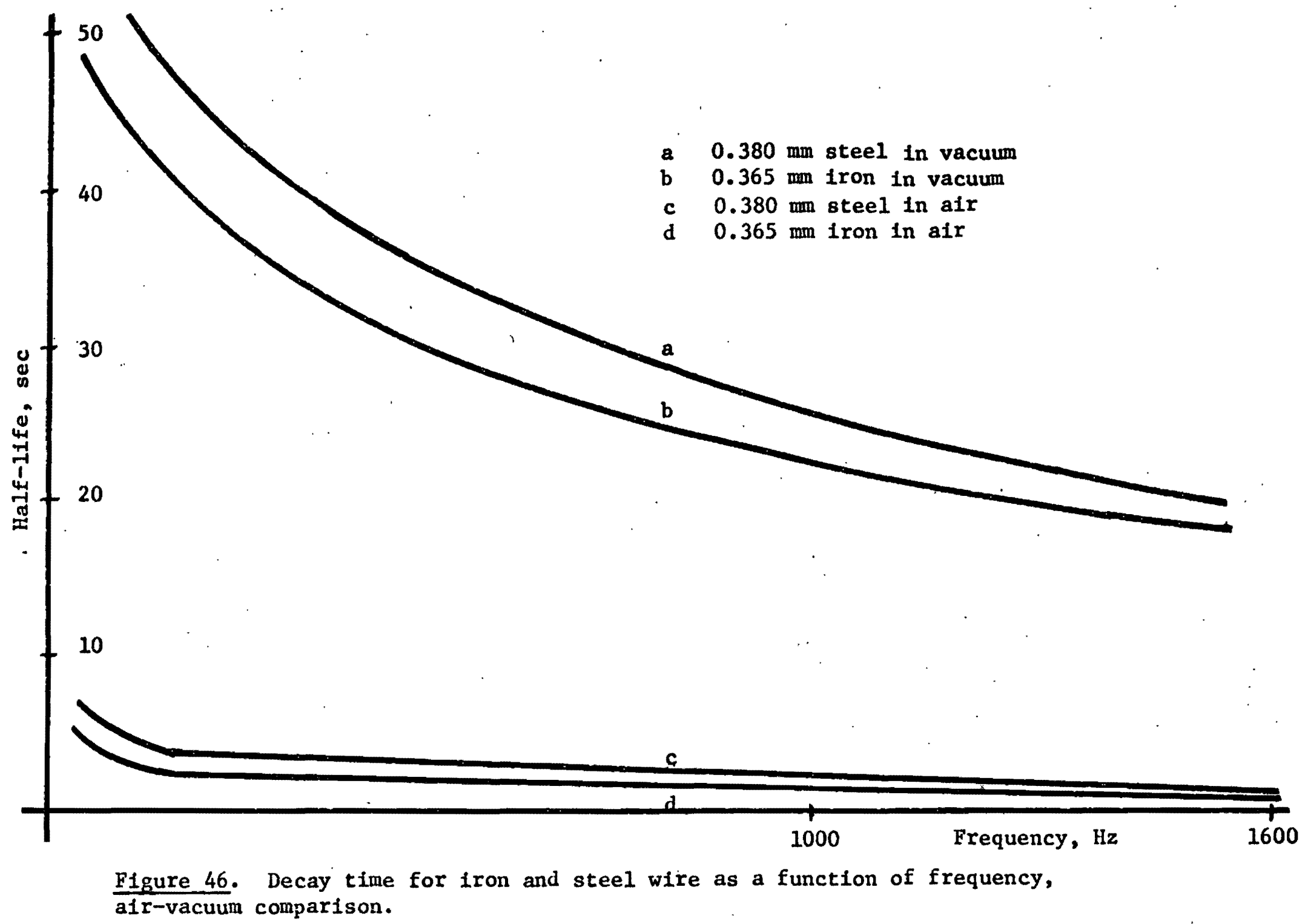


CONCLUSIONS AND RECOMMENDATIONS

\section{Conclusions}

Some of the most consistent features depicted in the data were:

1. For a given material and at a given frequency, the larger the diameter of the wire the longer it will vibrate. This is true without exception and is simply a result of the greater inertia of thicker wires.

2. For a given diameter of wire at a given frequency, the greater the density of the material the longer it will vibrate. This also is an inertial effect which was found to be generally true, see Figures $34-38$.

3. As the frequency of a given wire is increased, the duration of its decay time is decreased. The dependence of decay time on frequency is non-linear. The slope of these curves is the greatest at the lower frequencies.

4. For a selection of wire materials and sizes, the range of decay times among them is greatest at the fundamental and this range diminishes at higher frequencies. If tonal quality is related to decay time, then differences in tonal quality would be most noticeable for strings which are vibrating at the fundamental.

5. If an iron and a steel wire have nearly equal diameters, the steel wire will vibrate longer at any frequency, refer to Figure 41. On this graph two sets of iron and steel wires are 
shown. If curves $a$ and $b$ alone are considered, two possible conclusions are:

1- steel wire vibrates longer than iron, and/or,

2- larger diameters vibrate longer than smaller ones.

However, when curves $c$ and $d$ are also considered, the second of these conclusions is ruled out.

(It should be noted here that conclusions $\# 2$ and \#5 taken together seem to indicate that the steel wire was denser than the Iron wire. Since mass per unit length $(\mu)$ equals density $(p)$ times cross-sectional area $(A)$, $i e, \mu=\rho A$ or $\rho=\mu / A$, we find that

$$
\mu /\left.A\right|_{\text {stee1 }}>\mu /\left.A\right|_{\text {iron }}
$$

If equal diameter wires are considered, then $A_{\text {steel }}=A_{\text {iron }}$ and this means that $\mu_{\text {steel }}>\mu_{\text {iron }}$. Data from Table III neither confirms nor contradicts this.)

6. If the difference in diameter between an iron and steel wire is sufficiently large, the iron wire will vibrate longer than the steel, refer to Figures $34-35$.

7. When a given wire vibrates under specified conditions in air and then in a vacuum under these conditions, the decay time is Increased by a factor which may be as high as 25 , see page 60 . This indicates that the energy interactions between the wire and the air have greater relative importance than the energy interactions between the wire and its supports, and they also are greater than energy losses due to internal friction. Pigure 47 is a decay trace of a $0.280 \mathrm{~mm}$ diameter iron wire 
vibrating at its fundamental of $120 \mathrm{~Hz}$. Initially the pressure

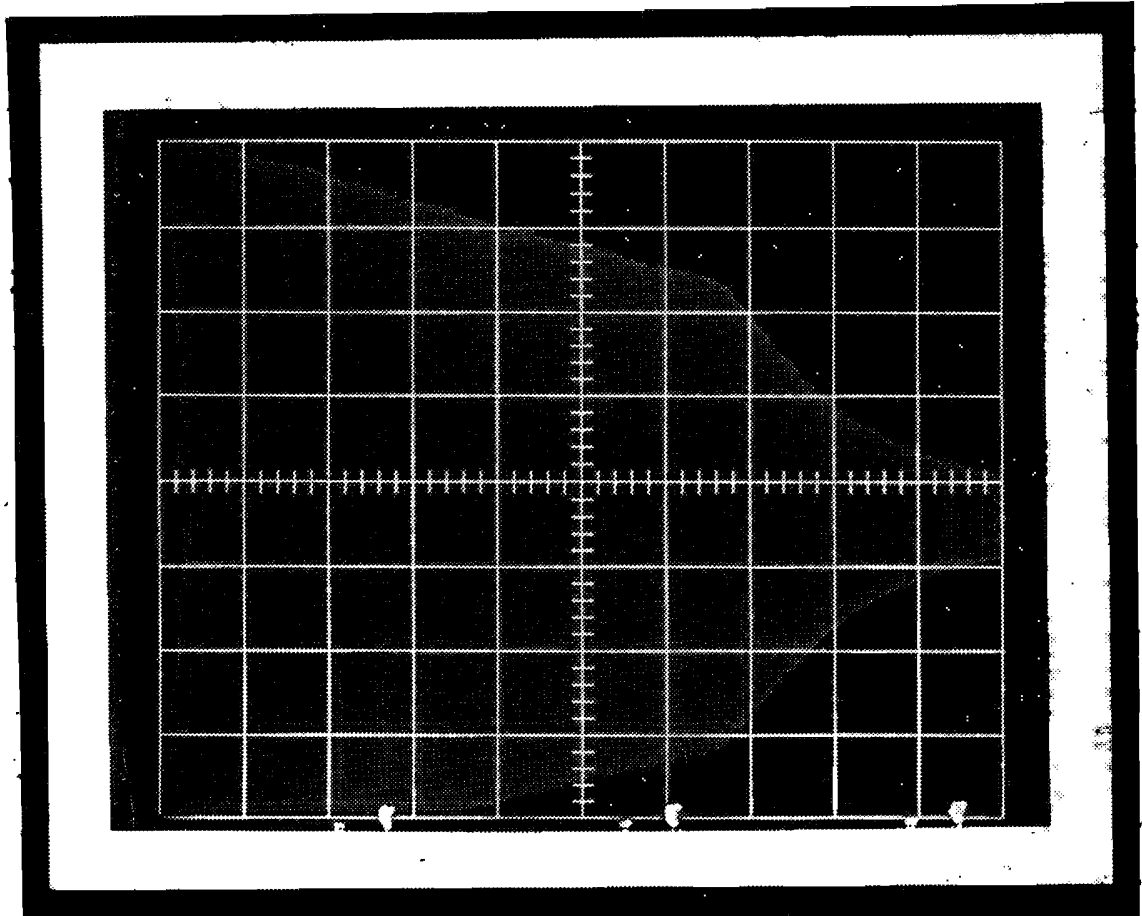

Figure 47. Decay trace illustrating the effect of air on a haxpsichord wire vibrating originally in a vacuum.

was 100 microns, and at this pressure the projected half-life was about 27 seconds. When air was introduced the wire experienced a rapid decrease in amplitude (10ss of energy), and was completely damped in an additional 11 seconds. The half-life of this wire in air was about 3 seconds. Thus it could be reasoned that high vacuum conditions must be used when investigating support problems or internal friction. Otherwise the predominating air interactions would tend to mask the other modes of energy 1oss.

8. The decay time of a given wire at a given frequency decreased as the supports were made more massive and/or vibrationally Isolated. 


\section{Recommendations}

The following suggestions are offered to those who may wish to Investigate the properties of harpsichord wires further:

1. Measure decay time as a function of frequency for wires in varying states of anneal in order to link internal friction to crystal size; shape, etc.

2. Compare decay characteristics for iron and steel wires under high vacuus to further probe support problems and the action of internal friction, ie; extend the scope of Figure 45 to lower pressures.

3. Make a purely theoretical study of the interactions between air molecules and a moving wire at varlous pressures. Determine the functional relation between viscous damping and pressure and sound radiation and pressure.

4. Study the characteristics of sound emission from an actual harpsichord, interchanging iron and steel strings. Develop tonal criteria both subjectively and technically.

5. Investigate the possibility of substitution of other wires on the harpsichord. Replace the traditional Iron, steel, brass, and bronze with alloys which may more closely duplicate the sound quality of the earlier instruments.

6. Look more closely at the dependence of resonant frequency on pressure. Attempt to develop practical applications. 


\section{A SELECTED BIBLIOGRAPHY}

1. Kirby, F.E. 1966. A Short History of Keyboard Music, The Free Press, 13-19.

2. Sumner, W.L. 1966. The Planoforte, MacDonald Press, 19-53.

3. Ratajak, Wm. P. 1973. private communications.

4. Pyle, R.W. Jr. and Schultz, T.S. 1966. "Decay Patterns of Harpsichord Strings," Journal of the Acoustical Society of America, Vol. 39, 1220 .

5. Martin, D.W. July, 1947. "Decay Rates of Piano Tones," Journal of the Acoustical Society of America, Vol. 19, 535-541.

6. Hundley, T.C., Martin, D.W., and Benfoff, H. June, 1956.

"Factors Contributing to the Multiple Decrement of Piano Tone Envelope." A summary of a report from the fifty-first meeting of the Acoustical Society of America, Cambridge, Mass.

7. Bennewitz, K. and Rötger, H. August 15, 1936. "Internal Friction of Solids," Phys. Zeits. 37, 578-588.

8. Zener, C. Jan. 1, 1938. "Internal Friction in Solids. Part IIGeneral Theory of Thermoelastic Internal Friction," Physical Review 53, 90-99.

9. Zener, C., Otis, W., and Nuckolls, R. Jan. 1, 1938. "Internal Friction in Solids. Part III- Experimental Demonstration of Internal Friction," Physical Review 53, 100-110.

10. Zenex, C. June 15, 1938. "Internal Friction in Solids. Part VGeneral Theory of Macroscopic Eddy Currents," Physical Review 53, 1011-1013.

11. Sears, F.W. and Zemansky, M.W. 1960 College Phystcs, AddisonWesley, 399-448.

12. Sanford, C.E. 1973-74. private communications.

13. Pain, H.J. 1968. The Physics of Vibrations and Waves, John Wiley and Sons, 71-96.

14. Morse, P.M. and Ingard, K.U. 1968. Theoretical Acoustics, McGraw-Hill, 36-60 and 95-143.

15. Rempfer, G.F. 1973-74. private communications. 
16. Landau, L.D. and Lifshitz, E.M. 1969. Mechanics, AddisonWesley, 87-93.

17. Zener, C. August 1, 1937. "Internal Friction in Solids. Part ITheory of Internal Friction in Reeds," Physical Review 52, 230-235.

18. Zener, C. April 1, 1938. "Internal Friction in Solids. Part IV-. Relation Between Cold Work and Internal Friction," Physical Review 53, 582-586.

19. Zener, C. 1965. Elasticity and Anelasticity of Metals, The Untversity Press, Chicago.

20. Bachhuber, C. 1974. private communications.

21. Barrett, C.S. 1952. Structure of Metals, McGraw-Hill, 336-364.

22. Miller, D.C. 1926. The Science of Musical Sounds, Macmillan, $78 f f$.

23. Sears, F.W. 1956. Thermodynamics, Addison-Wesley, 256-267.

24. Stewart, G.W. and Lindsay, B.R. 1930. Acoustics, D. Van Nostrand, 1-10.

25. Young, R.W. 1952. "Inharmonicity of Plain Wire Plano Strings," Journal of the Acoustical Society of America, Vol. 24, 267-273.

26. Blackham, E.D. December, 1965. "The Physics of the Piano," Scientific American, Vol. 113, 88-99.

27. Jefferies, L.A. 1940. "The Pitch of Complex Tones," American Journal of Psychology, LIII, 240-250.

28. Hunter, J.L. 1962. Acoustics, Prentice-Hall, 3-78.

29. Wylie, C.R. Jr. 1960. Advanced Engineering Mathematics, McGraw-H111, 194-213.

30. Bilhuber, P.H. and Johnson, C.A. 1940. "Influence of the Soundboard on Piano Tone Quality," Journal of the Acoustical Soclety of America, Vol. 11, 311-320.

31. Rschevkin, S.N. 1963. The Theory of Sound, Macmillan, 33-37. 


\section{APPENDIX A}

INTERCRYSTALLINE THERMAL CURRENTS AS A SOURCE OF INTERNAL FRICTION

Clarence Zener and associates did theoretical and experimental work on internal friction in the mid-i930's which culminated in a succession of papers, Zener $(8,9,10,17,18)$ and a book, Zener (19). Excerpts from some of Zener's work are presented here.

General Theory of Thermoelastic Internal Friction

Stress inhomogeneities in a vibrating body were found to give rise to fluctuations in temperature, and hence to local heat currents. These heat currents increase the entropy of the vibrating solid and thus are a source of internal friction. A general theory of this internal friction was developed and from it formulae were obtained for transversely vibrating wires and reeds. The formulae contain information regarding crystal orientation in single-crystal specimens.

\section{Intercrystalline Thermal Currents}

Zener and others designed an experiment to detect the contribution of Intercrystaline thermal currents to the internal friction of polycrystalline metals. In accordance with a theory developed by Zener, the internal friction is maximum when the vibration is partly isothermal and partly adiabatic with respect to adjacent grains. By passing in small steps from the nearly isothermal case of very small grain size through maximum internal friction to the nearly adiabatic 
case of large grain size, Zener was able to detect the relative importance of the intercrystalline currents. He interpreted the experiment to indicate that in annealed non-ferromagnetic metals at room temperature, intercrystalline thermal currents are the dominant cause of Internal friction at small strain, aside from possible macroscopic thermal currents.

\section{Microscopic Thermal Currents}

Although Zener's work concerns itself with vibrating metals of a variety of cross-sections, an extension of his findings on intercrystalline thermal currents has been made for the case of transversely vibrating wires.

On a microscopic scale it is assumed that every stressed grain is at a different temperature because of the random orientation of the grains and consequent random stress, le, stress inhomogeneity, see Figure 48.

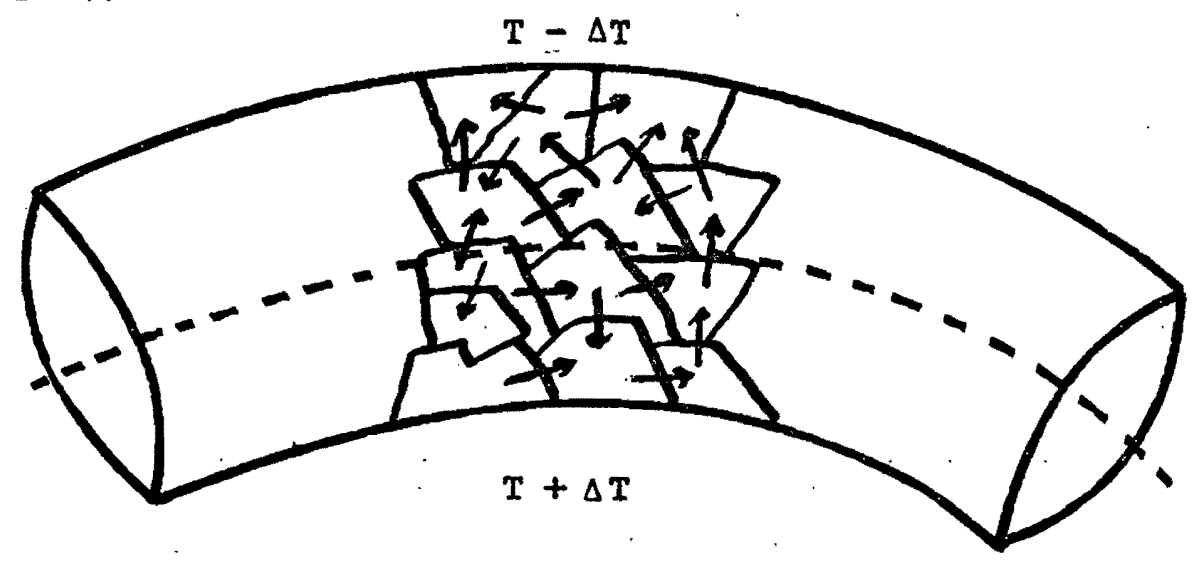

F1gure 48. Random orientation of grains and microscopic heat flow in a flexing wire. 
If the frequency is high and the grain size is large, very little heat flow takes place and the vibration is largely adiabatic. On the other hand, if the frequency is low and the grain size is small, heat transfer will be rapid enough to keep temperatures equal everywhere and the vibration will be nearly isothermal. This is true because a certain time will be required for adjacent grains to reach thermal equilibrium. This time will depend on the mass of the grain, proportional to $d^{3}$, and on the area of contact between adjacent grains, proportional to $\mathrm{d}^{2}$; also on the temperature difference $\Delta T$ between them. Thus with small grains with large contact areas and small mass, equilibrium is reached quickly, the opposite being true for large grains. 


\section{APPENDIX B}

REYNOLDS NUMBER CONSIDERATIONS

The Reynolds number is defined as, $R=\rho \mathrm{vL} / \varepsilon$ where $\rho$ is the density of the fluid through which an object with subsonic velocity $\checkmark$ and characteristic dimension $L$ is moving. $\varepsilon$ is the viscosity of the fluid.

Thus, for a typical harpsichord string vibrating in air at a frequency of $100 \mathrm{~Hz}$,

$$
\begin{aligned}
& \rho=1.3 \times 10^{-3} \mathrm{~g} / \mathrm{cc} \\
& I=3.0 \times 10^{-2} \mathrm{~cm} \text { (a typical diameter) } \\
& E=1.8 \times 10^{-4} \text { dyne- } \mathrm{sec} / \mathrm{cm}^{2}
\end{aligned}
$$

A string under these conditions would have a typical amplitude of $1 / 2 \mathrm{~cm}$. A representative velocity would be when the wire is halfway between its equilibrium position and its maximum displacement. Then the velocity would be

$$
\begin{aligned}
v & =2 \pi \mathrm{fA} / 2=\pi \mathrm{fA}=3.14(100) 1 / 2 \\
& =160 \mathrm{~cm} / \mathrm{sec}
\end{aligned}
$$

The Reynolds number has a value of about 35 for this data. When the Reynolds number is $>1$, energy losses are expected to be due primarily to inertial effects and the energy loss as a function of time should be non-exponential, Bachhuber (20). Further, when inertial effects are primarily responsible for energy loss, then the 
force on the moving object is proportional to the square of the veloc1ty, $F \propto v^{2}$. The rate of change of energy with time is

$$
\mathrm{dE} / \mathrm{dt}=\mathrm{Fv}
$$

thus $\mathrm{dE} / \mathrm{dt}=-\mathrm{kv} \mathrm{v}^{3}$. Since velocity is proportional to amplitude, $\quad \mathrm{dE} / \mathrm{dt}=-\mathrm{kA}^{3}$, and since energy is proportional to amplitude squared, $d\left(A^{2}\right) / d t=-k A^{3}$. This may be written as

$$
\begin{gathered}
d\left(A^{2}\right) / k A^{3}=-d t \text {. Differentiating gives } \\
2 A d A / k A^{3}=-d t \text {, then by integrating, this tecomes } \\
2 / k \int d A / A^{2}=-\int d t \text { or } 2 / k A=t+\text { constant } \leftarrow \leftarrow
\end{gathered}
$$

A plot of $1 /$ A v $t$ should yield a straight line. Figure 49 is a plot of $1 / A$ vs $t$ using data taken from Figure 23 . The fact that this graph is not linear seems to be a contradiction.. Perhaps Reynolds numbers are not the deciding criteria in this case.

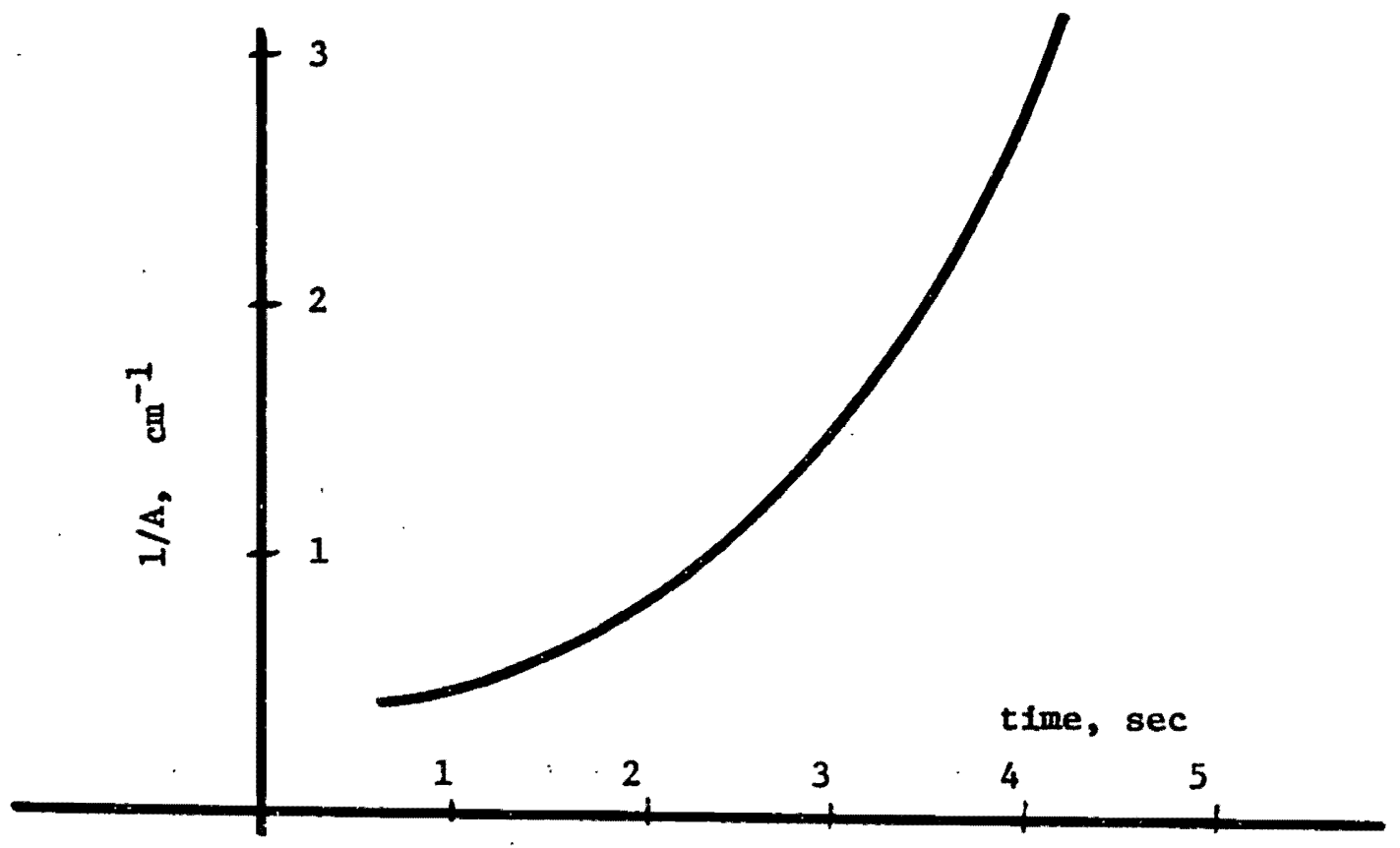

F1gure 49. Reciprocal amplitude vs time for data taken from the decay curve shown in Figure 23. 